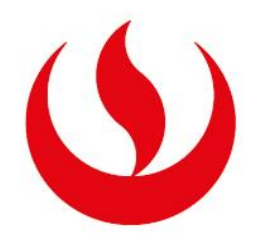

UNIVERSIDAD PERUANA DE CIENCIAS APLICADAS

FACULTAD DE COMUNICACIONES

PROGRAMA ACADÉMICO DE COMUNICACIÓN E IMAGEN EMPRESARIAL

\title{
La gestión comunicacional en el proceso de fusión empresarial de Cassinelli y Celima-Trébol en relación con los activos intangibles
}

\section{TESIS}

Para optar el título profesional de

Licenciado en Comunicación e Imagen Empresarial

\section{AUTORA}

Del Mar Rojas, Ana Ester (0000-0003-3258-3987)

\section{ASESOR}

Antezana Corrieri, Miguel Eduardo (0000-0002-7372-9420)

Lima, julio 2020 
DEDICATORIA

El presente trabajo va dedicado a Dios, quién supo guiarme y darme fuerzas para seguir adelante, enseñándome a enfrentar las adversidades sin perder las esperanzas ni decaer en el intento.

Para mis padres y hermano por ser parte de mi vida, por su apoyo, consejos, respaldo y comprensión en todo momento. Ellos me enseñan a diario principios, valores, empeño, carácter, perseverancia y coraje para lograr mis objetivos. 


\section{AGRADECIMIENTOS}

A Miguel Antezana, por ser un profesional y catedrático de excelencia, que se ha empeñado en brindarme apoyo moral, emocional y orientación para realizar esta investigación.

A Eduardo y amigos: Por haberme apoyado y alentado a seguir adelante en mi vida profesional.

A la Facultad de Comunicaciones de la Universidad Peruana de Ciencias Aplicadas por brindarme el conocimiento y excelencia académica. 


\section{RESUMEN}

El presente trabajo de investigación aborda la importancia de la gestión comunicacional en los procesos de fusión empresarial, basado en la dinámica de dos organizaciones peruanas. Asimismo, analiza los impactos en términos de imagen y reputación interna.

El objetivo general ahonda en la investigación de los impactos de la ausencia de la gestión comunicacional en procesos de fusión empresarial entre Cassinelli y Celima-Trébol, con el fin de identificar la relación causa-efecto entre dichas variables.

El Marco Teórico ha sido estructurado de manera que muestre el sentido y relación de los procesos de fusión empresarial con la comunicación. En ese sentido, se exponen las diferentes definiciones, clasificaciones y características de las fusiones empresariales. Así mismo, se muestra cómo es que una fusión organizacional puede presentarse como estrategia para el crecimiento externo de la empresa, las posibles consecuencias organizativas producto de ellas y su impacto en los activos intangibles a nivel interno. Por último, se expone el concepto de Gestión Empresarial, sus niveles dentro de una organización, las etapas y ventajas de este.

Luego, se abordan los temas de la Gestión Comunicacional, en términos de Comunicación e Identidad Corporativa, activos intangibles, Imagen y Reputación Corporativa, con el objeto de relacionarlos con el proceso de fusión en empresas de mejoramiento del hogar en el Perú.

En el capítulo tres, se exponen los Hallazgos y Resultados producto de la realización de entrevistas en profundidad aplicada a los altos mandos de la organización y encuestas a una muestra representativa de colaboradores, la cual buscó de manera directa identificar los impactos de la ausencia de una gestión comunicacional en el proceso de fusión empresarial.

Por último, se presentan las principales conclusiones derivadas del presente trabajo de investigación, en las que se evidencia la inexistencia de una adecuada estrategia comunicacional entre ambas marcas y un arduo proceso de adaptación basado en un nuevo ambiente laboral y; se exponen las recomendaciones que demuestran la relevancia de la gestión comunicacional en el desarrollo de la fusión empresarial. 
Palabras clave: Fusión y adquisición empresarial; gestión comunicacional; comunicación en fusiones; cultura organizacional; cambio organizacional; resistencia al cambio.

\title{
Analysis of communication management in the business merger process of the Cassinelli and Celima-Trébol companies and its impact on intangible assets
}

\begin{abstract}
This research work addresses the importance of communication management in business merger processes, based on the dynamics of two Peruvian organizations. In addition, it analyzes the impacts in terms of image and internal reputation.
\end{abstract}

The general objective delves into the investigation of the impacts of the absence of communicational management in business merger processes between Cassinelli and CelimaTrébol, in order to identify the cause-effect relationship between these variables.

The Theoretical Framework has been structured in such a way as to show the meaning and relationship of business fusion processes with communication. In this sense, the different definitions, classifications and characteristics of business mergers are exposed. Likewise, it shows how an organizational merger can be presented as a strategy for the external growth of the company, the possible organizational consequences resulting from them and its impact on intangible assets internally. Finally, the concept of Business Management is exposed, the levels within the organzition its stages and advantages.

Additionally, the issues of Communicational Management are addressed, in terms of Communication and Corporate Identity, intangible assets, Image and Corporate Reputation, in order to relate them to the merger process in home improvement companies in Peru.

In chapter three, the Findings and Results resulting from conducting in-depth interviews applied to the organization's senior managers and surveys of a representative sample of collaborators are presented, which directly sought to identify the impacts of the absence of a communicational management in the business merger process. 
Finally, the main conclusions derived from this research work are presented, in which the inexistence of an adequate communicational strategy between both brands and an arduous adaptation process based on a new work environment and recommendations are presented that demonstrate the great importance of communicational management in business merger processes.

Keywords: Business merger and acquisition; communication management; communication in mergers; organizational culture; organizational change; resistance to change. 
CAPÍTULO I: ESTADO DE LA CUESTIÓN.............................................................................. 14

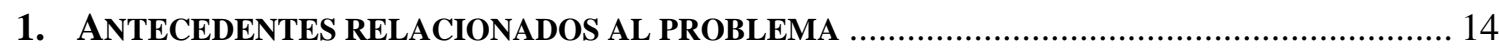

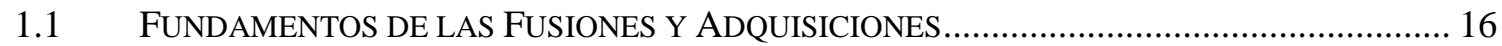

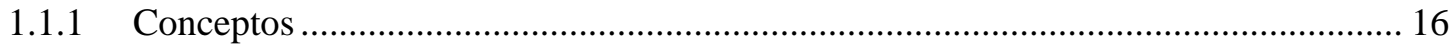

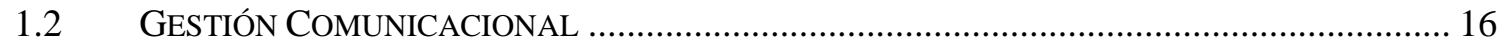

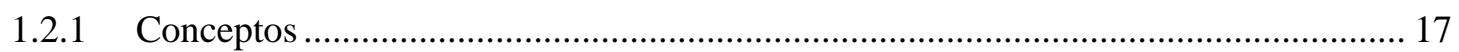

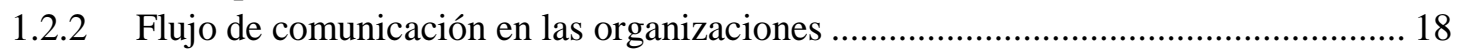

1.3 GESTIÓN COMUNICACIONAL EN PROCESOS DE FUSIÓN Y ADQUISICIÓN ........................... 19

1.3.1 La importancia de la gestión comunicacional en las fusiones .................................... 20

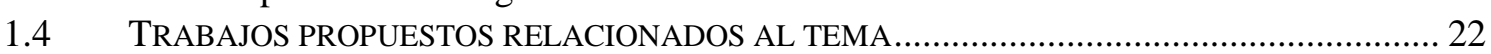

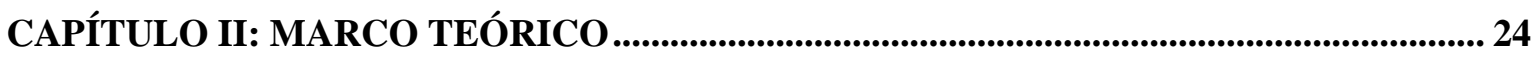

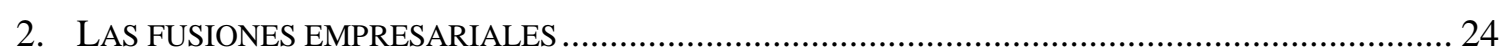

2.1 FUSIÓN DE EMPRESAS: DEFINICIÓN, CLASIFICACIÓN Y CARACTERÍSTICAS ...................... 24

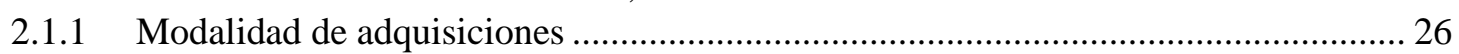

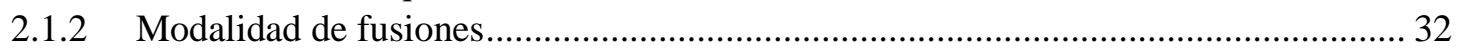

2.2 LA FUSIÓN COMO ESTRATEGIA DE CRECIMIENTO EXTERNO EN LA EMPRESA .................... 45

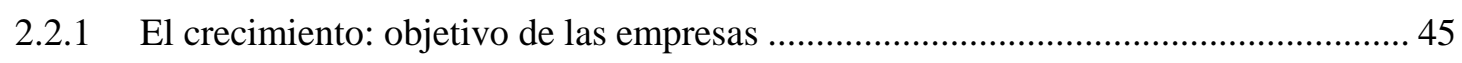

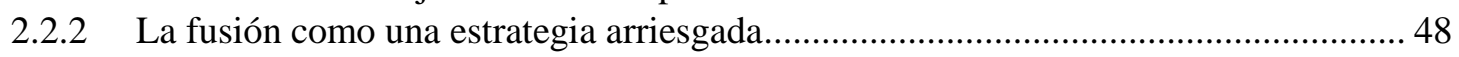

2.2.3 Efectos de las fusiones sobre las variables empresariales ........................................ 49

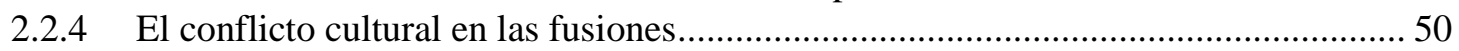

3. LAS FUSIONES EMPRESARIALES EN EMPRESAS DE MEJORAMIENTO DEL HOGAR EN PERÚ .... 53

3.1 LAS EMPRESAS DE MEJORAMIENTO DEL HOGAR EN PERÚ ........................................... 53

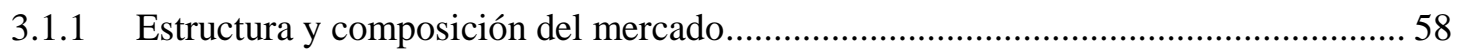

3.1.2 Los cambios recientes en las empresas de mejoramiento del hogar.............................60 60

3.2 El proceso de fusión en empresas de mejoramiento del hogar en Perú........................ 63

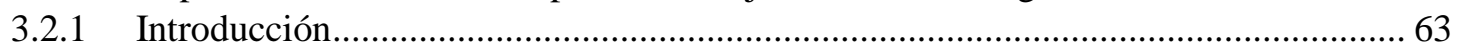

3.2.2 Las fusiones en empresas de mejoramiento del hogar en Perú ................................... 68

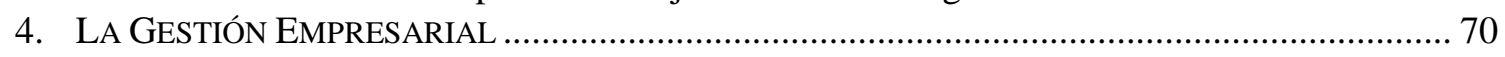

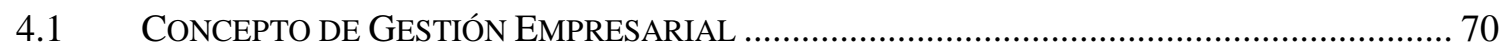

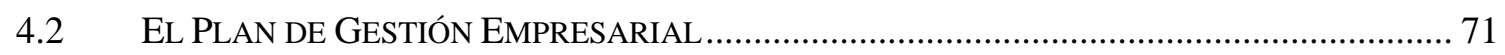

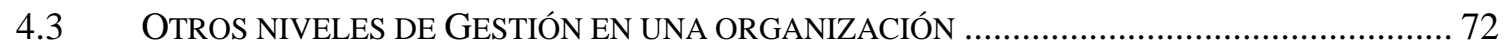

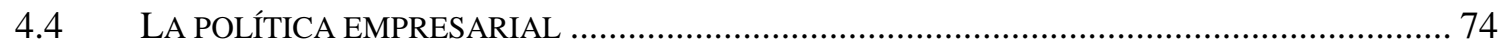

4.5 FACTORES CONDICIONANTES DE LA GESTIÓN EMPRESARIAL …..................................... 75

4.6 VENTAJAS DE LA GESTIÓN EMPRESARIAL ................................................................... 75

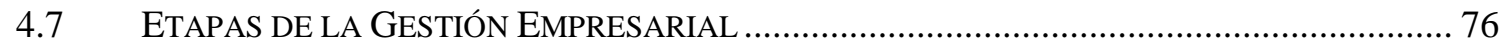

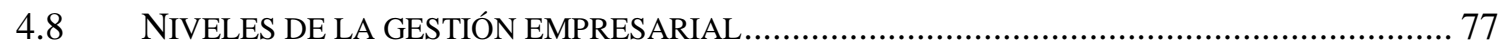

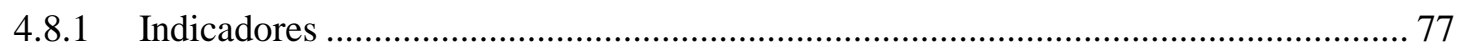

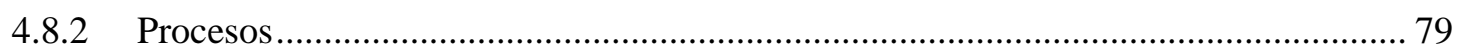

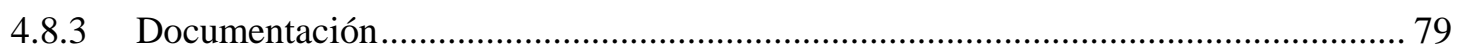

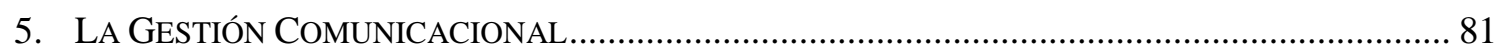

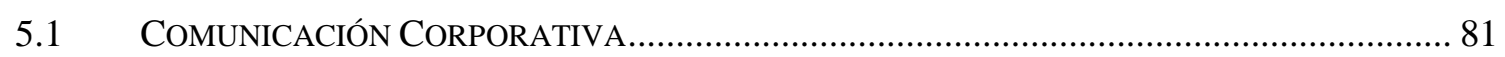

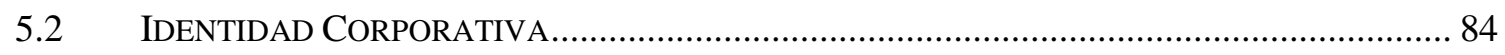

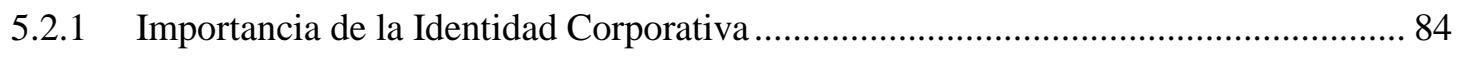

5.2.2 El Valor De La Identidad Corporativa ……................................................... 88 
5.2.3 Signos esenciales en la Identidad e Imagen Corporativa …....................................... 88

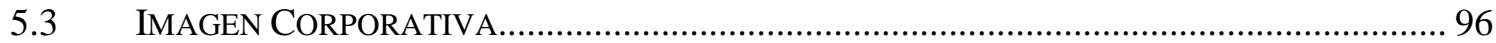

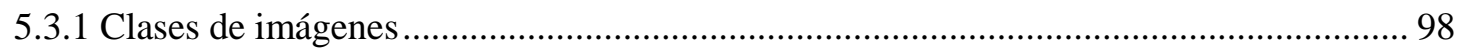

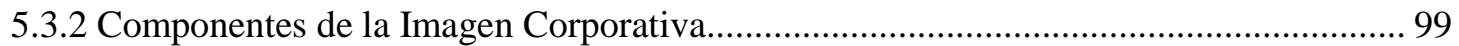

5.3.3 Fuentes de información para la construcción de la Imagen Corporativa........................ 100

5.3.4 ¿Imagen Corporativa o Identidad Corporativa? .......................................................... 101

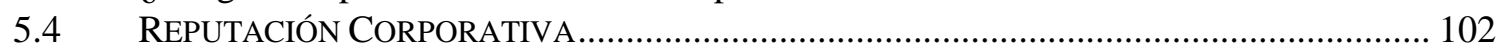

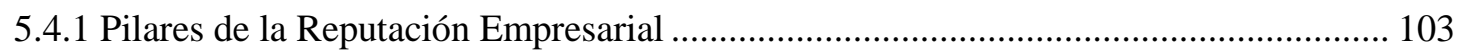

5.4.2 Características de la Reputación Corporativa.............................................................. 103

6. LA GESTIÓN COMUNICACIONAL EN LOS PROCESOS DE FUSIÓN Y ADQUISICIÓN................... 106

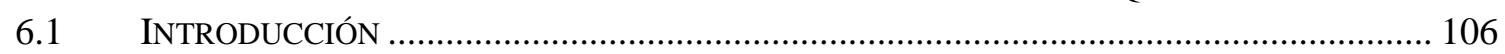

6.2 PROCESOS DE CAMBIO DE COMUNICACIÓN Y DE ORGANIZACIÓN EN FUSIONES ............. 110

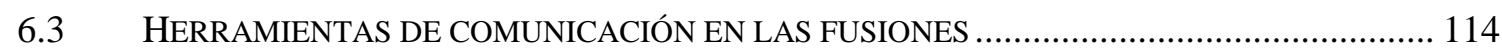

CAPÍTULO III: METODOLOGÍA ........................................................................................ 120

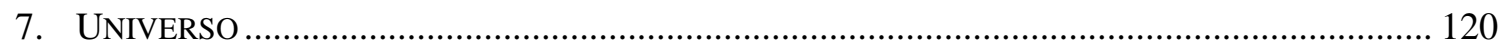

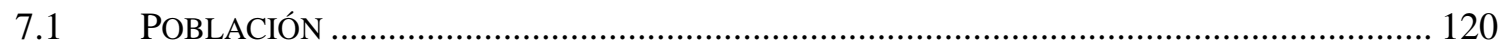

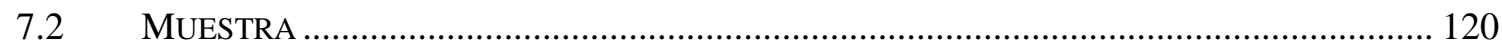

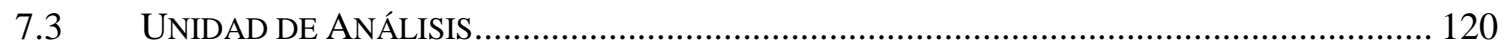

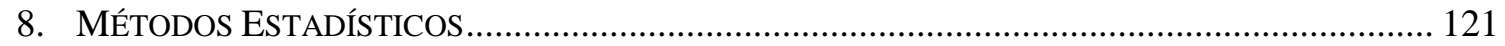

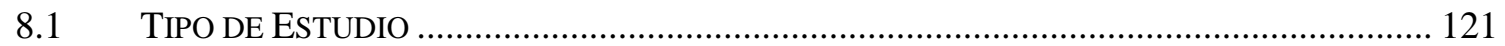

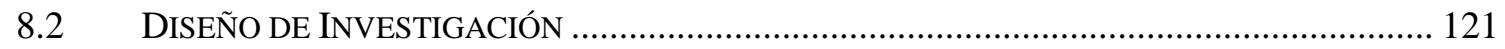

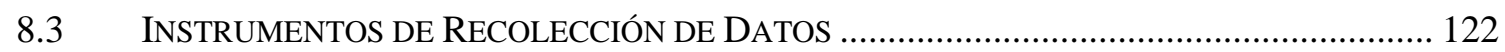

8.4 PROCEDIMIENTO Y ANÁLISIS ESTADÍSTICO DE DATOS .................................................. 123

CAPÍTULO IV: HALLAZGOS Y RESULTADOS.............................................................. 125

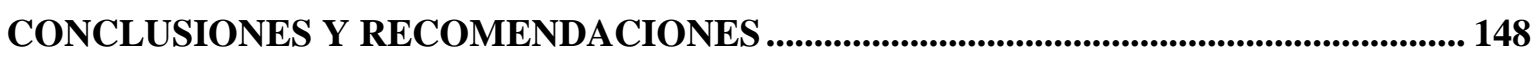

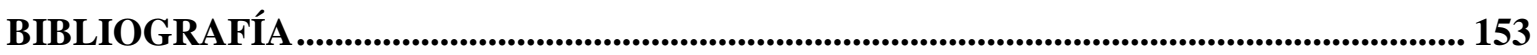

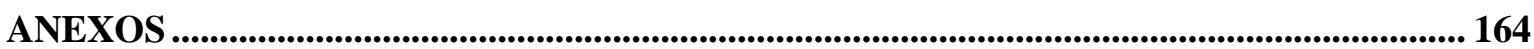




\section{ÍNDICE DE TABLAS}

Tabla $\mathrm{N}^{\circ} 1 \quad$ Tipos de especialización y diversificación................................................... 47

Tabla $\mathrm{N}^{\circ} 2 \quad$ Fusiones y adquisiciones en el rubro de retail $2006-2018 \ldots \ldots \ldots \ldots \ldots \ldots \ldots \ldots . . . . . .66$

Tabla $\mathrm{N}^{\circ} 3 \quad$ Clasificación de conceptos de Imagen.......................................................97

Tabla N 4 Definiciones de Reputación Corporativa por Stakeholder ........................105

Tabla $\mathrm{N}^{\circ} 5$ Factores para pronóstico del impacto del cambio en la organización.........114 


\section{ÍNDICE DE FIGURAS}

Figura $\mathrm{N}^{\circ} 1 \quad$ Las fusiones y su consolidación en el entorno empresarial..........................26

Figura $\mathrm{N}^{\circ} 2$ Modalidades de Adquisición de Activos...................................................27

Figura $\mathrm{N}^{\circ} 3$ Adquisición de activos. Mod: Acción de venta y Liquidación de sociedades 28

Figura $N^{\circ} 4$ Adquisición de Activos. Mod: Adquisición de activos Mod: Liquidación de sociedad y venta por los accionistas 29

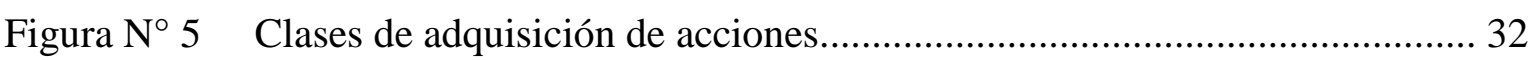

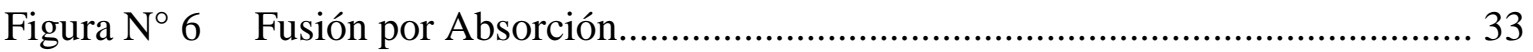

Figura $\mathrm{N}^{\circ} 7$ Alternativas estratégicas genéricas de crecimiento y

diversificación

Figura $\mathrm{N}^{\circ} 8$ Modelo de adquisición por medio de fusión triangular hacia adelante....... 42

Figura $\mathrm{N}^{\circ} 9$ Modelo de adquisición por medio de fusión triangular en reversa...............43

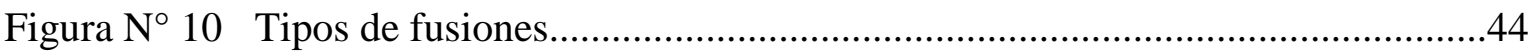

Figura $\mathrm{N}^{\circ} 11$ Riesgo cultural: factores culturales con relación a los factores estratégicos. .53

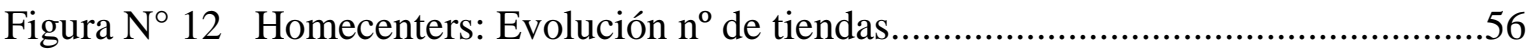

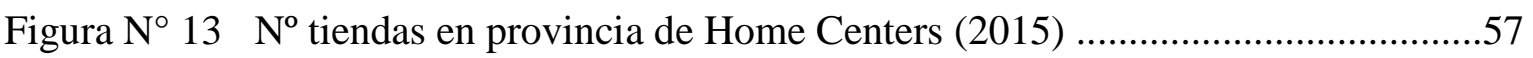

Figura $\mathrm{N}^{\circ} 14$ Ventas Home Centers 2012 - 2016.............................................................61

Figura $\mathrm{N}^{\circ} 15$ Evolución de mercado de fusiones y adquisiciones periodo 2010-2016......64

Figura $\mathrm{N}^{\circ} 16$ Evolución de mercado de fusiones y adquisiciones periodo 2010-2016......65

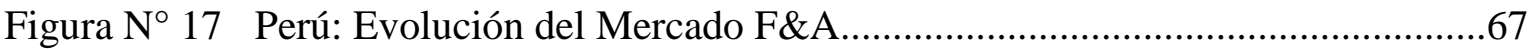


Figura $\mathrm{N}^{\circ} 18$ Visión dinámica y estratégica de los intangibles.......................................93

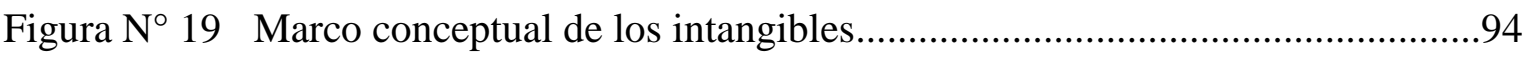

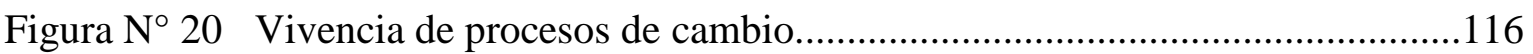

\section{ÍNDICE DE ANEXOS}

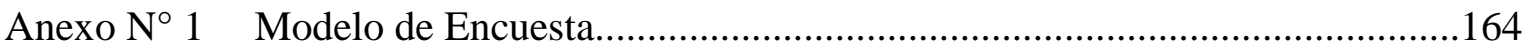




\section{INTRODUCCIÓN}

En las fusiones empresariales, los procesos, la cultura, las estructuras jerárquicas, de poder y, en general, la gran mayoría de componentes organizacionales son afectados por la gestión de cambio. Por esta razón, el estudio de las adquisiciones y fusiones se torna interesante en cualquier tipo de industria, ya que facilitan la reorientación de sus actividades, el aprovechamiento de economías de escala o la diversificación del riesgo, la entrada en nuevos mercados, así como los cambios en la gerencia y posibles giros en la estrategia de la entidad.

Sin embargo, todo cambio al interior de una empresa provoca cierto impacto en sus colaboradores y en sus procesos, existiendo incluso la posibilidad de que el impacto sea tan fuerte que pudiera desencadenarse una crisis organizacional. Así mismo, estas fusiones o adquisiciones pueden provocar tensiones y conflictos entre las empresas por los diferentes estilos de dirección y, sobre todo, por las diferentes culturas empresariales.

Además, esta táctica no solo presenta modificaciones en el interior o exterior de las entidades que se ven reflejados en la estructura, los estados financieros, los procesos, el mercado, la razón social; sino que también, presenta cambios en el capital humano, ya que es el principal recurso en donde se proyectan y enfocan todas las estrategias de la organización.

Sobre la base de lo expuesto, la dimensión comunicacional es uno de los ejes principales en los procesos de cambio organizacional pues facilitará la adaptación a las nuevas realidades e influirá en la percepción que los integrantes de la organización vayan a tener de dicha situación.

De este modo, si es que la fusión impacta de manera positiva o negativa a la empresa o, si es que no se comunica de manera anticipada, pertinente o asertiva a los colaboradores, puede ocasionar en éstos ciertos miedos, resistencias e incertidumbres al momento de implementar dicha fusión.

Esto se debe, a que la desinformación puede causar suposiciones y prejuicios infundidos acerca de las consecuencias del proceso sobre atribuciones laborales y personales. Por lo que puede entenderse como despidos colectivos, cambio de funciones, rotación entre las mismas 
áreas o rediseño en determinadas gestiones; lo que conlleva a la generación de estrés y a generar una resistencia alta al cambio que se traduce en un impacto negativo en la capacidad de adaptación y aceptación del proceso de fusión.

Por ello, es crucial realizar un trabajo interno dentro de las empresas para que pueda existir una buena Gestión Comunicacional, en términos de Comunicación, Identidad, Imagen y Reputación Corporativa con el único fin de crear en los colaboradores un vínculo, sentido de pertenencia y afinación con la filosofía, valores y objetivos de la empresa. Además, en el Perú, el mercado de fusiones y adquisiciones ha experimentado un desarrollo significativo en el 2015, por lo que ha otorgado la concentración de negocios y el volumen de transacciones por US\$ 4,630 millones al término del año. De esta manera, se efectuaron alrededor de 120 transacciones, lo que ha permitió situarnos en el tercer lugar después de México y Brasil (EY, 2016, p.12). Por ello, es interesante explorar y desarrollar el tema a profundidad, con el fin de obtener una aproximación a la cultura y gestión comunicacional que pueda asegurar el éxito del despliegue de fusión y/o adquisición.

El presente trabajo de investigación abordará el proceso de fusión de dos empresas peruanas: Cassinelli y Celima-Trébol para identificar el manejo de la comunicación interna y poder así, resaltar los elementos que deben tenerse en cuenta - en términos de comunicación- en la gestión de cambio por fusión organizacional.

\section{Hipótesis y objetivos de investigación}

\section{- Pregunta de investigación:}

A partir de lo mencionado anteriormente, surgió la siguiente pregunta de investigación: ¿En qué medida el proceso de fusión empresarial generó impactos positivos o negativos en la imagen y reputación internas de las compañías Cassinelli y Celima-Trébol? pregunta que fue respondida al término de la aplicación de los instrumentos de medición y el consecuente análisis de los datos que fueron recopilados durante el proceso de investigación.

\section{- Hipótesis}


La escasa gestión comunicacional en el proceso de fusión empresarial entre las compañías Cassinelli y Celima-Trébol, generó impactos negativos en la imagen y en la reputación internas.

\section{- Objetivo general}

Investigar los impactos intangibles de la gestión comunicacional en el proceso de fusión empresarial entre Cassinelli y Celima-Trébol, sobre la base de técnicas de investigación mixtas, e identificar la relación causa-efecto entre dichas variables.

\section{- Objetivo específico 1}

Identificar los componentes en el acompañamiento de la gestión comunicacional para los procesos de cambio por fusión en dos empresas peruanas: Cassinelli y Celima-Trébol durante el lapso de un año.

\section{- Objetivo específico 2}

Determinar los principales activos intangibles a nivel interno que surgieron en el proceso de fusión empresarial de Cassinelli y Celima-Trébol como consecuencia del acompañamiento comunicacional.

\section{- Objetivo específico 3}

Establecer la relación causa-efecto de la presencia o ausencia de la dimensión comunicacional en el proceso de cambio por fusión empresarial de las empresas Cassinelli y Celima-Trébol. 


\section{CAPÍTULO I: ESTADO DE LA CUESTIÓN}

En los últimos años, el crecimiento externo se ha convertido en una herramienta empleada por las organizaciones para optimar sus ventajas competitivas. Este crecimiento, se forja cuando una entidad acrecienta sus competencias y recursos, uniéndose o absorbiendo a otra entidad (Marín, 2008, p. 78). De esta manera, presenta un abanico de ventajas para la organización; como, por ejemplo, mejorar la participación en el mercado sin producir una sobrecapacidad potencial, poseer un crecimiento vertiginoso, adquirir activos humanos o técnicos y permitir el ingreso a determinados segmentos de mercado. Sin embargo, posee ciertas desventajas como los conflictos estructurales y culturales tras el proceso de fusión o adquisición (Zozaya, 2007, p. 43).

Bajo la misma línea, Hoang (2008) afirma que el crecimiento externo es en medida, más arriesgado y caro que el crecimiento interno, pero brinda resultados a corto plazo. Por lo que, es recomendable realizarlo si la empresa busca conseguir de manera rápida una cuota mayor de mercado, evitar el riesgo de caer en posesión de la competencia o ingresar con fuerza en otros mercados (p.55).

En la actualidad, muchas empresas que operan en el mercado peruano optan por la estrategia del crecimiento externo por medio de fusiones o adquisiciones como un medio que promueve la competitividad y rentabilidad en mercados globalizados. A continuación, se explicarán los antecedentes, fundamentos y conceptos de las F\&A.

\section{Antecedentes relacionados al problema}

A lo largo de los años, el tema de las Fusiones y Adquisiciones (F\&A) comprende seis periodos representativos. Éstos, responden a las maneras de integración predilectas como el principal factor de investigación (DePamphilis, 2011, p. 61). Este planteamiento es atractivo, ya que en cada uno de los periodos y en cada uno de los rubros empresariales, el estilo sobresaliente dio respuesta a objetivos específicos y tendencias marcadas por sector. 
a) Periodo 1897 - 1904: Conocido como el "periodo de consolidación horizontal", debido a que las principales fusiones de la época se dieron en el sector de la industria minera y la transportación, por lo que las grandes entidades absorbieron a las más pequeñas.

b) Periodo 1916 - 1929: Denominado como el "periodo de aumento de la concentración”, ya que se incentivó a ejercer una concentración industrial desde el inicio de las fusiones horizontales.

c) Periodo 1965 - 1969: Llamado también como "la era del conglomerado" por la llegada y desarrollo de la ingeniería financiera que representa una pieza clave en el desarrollo de las fusiones.

d) Periodo 1981 - 1989: Reconocido como "la era de la reducción" por la manifestación de compradores financieros que emplearon el método de compra apalancada que se basa en la adquisición de una determinada organización con fuente de financiamiento externo. Además, otro de los métodos aplicados fue la adquisición hostil que no es más que las compras que se realizan a ciertas industrias y que no se encuentran en venta, pero cuando está interesada en adquirirlas, puede tener el dominio de más del 50\% de las acciones y por lo tanto, puede llegar a tener el control de la nueva empresa.

e) Periodo 1992 - 2000: Más conocido como "la era de las Megafusiones estratégicas", debido a que en este periodo se evidenció la reducción de las barreras de negocio y la transformación de las tecnologías de la información.

f) Periodo 2003 - 2007: Llamado "el renacimiento del apalancamiento" por el incremento de las altas inversiones de capital privado y las adquisiciones de apalancamiento.

Las fusiones y adquisiciones para potenciar el crecimiento de los negocios como estrategias empresariales comenzaron a fortalecerse a finales del siglo XX. En el año 2000, lograron establecerse en el punto más alto del periodo. Sin embargo, en los primeros años del siglo XXI, empieza una etapa de recesión que luego, en el año 2004 vuelve a tomar fuerza y mejora la situación económica mundial (Bain \& Company, 2004, p. 12).

Por otro lado, notamos que en el año 2006 hubo mayor crecimiento de las F\&A a nivel global, logrando los 2,6 billones de euros y el volumen mundial aumentó en un $35 \%$ en relación con el año anterior. De esta manera, superó el récord del año 2000, en donde la burbuja tecnológica transportó a las compañías a una actividad delirante de adquisiciones (Zozaya, 2007, p. 44). 


\subsection{Fundamentos de las Fusiones y Adquisiciones}

En esta sección, se exponen los fundamentos teóricos que dan soporte a la investigación y con ello, se realiza una revisión de determinados conceptos y teorías de ciertos autores que se han centrado en los temas de fusión y adquisición.

\subsubsection{Conceptos}

Para abordar correctamente el tema de la investigación, se debe partir por el análisis del concepto de F\&A y, además, se debe evaluar las diversas perspectivas que poseen los autores.

Por ello, Soto Mora (2014) afirma que las fusiones se identifican por ser operaciones en las que interceden como mínimo dos entidades independientes jurídicamente. Una de estas dos empresas, es la que perderá su personalidad jurídica y dicho proceso, involucrará una cierta integración de los patrimonios de las entidades fusionadas (p. 35). Por otro lado, se define como fusión o adquisición a la combinación de dos o más compañías en una nueva (Wallace, 2012, p. 73).

Por otro lado, otros autores como Hoang (2008) poseen conceptos más amplios sobre el término de F\&A en sus investigaciones y señalan que puede tratarse de un número de diversas transacciones, tales como la compra y venta de organizaciones, la sucesión corporativa, alianzas, la concentración entre empresas, la cooperación y conglomeración para la formación de entidades, la independencia de las empresas, la compra de participaciones, entre otros (p. 56).

\subsection{Gestión Comunicacional}

A inicios del siglo XXI, el término gestión toma cada vez más relevancia al desarrollar actividades necesarias para garantizar la solidez en cuanto a las administraciones y direcciones de las organizaciones. 


\subsubsection{Conceptos}

Carlos Fernández (2005) señala que la gestión de las estrategias comunicacionales son las diversas acciones efectuadas con el fin de alcanzar los objetivos planteados y obtener los resultados esperados cuando se definen determinados proyectos estratégicos en las organizaciones (p. 34).

En este sentido, las instituciones deben ser gestionadas de manera eficiente para conseguir los objetivos y metas propuestas, en donde el personal debe alimentar constantemente los canales de comunicación para que sean muy efectivos y en beneficio de todos los colaboradores (Sergio Guzmán, 2011, p. 77).

Asimismo, la gestión debe apoyarse en una comunicación que consiga el diálogo, guíe la búsqueda de las ideas, valorice el silencio como acto de pensamiento, sepa escuchar y brinde la total transparencia en las rediciones de cuentas de la compañía para lograr acentuar las tendencias que pueden surgir a nivel global (Saniz, 2015, p.48).

De esta manera, el concepto de comunicación cumple un papel esencial que le permite adecuarse a los drásticos cambios provenientes del mercado y así, poder responder a las exigencias que la sociedad realiza continuamente. Bajo esta premisa, la comunicación garantiza la veracidad y fluidez en cuanto a la transmisión de mensajes al compensar a los diversos públicos internos y externos.

Como consecuencia, las empresas requieren mantener una comunicación que les permita beneficiar los procesos administrativos y lograr que la gerencia tenga una comunicación global para afrontar los nuevos desafíos en beneficio del desarrollo cultural y económico de los colaboradores y, transformen mentalidades y actitudes como único modo de responder a los cambios acelerados del entorno (Ortega, 2008, p.34).

Con todo lo expuesto en las líneas anteriores, es crucial la gestión comunicacional para afianzar las relaciones interinstitucionales, establecer lineamientos de contenidos e información para los públicos internos y externos y, disponer de una gerencia específica que permita lograr vínculos efectivos y mantener políticas comunicacionales. Asimismo, es 
preciso humanizar el proceso administrativo por medio de las relaciones interpersonales con el fin de que fortifiquen el entendimiento bilateral y genere una alta compresión entre todos los colaboradores. Por ello, es fundamental reconocer los principios básicos de la empresa que certifiquen la pertinencia social y posible repercusión en los públicos internos y externos de ésta.

Por último, Sergio Guzmán (2011) indica que la comunicación organizacional se divide en dos tipos:

\section{- Comunicación Interna}

Es denominada como el conjunto de actividades o programas desarrollados por cualquier compañía para la creación y mantenimiento de estrechas relaciones o vínculos entre sus miembros. Por ende, está enfocada al personal de la empresa, ya sea a los directivos, gerentes, colaboradores y obreros a través de la utilización de diversos medios de comunicación que permitan que estén informados, integrados y motivados para contribuir y fortalecer su labor en términos de logros de los objetivos empresariales (p. 77).

\section{- Comunicación Externa}

Es aquella que se enfoca en los diferentes públicos externos de la entidad como, por ejemplo, los accionistas, distribuidores, proveedores, funcionarios gubernamentales, clientes, medios de comunicación, etc. Por tanto, es considerada como la agrupación de mensajes expuestos por cualquier institución frente a sus diferentes públicos externos, con el fin de mejorar y conservar estrechos vínculos con ellos. Asimismo, pretenden proyectar una imagen favorable y en determinadas ocasiones, fomentar sus productos o servicios (p. 78).

\subsubsection{Flujo de comunicación en las organizaciones}

Dentro de este marco, es sustancial conocer el enfoque en el que se origina la comunicación dentro de una compañía. A continuación, se explican los flujos de comunicación más empleados en las organizaciones (Saniz, 2015, p.50): 
- Comunicación Descendente

Se le denomina a la comunicación que circula a partir los niveles más altos de una empresa hasta los más bajos y se compone de 5 tipologías: instrucciones organizacionales, explicación referente a lo laboral, información acerca de los procedimientos, retroalimentación al colaborador con respecto a la acción y, por último, información de característica ideológica para comenzar el entendimiento de una misión por cumplir (p.50).

- Comunicación Ascendente

Este tipo de comunicación comienza en los niveles más bajos de la entidad hasta los más altos y comprende el uso de las siguientes herramientas: reuniones grupales, buzón de sugerencias y procedimientos ante posibles quejas (p.50).

\section{- Comunicación Horizontal}

Se conoce como comunicación horizontal a aquella que transita entre funciones específicas de los colaboradores y que son relevantes para coordinar e integrar los diversos trabajos en una institución (p.51).

- Comunicación Diagonal

Esta comunicación cruza diversas funciones y niveles de una empresa y, es sustancial cuando los miembros de la misma poseen obstáculos al comunicarse a través de los otros distintos canales (p.51).

\subsection{Gestión Comunicacional en procesos de fusión y adquisición}

Según Rivero (2010), la Gestión Comunicacional es el conjunto de diversas etapas o fases que son establecidas por una organización para dirigir y controlar todo lo que engloba el sentido de comunicación. De esta manera, debe estar alineada la gestión integral de la compañía, debe influir directamente en todas las actividades que se realizan dentro de la 
misma, y además, debe definir los diversos objetivos que establecen las bases de contacto con sus públicos (p.69).

En las fusiones, la Gestión Comunicacional se torna fundamental debido a que, crea, desarrolla, ejecuta y evalúa todo el proceso para mitigar los rumores y las especulaciones que pueden tener los colaboradores con referencia a la organización. También, permite a reflejar los intereses, estrategias y directrices de la nueva entidad constituida (Trelles, 2002, p. 34).

Para Gregory (2013), la decisión estratégica de emprender una Gestión Comunicacional con una visión general es equivalente a proyectar mayor capacidad en cuanto a anticipar, adaptar y transformar sucesos o hechos que puede atravesar la empresa. Variables que hoy en día, son primordiales para enfrentar los propósitos y desafíos que persiguen las diversas organizaciones (p. 88).

\subsubsection{La importancia de la gestión comunicacional en las fusiones}

La comunicación como acción estratégica es un aspecto fundamental en el cuidado de la difusión de información confidencial de la compañía. Es por esta razón, que es crucial considerar las nueve reglas de la comunicación en procesos de fusiones o adquisiciones (Ritter, 2005, 191):

1. No diferenciar la comunicación interna y externa de la empresa

2. Ceñirse a los mensajes clave previamente señalados.

3. El valor de las acciones en la bolsa se fundamenta en futuras posibilidades.

4. El valor de las acciones está comprometido por diversos elementos, no solo por los efectos operativos.

5. No se debe mentir en ninguna circunstancia.

6. Se deben evitar los diálogos privados.

7. Evitar que el personal de la empresa se vea envuelto en brindar declaraciones especulativas.

8. Los colaboradores de la entidad pueden ser responsables por cualquier declaración falaz, engañosa o falsa. 
9. Si existen dudas, se debe contactar al área de Comunicaciones Corporativas.

Por otro lado, en la actualidad, las fusiones son consideradas como uno de los instrumentos esenciales del modelo económico que admiten por medio de la unificación, desarrollo, productividad, competitividad y rentabilidad, el acompañamiento en la gestión de comunicación sujetos al estilo de gerencia, estructura y precisiones de la entidad en cuestión (Saniz, 2015, p.51).

Por lo general, las áreas de las compañías que son producto de los procesos de fusión o adquisición resultan afectadas, ya sea en reducción de recursos o de personal. Por ello, es que la gestión comunicacional debe darse de la manera más efectiva e inmediata para poder internalizar la transformación en los públicos internos como externos. De esta manera, se darán a conocer las implicaciones de los nuevos servicios, la imagen que se desea proyectar y la nueva forma de hacer las cosas, con el objetivo de que entiendan, reconozcan y acepten el proceso de fusión o adquisición para alejarlos de cualquier pensamiento de inestabilidad (Alexandris, 2012, p. 39)

Cording (2008) afirma que en medida en que los colaboradores tengan asumido, comprendido e interiorizado el proceso de fusión o adquisición, se puede expresar, con mayor garantía, el éxito en los momentos de verdad y construir una nueva imagen organizacional. Para ello, es imprescindible involucrar al personal en el levantamiento de los nuevos valores y dialogar con ellos los retos, propósitos y decisiones de la empresa. Asimismo, es crucial darles un acercamiento a los nuevos postulados, brindarles capacitaciones y permitirles la participación en asuntos relacionados a la institución, con el fin de vincularlos y crearles espacios de comunicación (p. 87).

El área de Comunicación y los demás departamentos de la compañía deben trabajar estrechamente, conversar, diseñar, acordar y efectuar procedimientos que impliquen a los públicos internos y externos. De esta manera, será posible administrar los esfuerzos bajo una sola directriz, conseguir cierta correlación y alineación con los objetivos y, reforzar la calidad de los servicios que son considerados como una ventaja competitiva de la empresa (Adiego Calvo, 2015, p. 54). 
Con ello, vemos la importancia del Departamento de Comunicación, ya que son los que se encargan de dar a conocer la información, novedades y noticias de la entidad. Además, de comprender lo que está sucediendo en el entorno, identificar las ventajas de la fusión o adquisición y prepararse para los nuevos desafíos a fin de asumir una posición próspera con referencia a las variaciones administrativas que involucran los procesos de F\&A.

\subsection{Trabajos propuestos relacionados al tema}

El impacto del tema de investigación ha llamado la atención de diversos intelectuales a lo largo del mundo. Por lo que, los estudios relacionados constituyen una fuente relevante de información para el desarrollo de este proyecto de tesis. En este apartado, se muestran algunos proyectos de investigación relacionados con el tema de fusiones y adquisiciones.

El primer proyecto se encuentra vinculado a un estudio de trabajo acerca de la fusión entre Telecom Argentina y Cablevisión, bajo el título de "Liderazgo y comunicación interna durante los procesos de fusión o adquisición entre empresas de telecomunicaciones" del autor Raúl Darío Palomino (2018). Éste, pretende analizar la influencia de la cultura y liderazgo dentro de los procesos de fusión y adquisición entre organizaciones de telecomunicaciones, con el objetivo de entender la relevancia de estos factores, apoyar la necesidad de contar con un liderazgo transformacional y mantener una integración cultural para afrontar el periodo de transición de los procesos de fusión de manera efectiva. Entre los principales hallazgos encontramos:

- La fusión surgió como una estrategia para aprovechar las ventajas competitivas de ambas entidades en el mercado pese al contexto de la fuerte devaluación monetaria de Argentina que puso en riesgo el proceso de transición.

- Con respecto al lado comercial, las sinergias de las compañías permitieron obtener mejores ganancias al ofrecer productos empaquetados que fidelizaron a los clientes y sumaron nuevos suscriptores potenciales.

- Ambas organizaciones son sindicalizadas, por lo que mantienen una estructura de culturas diferenciadas y se convierte en una amenaza para el éxito de la nueva empresa. 
Por otro lado, en el año 2017, Catalina Ortiz, Liliana Ríos y Sindy Martínez publican el trabajo de investigación titulado "Impacto de las Fusiones y Adquisiciones Empresariales en la Cultura Organizacional Contemporánea" que busca examinar cómo las tácticas de fusión y/o adquisición corporativa impactan en la cultura organizacional en el ámbito laboral moderno por medio de tres sucesos: a) adquisición de la compañía Rica Rondo por parte de Alimentos Cárnicos (Grupo Nutresa), b) fusión entre Hewlett Packard y Compaq y c) fusión de dos grandes firmas petroleras: Esso Colombiana Limited y Mobil de Colombia. Sus principales hallazgos son los siguientes:

- Las estrategias de fusión y adquisición institucional se pueden realizar correctamente, empleando herramientas que conllevan a reducir el impacto negativo para la institución y el personal involucrado.

- En el caso de que dichos procedimientos se planeen y gestionen estratégicamente, partiendo de la relevancia de la cultura organizacional, se obtendrán los resultados esperados.

Por último, el estudio titulado "La Comunicación en un proceso de Fusión Organizacional" de los autores Jair Meyer, Diana Luna, Aura Cartagena y Sandra Gómez, relacionado a la fusión entre una empresa colombiana del sector financiero con una extranjera del mismo sector (2005) - no se especifican los nombres reales de las compañías -; pretende realizar un análisis del proceso comunicativo en las diferentes fases atravesadas por las instituciones en el proceso de fusión. De esta manera, se establecen las formas y barreras de comunicación que se crearon en el proceso y además, se desarrolla la gestión de la comunicación en la adaptación y asimilación del proceso de cambio. Partiendo de esa premisa, se despliegan los principales hallazgos:

- La comunicación se dio en cascada, transmitida de los niveles superiores hacia abajo. Sin embargo, fue reactiva, ya que se fue dando en la medida en que se presentó la necesidad de brindar esta información.

- Existieron efectos producidos por el proceso de fusión tales como la deserción de personal, desmotivación, impacto en la productividad, efectos en la identificación y el sentido de pertenencia por parte de los colaboradores. 


\section{CAPÍTULO II: MARCO TEÓRICO}

\section{Las fusiones empresariales}

\subsection{Fusión de empresas: definición, clasificación y características}

Según la Real Academia de la Lengua Española, la fusión es toda aquella labor de fundir o fundirse; coalición de intereses o integración de determinadas empresas en una sola entidad que habitualmente se encuentra regulada con el fin de evitar abundantes concentraciones de poder sobre el mercado (RAE, 2017, p.1101).

Asimismo, Mergerstat (2000), la mayor base de datos online que contiene la trayectoria de las operaciones de las fusiones y adquisiciones en Estados Unidos manifiesta lo siguiente:

Una fusión puede ser definida como una situación en la que dos o más empresas independientes se unen, o bien, cuando una o más personas que están controlando ya al menos una compañía, adquieren, directa o indirectamente, el control de todas las partes o, al menos, se encarga de una de ellas. Por lo que, en una fusión, las dos o más empresas crean una nueva entidad y en una adquisición, la compañía objetivo o adquirida pierde su autonomía económica y legal (párr.4).

Además, el autor Juan Mascareñas (2005) sostiene que "la fusión es la reunión de dos o más entidades ya preexistentes. Se da cuando una u otra es absorbida por constituir una nueva compañía subsistente y esta última, hereda los derechos y obligaciones de las sociedades intervinientes" (p.56).

También, Cabre (2007) señala que una fusión se efectúa cuando dos o más empresas deciden vincular su patrimonio de manera voluntaria, o a través de la decadencia de ambas y formación de una nueva entidad, o, por último, absorbiendo una a otra. En otras palabras, una fusión se produce cuando una empresa adquiere la participación de otra que le da el dominio sobre ésta, con o sin el contrato de la junta administrativa de la entidad adquirida (p.67).

De la misma manera, la fusión de sociedades comerciales es una disolución de las corporaciones a través de la cual, una empresa desaparece por el traspaso sistémico de su 
patrimonio a otra ya preexistente o se forma mediante las aportaciones de los patrimonios de dos o más entidades que en ella se fusionan (Laniado \& Beltrando, 2003, p.76).

Por su parte, la Organización para la Cooperación y Desarrollo Económico Argentina (2007), afirma que "la fusión es la transmisión del patrimonio de una o varias compañías a través de la absorción por parte de una sociedad. La fusión es una operación por la que las entidades pueden incrementar su producción o penetrar en nuevos mercados" (p.34).

Por otro lado, Timothy Galpin, sostiene que la fusión no es nada menos que un acto jurídico por el cual, se unen los patrimonios de dos o más empresas cuyos nombres desaparecen o, en determinados casos, alguna de estas sociedades sobrevive para acoplarse en una organización unitaria que los sustituye dentro de un entorno comercial. Esto, con el fin de dar como resultado la creación de una nueva compañía o la absorción realizada por parte de la que sobrevive (Galpin, 2000, p. 89).

En Perú, la Ley General de Sociedades (Ley Nº 26887 del 2015), estipula:

La fusión dos a más sociedades se congregan para constituir una sola consumando los requerimientos prescritos por esta ley. Puede adquirir alguna de las siguientes estructuras:

a) La fusión de dos o más sociedades para establecer una nueva colectividad produce la pérdida de la personalidad jurídica de las unidades asociadas y la transmisión en bloque, y a título global de sus patrimonios a la nueva cooperativa; o,

b) La absorción de una o más sociedades por otra colectividad existente suscita la decadencia de la personalidad jurídica de la unidad o unidades absorbidas. La cooperativa absorbente asume, a título universal, y en bloque, los patrimonios de las absorbidas.

En ambos casos los socios o accionistas de las sociedades que se extinguen por la fusión reciben acciones o participaciones como accionistas o socios de la nueva sociedad o de la sociedad absorbente, en su caso (p.68). 
Con todo lo expuesto anteriormente, podemos decir que la fusión de las empresas es la agrupación de dos entidades o más que tienen como fin en común, el lograr la optimización de los resultados y el fortalecimiento financiero a futuro.

Figura 1: Las fusiones y su consolidación en el entorno empresarial

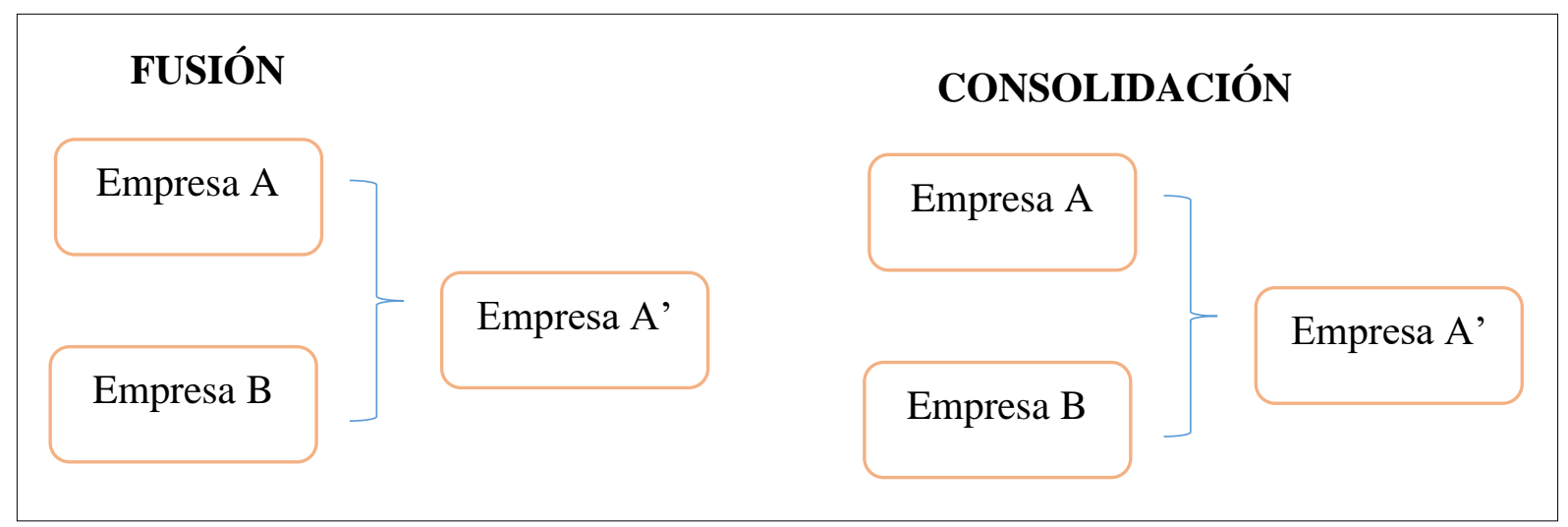

Fuente: Juan Mascareñas Perez-Iñigo, 2005, p. 67

\subsubsection{Modalidad de adquisiciones}

Las fusiones y adquisiciones se pueden clasificar de múltiples maneras. Por ejemplo, por su financiamiento, por sus operaciones amistosas u hostiles, por compras directas o en mercado abierto, por pagos en efectivo o con acciones, por operaciones públicas de adquisición (OPAs), entre otras. Con ello, se puede agrupar en dos grandes modalidades: por adquisiciones y por fusiones (Laniado \& Beltrando, 2003, p. 94). 
Figura 2: Modalidades de Adquisición de Activos

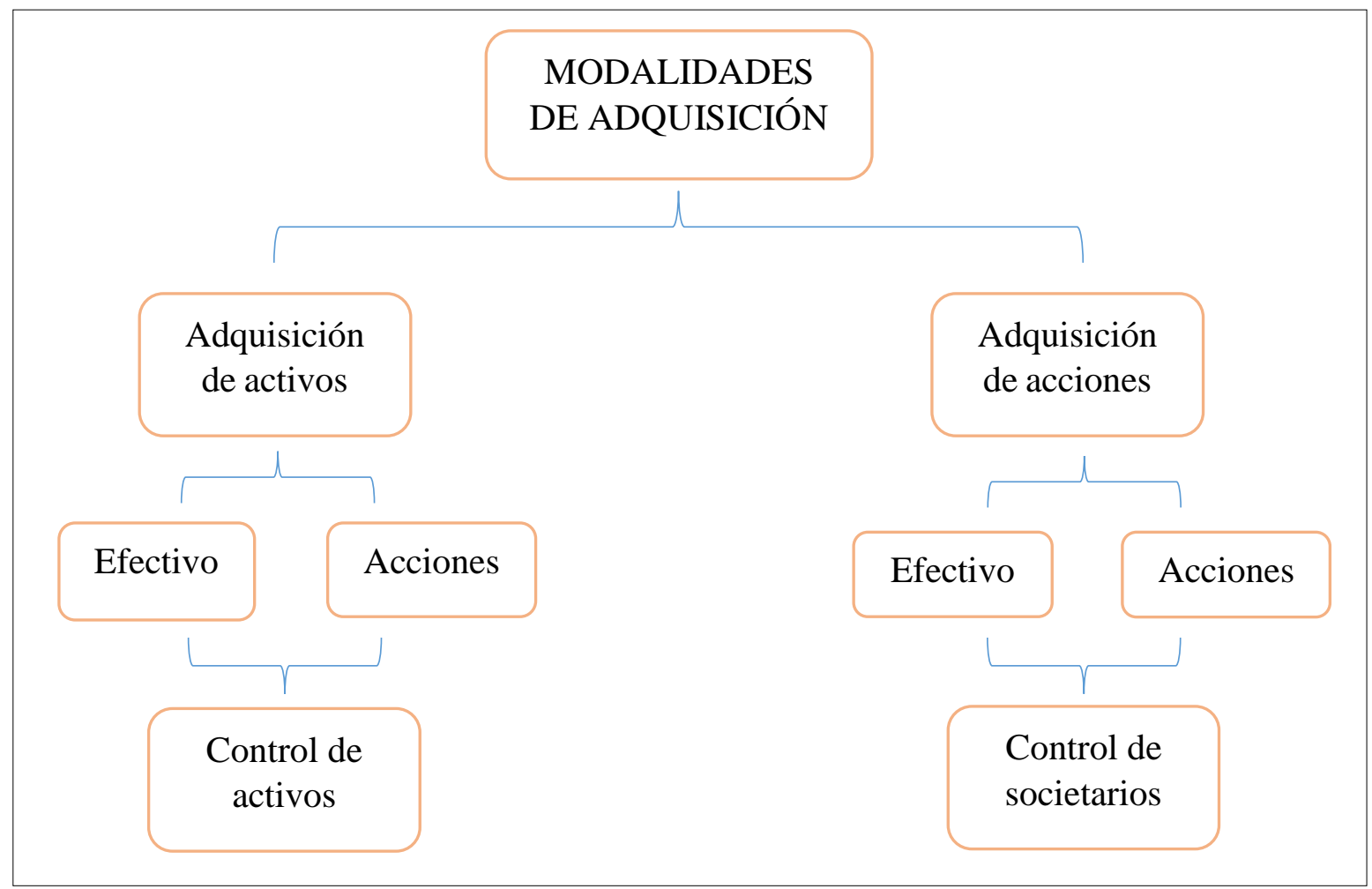

Fuente: Cabre Q., Olivares A., Pina D. y Salveraglio S., 2007, p. 35

\subsubsection{Adquisición de activos}

La combinación de activos se efectúa cuando una determinada entidad adquiere los activos de otra o cuando se forma una nueva empresa para adquirir los activos de una o más ya existentes. Es decir, es una modalidad por la que se obtiene el control de una compañía por medio de la adquisición de los activos que lo conforman. Cabe resaltar, que este conjunto de activos que constituyen una empresa en marcha es necesario para generar flujos de dinero y beneficios para el futuro (Forsyth, 2011, p. 126).

Según Robert Clark (2000), esta modalidad posee dos categorías. En primer lugar, la "operación de venta y liquidación societaria" o en sus términos en inglés (the corporate sale and liquidation transaction) en la cual, la venta de los activos se realiza directamente por la empresa a favor del adquirente a través del pago o contraprestación que se realiza en primera instancia. En otras palabras, la entidad que oferta sus activos continúa existiendo de manera independiente, pero sin ninguna actividad comercial (p. 418-424). 
Por otro lado, en segunda instancia, se encuentra la venta de los activos que forjará la disolución y liquidación de la compañía vendedora con el único fin de que sus accionistas se beneficien con la contraprestación pagada (Clark, 2000, p. 419-420).

Las consecuencias que se ejercerán sobre las partes intervinientes en este tipo de modalidad van a depender del tipo de contraprestación pactada. Es decir, si el pago se efectúa en acciones, la entidad objetiva se convertirá en la accionista del adquirente (asumiendo que ésta es una empresa que disponga crear y emitir acciones favoreciendo a su público objetivo) (Salinas, 2006, p.57).

Figura 3: Adquisición de activos

Mod: Acción de venta y Liquidación de sociedades

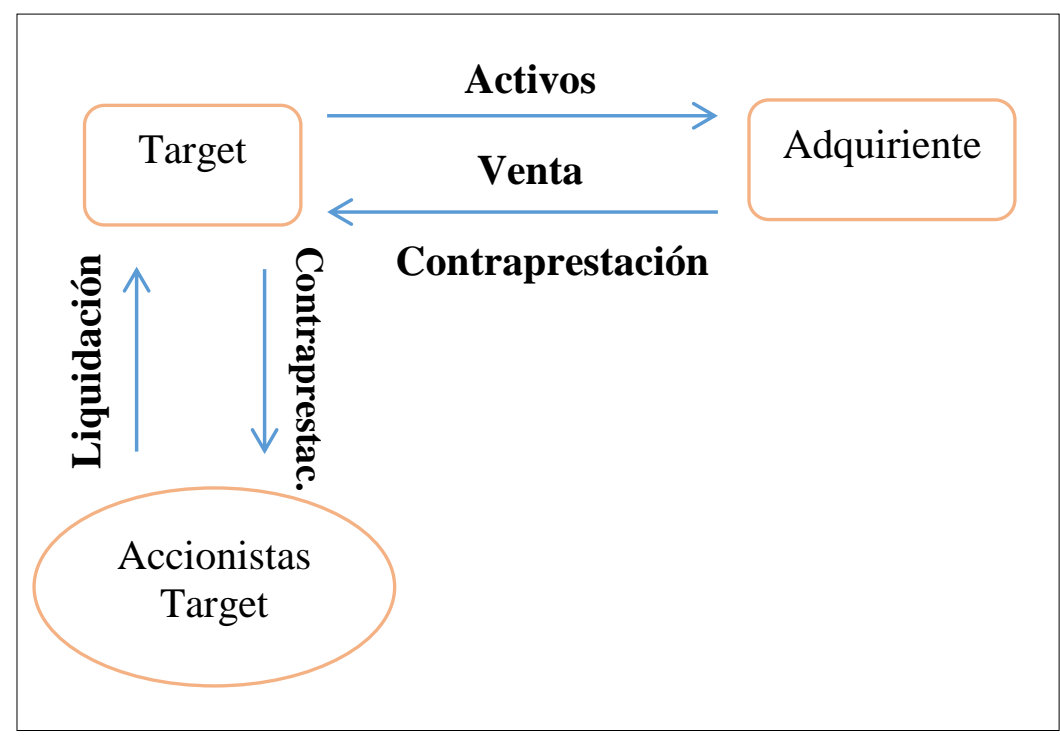

Fuente: Clark, 2000, p. 419 [Traducción propia]

En segundo lugar, la otra categoría de esta modalidad tiene por nombre "liquidación societaria y venta por los accionistas" o en sus términos en inglés (liquidation and shareholder sale transaction). Ésta consiste en disolver y liquidar la entidad propietaria de los activos que se planean adquirir para poder así, distribuirlos a los accionistas de dicha compañía en proporción a sus participaciones accionarias (Clark, 2000, p. 421).

Luego, los accionistas serán los encargados de vender directamente los activos, con el fin de percibir la contraprestación pactada con el adquirente. Como podemos ver, la principal 
diferencia de esta categoría con la anterior reside en que la adquisición no se efectúa directamente entre el adquirente y la empresa objetivo (que ya pasó por el proceso de liquidación), sino por el contrario, entre la primera sociedad y los accionistas de la segunda (Forsyth, 2011, p. 129).

Figura 4: Adquisición de activos Mod:

\section{Liquidación de sociedad y venta por los accionistas}

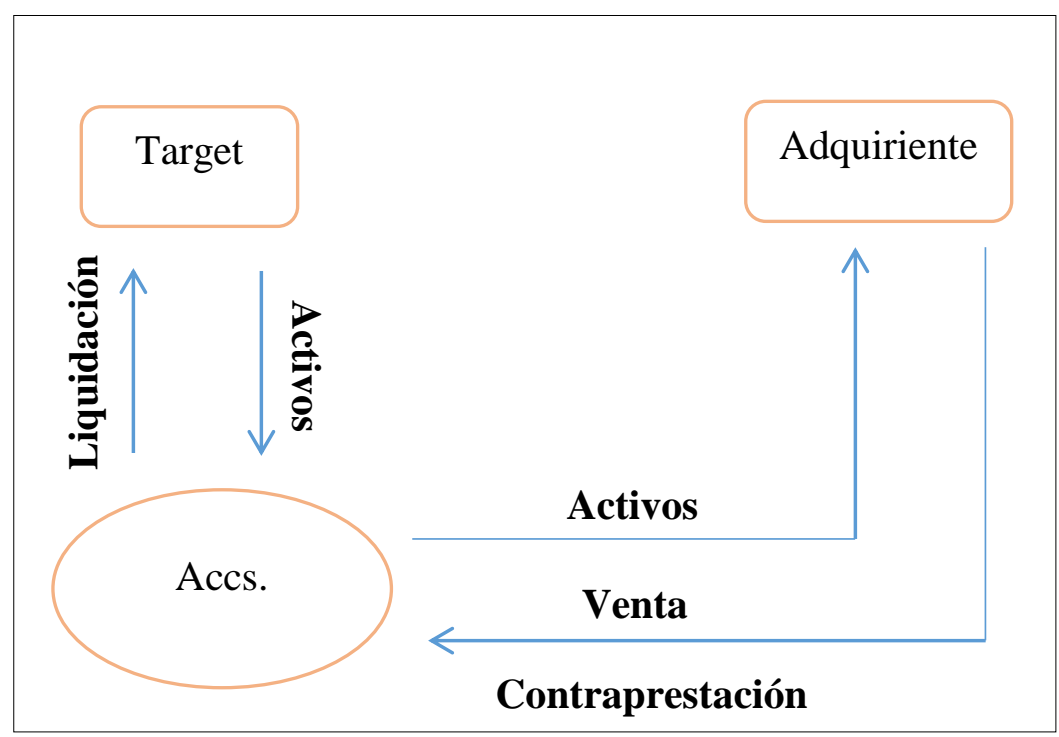

Fuente: Clark, 2000, p. 423 [Traducción propia]

Como en la primera categoría, la selección de una contraprestación en acciones o en efectivo provoca diversas implicaciones legales y estructurales para los participantes.

Como señala Laniado \& Beltrando (2003), es que, si bien en esta categoría la sociedad que vende los activos no es la empresa objetivo sino sus accionistas, el marco legal (ya sea una contraprestación en acciones o en efectivo) continuará el mismo que describimos en la categoría anterior pero solo cuando el vendedor accionista sea una compañía, debido a que fueron pensados para la parte vendedora como entidad objetivo. Cabe resaltar, que en caso el vendedor accionista sea una persona natural, la disposición dependerá de cada uno de ellos (p. 94).

Por último, es importante señalar las ventajas para el potencial adquirente que posee esta modalidad: (a) la probabilidad de elegir el tipo de pasivos o las obligaciones que serán asumidas por el adquirente dependiendo de los requerimientos que necesita para el negocio, 
con el único fin de no correr el riesgo de apropiarse de algún pasivo contingente o que se encuentre oculto y; (b) la probabilidad de no involucrar en grandes medidas a los accionistas minoritarios de la empresa objetivo. Esto es lo que diferencia una adquisición de una fusión propiamente dicha, el mejor precio de los activos de una sociedad por la posibilidad de controlar y minimizar el riesgo del comprador (Ross, Westerfiel \& Jaffe, 2000, p. 774).

Por otro lado, Salinas (2006), sostiene que esta modalidad también presenta determinadas desventajas tales como: (a) el conllevar a la formalización de la transferencia de los activos conforme pase más el tiempo (por ejemplo, los inmuebles); (b) los elevados costos de transacción que conlleva la adquisición de los contratos de compraventa con cada uno de los accionistas de la entidad; y, (c) el impacto tributario que puede generar la transferencia monetaria o accionaria (p.57).

\subsubsection{Adquisición de acciones}

La combinación por adquisición de acciones se traduce a la adquisición del más del $50 \%$ de las acciones comunes que una empresa puede realizar, ya sea en circulación, con voto o formando nuevas empresas para adquirir el control total de dichas acciones. Es importante señalar, que el tener más del 50\% la empresa, significa obtener el control sobre la otra entidad. En otras palabras, se produce cuando una sociedad realiza una oferta de compra (ya sea de la totalidad o parcialidad del capital social) a los accionistas de otra compañía cotizada en base a ciertas condiciones como el precio y, porcentaje de capital social de compra y tiempo (Ross, Westerfiel \& Jaffe, 2000, p. 77).

Además, Eduardo López Sandoval (2015), manifiesta que existen tres clases de adquisición de acciones (a) las adquisiciones en el mercado abierto que están divididas en negociación directa, ramassage y cesión de control; (b) a las ofertas públicas de adquisición (OPAs); y (c) las emisiones directas (p. 45). A continuación, se explicará cada una con mayor detalle.

En primer lugar, las adquisiciones en el mercado abierto son aquellas compras de acciones que previamente, han sido emitidas y pertenecen a los accionistas de la empresa objeto de adquisición. De esta manera, las adquisiciones se efectúan mediante transacciones individuales con cada uno de los accionistas. En un primer plano, se realizan a través de 
"compras al goteo" o "ramassage", conformadas por diversas series de operaciones previamente negociadas de manera bursátil que se encuentran consignadas a lograr una cantidad significativa de acciones que faculten tener el control de la sociedad objetiva (López, 2015, p.46).

Bajo el mismo contexto, en un panorama de adquisiciones que se ejecutan de manera extrabursátil, existen dos grandes posibilidades: (a) las denominadas "negociaciones directas" que son producto de continuas operaciones de compra con diferentes accionistas de la sociedad, hasta lograr conseguir una significativa proporción de acciones que permitan el control. Es una situación muy similar al ramassage pero de manera extrabursátil y basada en la negociación directa con los distintos accionistas de la empresa objetiva. Por otro lado, la segunda posibilidad es las "cesiones de control" que son causadas cuando las acciones se obtienen en conjunto y el accionista es el que conserva el control directamente (López, 2015, p. 51).

En segundo lugar, las ofertas públicas de adquisición - OPAs o en sus términos en inglés (Tender offer o Takeover bid), son ofertas públicas enfocadas en la adquisición de acciones con derecho a voto de entidades valiosas orientadas a todos los accionistas de la sociedad (Ross, S.; Westerfiel, R. \& Jaffe, 2000, p. 79).

Según el artículo $68^{\circ}$ de la Ley de Mercado de Valores y la Resolución CONASEV N 0092006-EF/94.10 y sus modificatorias (Reglamento de OPA), en el Perú, las OPAs son de carácter obligatorio en cuestión de que se adquiera o se obtenga una "participación significativa" en una determinada corporación (p. 23).

Por último, las emisiones directas se producen cuando las sociedades objetivas generan acciones que pueden ser usadas principalmente para efectos de la adquisición. Un claro ejemplo, es el incremento del capital social para el registro de las acciones por parte del adquirente (López, 2015, p. 53). 
Figura 5: Clases de adquisición de acciones

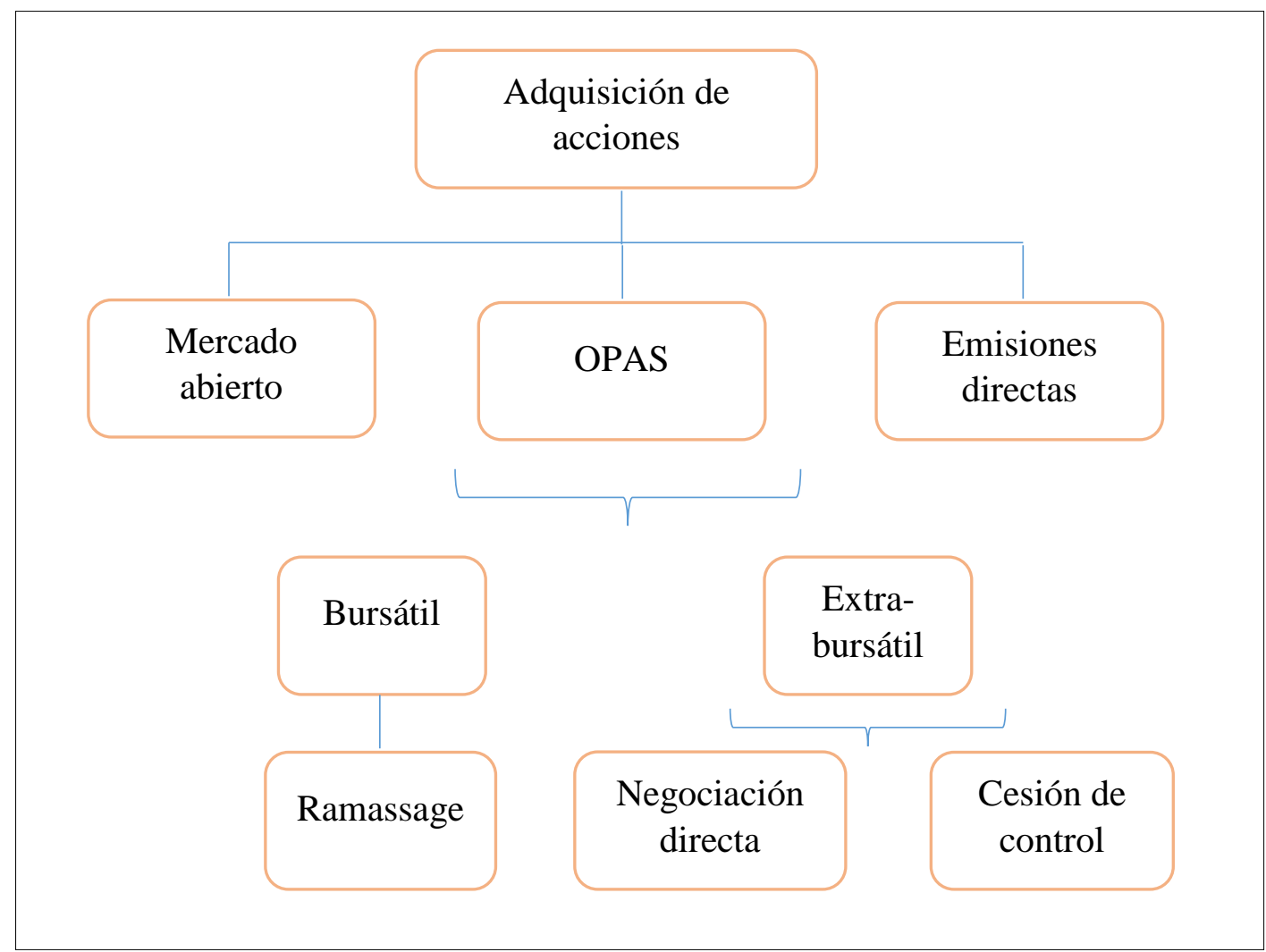

Fuente: López, 2015, p. 54

\subsubsection{Modalidad de fusiones}

\subsubsection{Fusión por Absorción y Fusión por Incorporación}

Las fusiones por absorción o incorporación son una o más empresas que desaparecen o se extinguen porque son absorbidas por una tercera ya preexistente que continuara operando. En este ejercicio, una o varias sociedades como resultado de su disolución sin liquidación transfieren en conjunto a otra entidad ya existente todos sus patrimonios sociales (activos y pasivos) que la sociedad absorbente adquiere por sucesión universal. Esto último, se realiza a través de la atribución a los socios de las empresas absorbidas o en proporción a sus participaciones respectivas. Hablamos en términos del total de los valores específicos de la ampliación del capital social que la corporación absorbente ha de efectuar, como contraprestación por la contribución recogida, y en cuestión, de una retribución en dinero (Galpin, 2000, p. 89). 
Esta operación presenta ciertas características tales como: (a) la compañía absorbida desaparece y su patrimonio es transferido en conjunto a la entidad absorbente (acontecimiento que se produce en todos los tipos de fusión); (b) la empresa absorbente es una empresa ya existente; (c) las nuevas participaciones o acciones creadas producto de la ampliación de capital se le otorgan a los socios de las empresas absorbidas, en proporción a sus aportaciones; (d) la compañía absorbente obtendrá todos los derechos y obligaciones de las compañías absorbidas; y (e) la corporación absorbente aumenta su capital social en contraprestación por las aportaciones recibidas (Laniado \& Beltrando, 2003, p. 59).

Figura 6: Fusión por Absorción

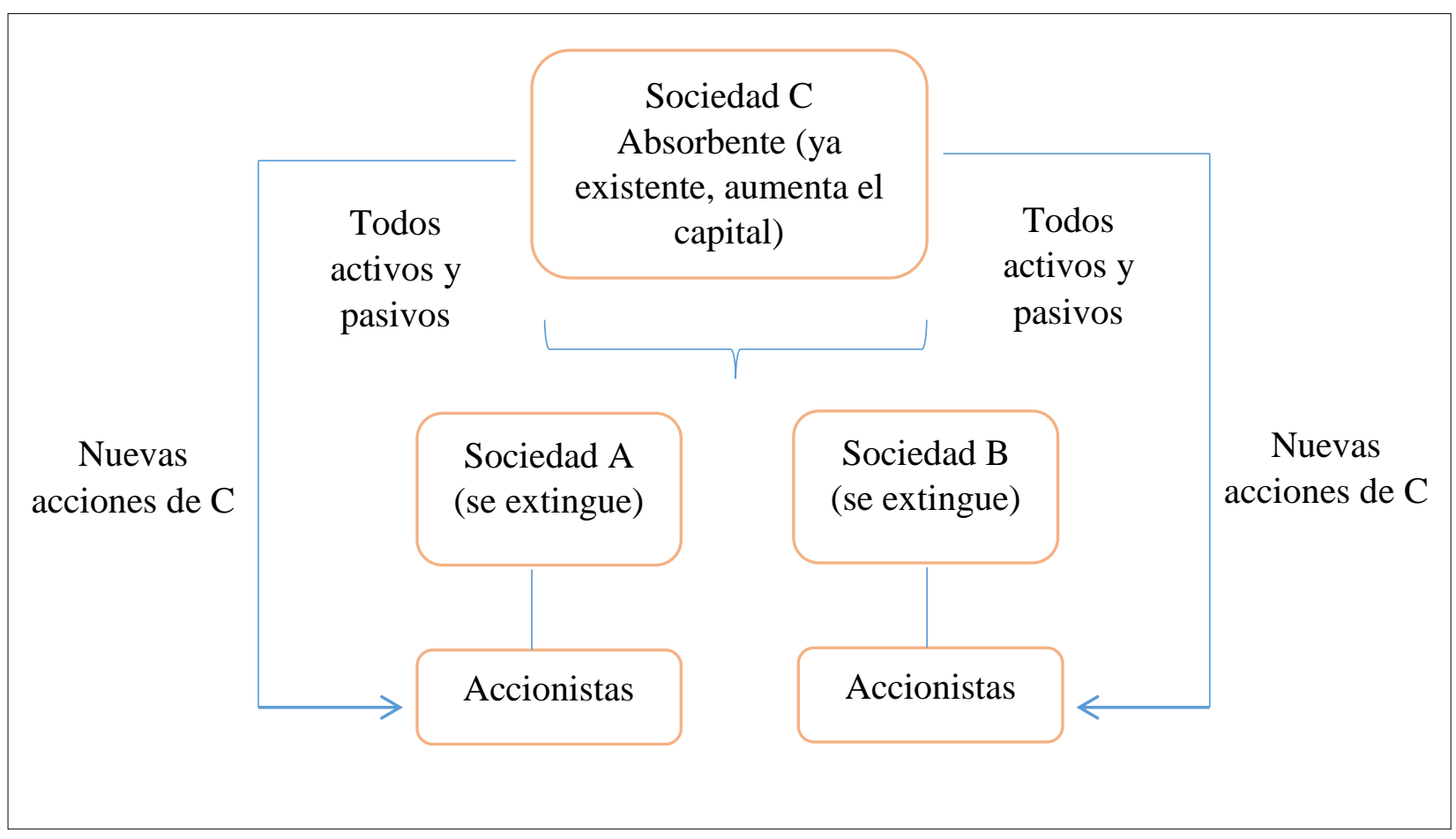

Fuente: Timothy Galpin et al., 2000, p. 94 [Traducción propia]

Timothy Galpin (2000) afirma que la fusión por absorción puede definirse en dos clasificaciones. En primer lugar, la combinación de empresas no relacionadas que se vincula a las empresas fusionadas que no mantienen una relación accionaria. Esto quiere decir, que el importe del patrimonio de las empresas que desaparecen suele incrementar el capital de la sociedad absorbente. En segundo plano, encontramos la combinación de empresas relacionadas que también, es denominada como combinación circular, debido a que la compañía que sobrevive es accionista que desaparece, por lo que corresponde a una 
adquisición de acciones propias. En otras palabras, equivale a una disminución en el porcentaje de la participación del accionista adquiriente en el capital que desparece, debido a que este monto monetario pertenece a la nueva sociedad absorbente (p.73).

Los beneficios que posee la fusión por absorción son diversos: (a) por lo general, es la forma más rápida de expandirse y de posicionarse en el mercado, eliminando directamente a la competencia; (b) la sociedad que efectúe el proceso de fusión obtendrá mayor personal clave, activos intangibles, equipo de investigación, patentes y marcas, prestigio y rápido ingreso a mercados deseables; (c) la óptima combinación de muchas partes de las entidades fusionadas, permite lograr minimizar los costos adherentes; (d) una buena gestión de la fusión por absorción, trae una mejor presencia o imagen corporativa, lo que contribuye a obtener la preferencia de los clientes y su fidelización (Laniado \& Beltrando, 2003, p. 59).

\subsubsection{Fusiones Horizontales, Verticales y Conglomerados}

Las fusiones y adquisiciones son mecanismos por los cuales, las compañías muestran diversos tipos de tácticas a nivel corporativo que facilitan la incorporación de nuevos mecanismos de negocio al portafolio corporativo con el objetivo de lograr objetivos de crecimiento y diversificación (Laniado \& Beltrando, 2003, p.96).

Las estrategias empresariales se clasifican por el modo que adquieren los diversos modelos de diversificación. En este sentido, existen diversas opciones de diversificación según la dirección o el sentido de esta.

Ansoff (2002), autor de la obra Corporate Strategy, propone un concepto normativo referente a la estrategia corporativa en el que contiene una matriz de análisis estratégico. Ésta última, es una herramienta clave para conceptualizar los elementos de crecimiento y diversificación de la empresa, además ayuda a entender la lógica que siguen las entidades en la implantación de dichas estrategias (p.87). Siguiendo la matriz propuesta por el autor, se puede exponer la clasificación de las estrategias genéricas: 
Figura 7: Alternativas estratégicas genéricas de crecimiento y diversificación

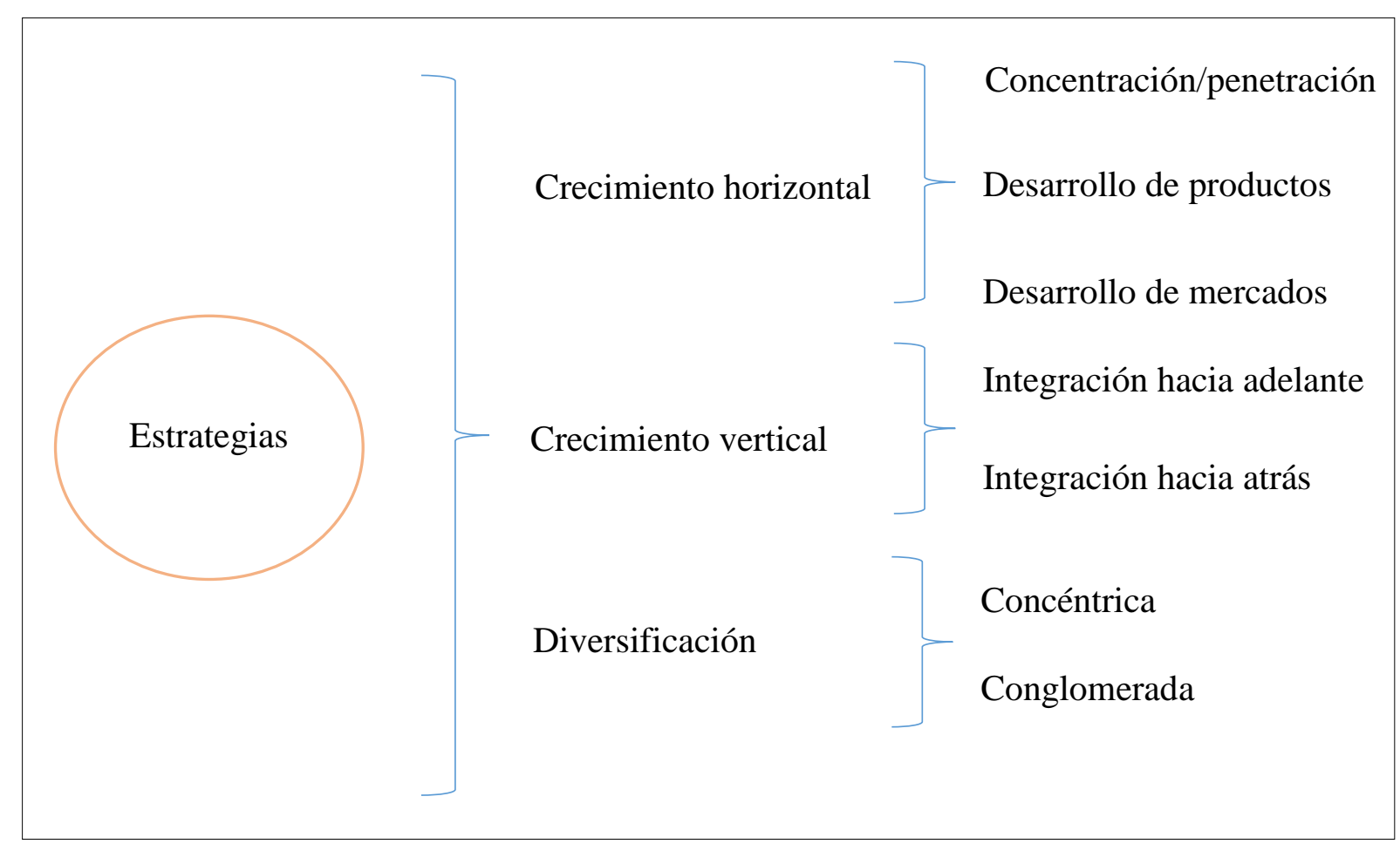

Fuente: Ansoff, 2002, p.89 [Traducción propia]

Por otro lado, Walter (1985) \& Kitching (1967), sostienen que, en base al criterio de diversificación empresarial, las fusiones y adquisiciones pueden agruparse de la siguiente manera:

- Verticales

- Horizontales

- Conglomerados de empresas

- Concéntricas

De esta manera, la clasificación de las fusiones y adquisiciones establecidas por el criterio de diversificación posee tres clases cuyo fin es tener una nueva entidad que contribuya al conjunto de capacidades que no están consideradas en ninguna de sus partes. Es así, como esta clasificación comprende los diversos métodos que se utilizan en una empresa para lograr 
uno de los objetivos más esperado de las fusiones, el crecimiento externo de la compañía. El cumplimiento de este objetivo da pie a las sinergias corporativas (Walter, 1985 \& Kitching, 1967, p. 81-86).

Por lo general, las fusiones verticales y horizontales se sustentan en un determinado tipo de sinergia: la sinergia operativa. Esto se debe, a que buscan alcanzar economías de escala que impidan que los volúmenes mínimos de actividad se tornen críticos para la supervivencia de la compañía, logrando así, la reducción de los cortes operativos de la entidad combinada (Galpin, 2000, p. 92).

Por su parte, Cooke (1986) manifiesta que los conglomerados suelen expresarse en sinergias financieras, siendo la opción más habitual para alcanzar este tipo de sinergia. Con ello, se quiere reducir el coste del capital, ya que el volumen de recursos que maneja el grupo empresarial es mayor. Los conglomerados son aquellas sociedades que compran a otra que pertenece a un sector completamente diferente al suyo (p.88).

A continuación, explicaremos las diversas clasificaciones de las fusiones y adquisiciones.

\section{A) Fusiones Verticales}

Las fusiones verticales son aquellas que se basan en la unión con una de las partes relevantes de la empresa como, por ejemplo, el proveedor con el consumidor. Este tipo de fusiones se efectúan con el fin de alcanzar mayor potencialidad, competitividad y, consolidar la existencia y rentabilidad de las entidades fusionadas (Forsyth, 2011, p. 130).

Asimismo, Clark (2000) sostiene que este tipo de fusión se da cuando dos compañías que operan en diferentes niveles de la cadena de valor de un determinado sector combinan esfuerzos de manera tal, que la sociedad resultante adquiera nuevas funciones. Además, esta clasificación se enfoca en la lógica de integrarse tanto verticalmente como hacia arriba o hacia abajo pero siempre dentro de la misma línea de la cadena de valor del sector (p. 421).

Del mismo modo, Clark (2000) señala que existen tres principales razones por las que una empresa se fusiona de manera vertical: (a) for full access to the various distribution channels, 
(b) for the use of a certain brand image and, finally, (c) for the service of the suppliers and security of the corporation's supplies [(a) por el completo acceso a los diversos canales de distribución, (b) por el uso de una determinada imagen de marca y, por último, (c) por el servicio de los proveedores y seguridad de los suministros de la corporación] (p. 422).

Ansoff (2002) manifiesta que las fusiones verticales se dan principalmente por las siguientes razones: (a) la relación que poseen con la seguridad de los suministros y el servicio de los proveedores; (b) la relación que tienen con el coste; (c) la relación que asumen con el acceso a canales de distribución y; (d) la relación que adquieren con el uso de una imagen de marca (p. 90).

Por otro lado, las estrategias empresariales con mayor uso en este tipo de fusión se dividen en dos: las estrategias de integración hacia delante o en su denominación en inglés "forward integration" y las estrategias de integración hacia atrás o backward integration en inglés (Cooke, 1986, p.89).

Por un lado, la estrategia de integración hacia delante (forward integration) responde al logro de obtener un mayor grado de acercamiento y cercanía a los clientes, así como también, aproxima los productos a los clientes potenciales de una corporación. De este modo, se mejora o se asegura óptimamente el control sobre las ventas y sobre el trabajo empleado por los canales de distribución, con el fin de lograr un mejor balance en cuanto a los sistemas de comercialización y producción, así como también, tener un mejor control del mercado en el que se encuentra situada la entidad (Ansoff, 2002, p. 89).

En esta clasificación, se encuentran todas aquellas sociedades que realizan actividades asociadas al margen de contribución que la empresa produce, por ejemplo, la distribución, el transporte, las reparaciones, entre otros servicios (Galpin, 2000, p. 93).

Por otro lado, se encuentra la estrategia de integración hacia atrás (backward integration), que permite tener un grado de acercamiento hacia las materias primas, logrando el control de los materiales esenciales para un tener un óptimo proceso productivo. Esto se ve reflejado con mayor notoriedad, en aquellos casos en donde el producto final refleja la imagen de marca de la compañía (Ansoff, 2002, p. 91). 
Cooke (1986) sostiene que con esta estrategia se puede garantizar el control de calidad de los diversos materiales que la empresa posee y, además, permite tener un suministro adaptado a las exigencias de producción y de la estabilidad de precios para la comercialización de los productos. (p.91). Además, declara que esta estrategia suele ser usada en sociedades con rubros o actividades relacionadas a los insumos de la compañía tales como maquinaria, materias primas y mano de obra (p.93).

\section{B) Fusiones Horizontales}

Las fusiones horizontales son aquellas en donde las entidades absorbentes deciden adquirir otra u otras empresas que forman parte de su mismo rubro o actividad económica y que, además, operan dentro de los mismos mercados geográficos (Forsyth, 2011, p. 132).

Asimismo, Giner (2009), declara lo siguiente:

Son las que tiene lugar entre dos empresas de un mismo sector y con líneas de productos relativamente similares, implican unión de empresas entre competidores directos. La idea de las fusiones horizontales es generar nuevos negocios relacionados a la estructura del mercado ya existente (p. 131).

Por otro lado, García, Martín, \& Benitez (1995), revelan que las estrategias empleadas en la fusión horizontal se encuentran orientadas a la incorporación a nuevos mercados basados en tres clases que se expondrán a continuación:

En primer lugar, se encuentran las estrategias de integración hacia atrás (backward integration), que admiten un grado de acercamiento hacia las materias primas, permitiendo un mayor control de los materiales que son relevantes para la realización del proceso productivo, sobre todo, aquellos en donde el producto final refleja la imagen de marca de la corporación (p.146).

Con esta estrategia, la empresa garantiza el control de calidad de materiales y, además, mantiene un suministro que va acorde a las exigencias de la producción y de la estabilidad 
de los precios de venta. Como se ha mencionado con anterioridad, la estrategia de integración hacia atrás es empleada en sociedades enfocadas a la realización de actividades que conciernen a los insumos de la empresa tales como materias primas, maquinaria y mano de obra (Ansoff, 2002, p. 93).

En segundo lugar, Ansoff (2002) menciona que las estrategias de concentración y/o penetración se encuentran orientadas a lograr la obtención de un mayor grado participativo o cuota de mercado en el sector en donde la entidad compite (p. 93).

Asimismo, tenemos las estrategias de desarrollo de productos, en donde las compañías las utilizan para lograr alcanzar los objetivos dentro de los sectores en los que la sociedad compite (Ansoff, 2002, p. 94).

Por último, Ansoff (2002) describe las estrategias de desarrollo de mercados que consisten en ofrecer los mismos productos y/o servicios en nuevos segmentos de mercado (p. 94).

Según Mascareñas (1996), el objetivo principal de la fusión de dos empresas de forma horizontal (estando éstas ya unidas en una sola) es el de consolidarse como una compañía superior con un poder más elevado en el mercado y, además, con operaciones que fomenten una reducción mayor en sus costos. También, sostiene que, mediante las sinergias operativas, se puede alcanzar la creación de un nuevo producto y/o servicio que nace de la fusión de dos sociedades que producen un mayor crecimiento en los ingresos de manera inmediata o a largo plazo (p. 235).

\section{C) Fusiones Conglomeradas}

Las fusiones conglomeradas son aquellas que se producen entre empresas cuyas actividades laborales no poseen relación entre sí. Es decir, se da cuando una compañía compra a otra entidad que corresponde a un sector completamente diferente al suyo (Forsyth, 2011, p. 136).

Asimismo, López (2015) señala que tampoco existe una estrecha relación entre los productos de las empresas vinculadas, por lo que puede entenderse en base a tres tipos: (a) la extensión 
de productos, con el fin de aumentar la línea de productos; (b) la extensión geográfica; y, (c) los conglomerados puros que engloba lo mencionado anteriormente (p.103).

A continuación, se explicarán estas tres clases de fusiones conglomeradas.

En primer lugar, tenemos la fusión para la extensión del producto que se exterioriza cuando dos entidades utilizan sistemas de producción o de distribución muy similares pero sus productos no compiten directamente entre sí (López, 2015, p.103).

Por otro lado, López (2015) asegura que la fusión para la extensión del mercado se da cuando las corporaciones fusionadas fabrican productos similares, pero en mercados diferentes (p.103).

Por último, la fusión sin relación se hace presente cuando las sociedades fusionadas no poseen ninguna relación y el único propósito de este ejercicio es el de ingresar en nuevos mercados o por alguna otra de las razones mencionadas anteriormente (p.104).

\subsubsection{Fusiones Directas y Fusiones Triangulares}

La fusión directa se manifiesta cuando dos entidades se fusionan bajo un acuerdo de conformidad aprobado por ambas, en donde una o las dos se extingue con el fin de que la empresa sea asumida por la otra o surja una nueva producto de la fusión. Dentro de esta clasificación, encontramos a la fusión por absorción y la fusión por incorporación (López, 2004, p. 52).

Por otra parte, López (2004) señala que la fusión triangular implica la participación de tres sociedades en la operación: las dos organizaciones principales y una subsidiaria de fusión o merger sub. Esta última, es constituida solo para el efecto, no posee ningún activo ni negocio y es la que se fusionará formalmente con la entidad objeto de fusión (p. 53).

En el caso de que la entidad foco o taget sea absorbida por la organización subsidiaria y sobreviva al proceso de fusión, la operación es conocida como una fusión triangular hacia adelante o en sus siglas en inglés: forward triangular merger. Por otro lado, en el caso de que 
la subsidiaria sea absorbida por la entidad foco o taget, la fusión se denomina una fusión triangular en reversa o reverse triangular merger. En ambos casos, lo más relevante es que la organización adquirente se va a convertir en la accionista controladora de dicha entidad resultante de la adquisición (ya sea cuando hablamos de la subsidiaria o del target) y como consecuencia, será el controlador indirecto de los activos de la entidad objetivo (López, 2004, p. 53).

Bajo el mismo enfoque, López (2004) afirma que las fusiones triangulares poseen dos ventajas importantes. En primer lugar, evadir la acción del derecho de división de los accionistas de la matriz adquirente y, además, bloquear cualquier potencial obligación contingente u oculta de la fusión en la subsidiaria (p. 54).

A continuación, detallaremos las implicaciones estructurales y legales de las fusiones: 
Figura 8: Modelo de adquisición por medio de fusión triangular hacia adelante

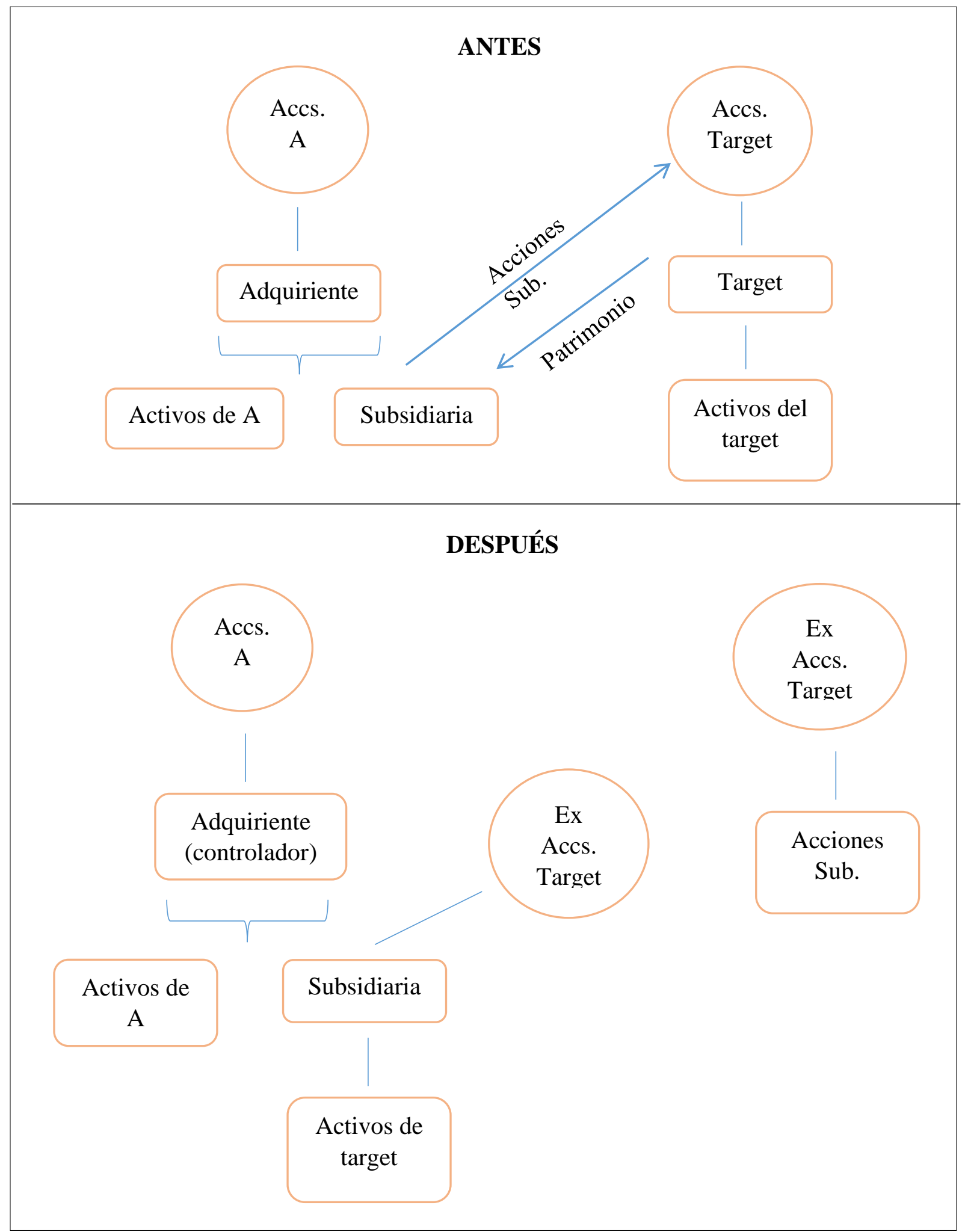

Fuente: López, Eduardo (2004) Leveraged buyouts a la luz de la regulación societaria peruana sobre asistencia financiera prohibida". Advocatus 10. Revista editada por los alumnos. Lima: Universidad de Lima, Facultad de Derecho. 
Figura 9: Modelo de adquisición por medio de fusión triangular en reversa

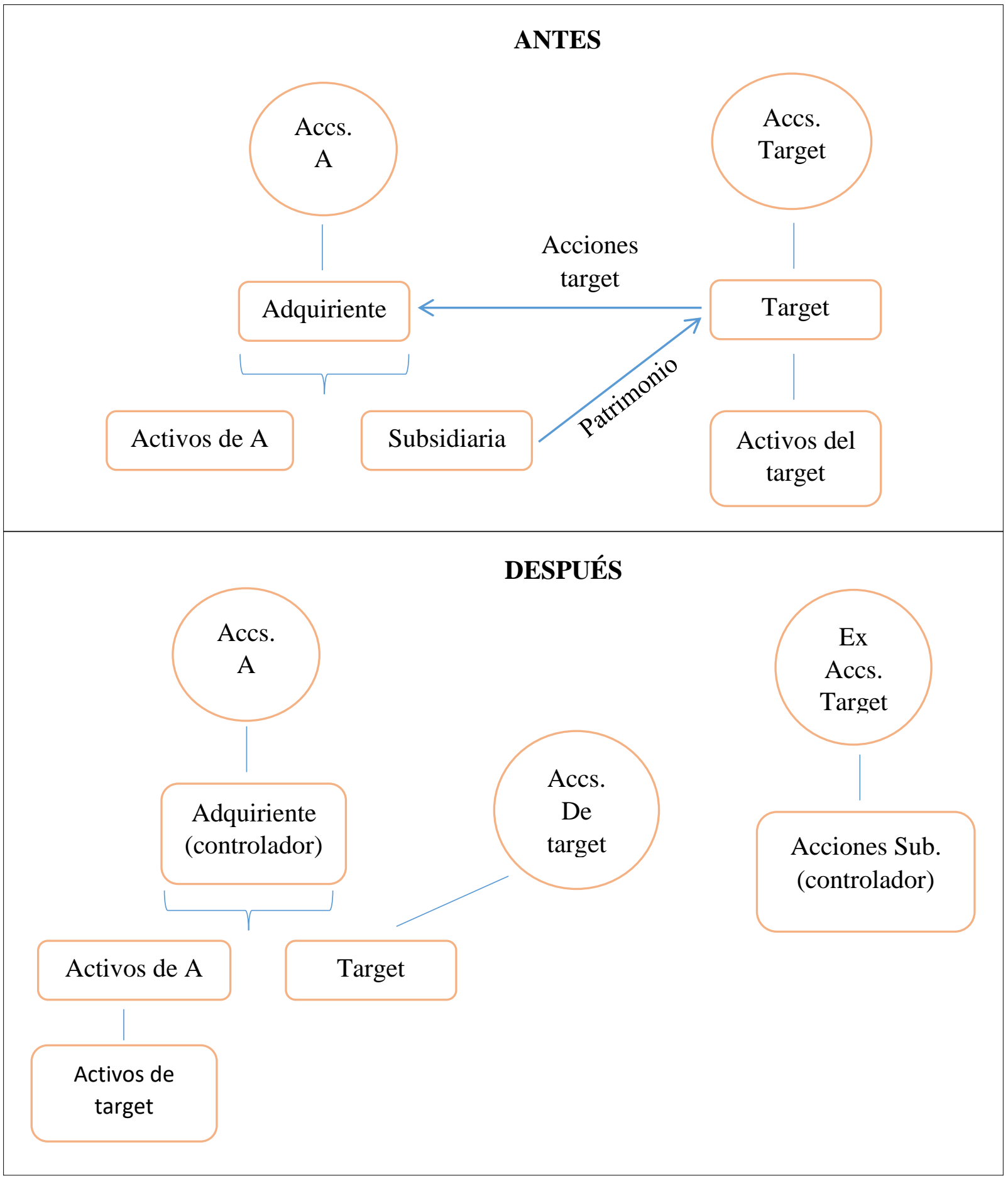

Fuente: López, Eduardo (2004) Leveraged buyouts a la luz de la regulación societaria peruana sobre asistencia financiera prohibida". Advocatus 10. Revista editada por los alumnos. Lima: Universidad de Lima, Facultad de Derecho. 
El marco legal aplicable para las fusiones triangulares es el mismo que el descrito para el caso de las fusiones por absorción y/o por incorporación, por lo que nos remitimos a lo manifestado para dicha clasificación.

Figura 10: Tipos de fusiones

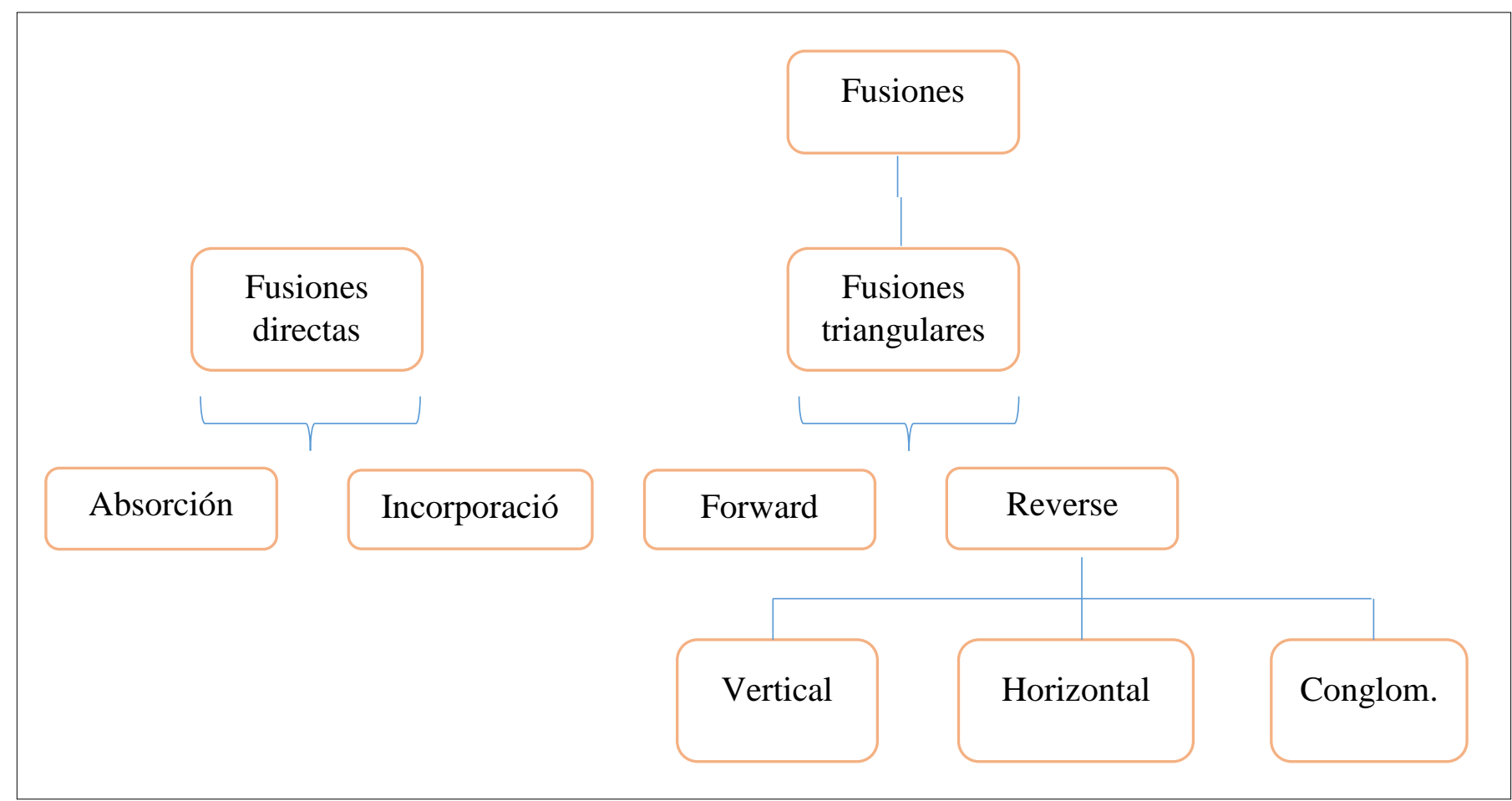

Fuente: López, Eduardo (2004) Leveraged buyouts a la luz de la regulación societaria peruana sobre asistencia financiera prohibida". Advocatus 10. Revista editada por los alumnos. Lima: Universidad de Lima, Facultad de Derecho.

Por todo ello, cabe recalcar que Cassinelli y Celima - Trébol experimentó un proceso de Modalidad de Fusión Horizontal con estrategia de Concentración y/o Penetración, ya que se presentó la integración de estas empresas por medio de una coalición de intereses, no existió ningún requisito sobre la forma de accionar en conjunto, no implicó ninguna pérdida de individualidad de las partes y además, se buscó el lograr la optimización de los resultados y el fortalecimiento financiero a futuro como utilidad en común. Asimismo, ambas entidades absorbentes adquirieron otra que formaba parte de su misma actividad económica y operaba dentro del mismo mercado geográfico. Por último, como parte de la estrategia, incorporaron una nueva organización para ingresar a nuevos mercados que sean de índole más participativo y en el sector en donde la entidad compite. 
2.2 La fusión como estrategia de crecimiento externo en la empresa

\subsubsection{El crecimiento: objetivo de las empresas}

Junto con el tema de la concentración empresarial, encontramos el concepto de crecimiento que se hace evidente en el objetivo empresarial.

La Comunidad de Madrid, publicó un artículo llamado "Estrategias de Crecimiento de la Empresa", respaldado por El Fondo Social Europeo de la Unión Europea (2017), en donde sostienen que el crecimiento acelerado de una entidad es la base de su desarrollo y supervivencia a largo plazo, así como el respaldo de poseer un flujo de ingresos muy favorable. Esto representa el sueño tangible de cualquier empresario (p.1).

Del mismo modo, sostienen que las empresas poseen una estrategia de crecimiento cuando:

- Crecen más rápidamente que los mercados en los que operan.

- Poseen márgenes superiores que la media.

- Intentan no entrar, posponer o eliminar la competencia en precios en su industria.

- Desarrollan regularmente nuevos productos y servicios, nuevos mercados, nuevos procesos, y nuevos usos para los productos antiguos.

- Tienden a crear nuevos conceptos y tendencias, introduciendo nuevas reglas de juego en su mercado, promoviendo la demanda de algo que no existía anteriormente (La Comunidad de Madrid, 2017, p.1).

Según Pablo Martinicorenana (2007), el crecimiento de una organización se produce cuando existen recursos ociosos o infrautilizados a los que se les intenta buscar una utilidad y explotarlos, en lugar de transferirlos a otra entidad dentro del mercado (p.12).

Asimismo, afirma que la empresa crece en el momento en el que generara un volumen mayor de recursos excedentarios, con el fin de que no se reduzca la rentabilidad de cara a los recursos propios y así, poder mantener la creación de valor (Martinicorena, 2007, p.13).

De esta manera, (Martinicorena, 2007) establece los siguientes beneficios provenientes del crecimiento empresarial: 
- Mayor prestigio por parte de los directivos y mejores posibilidades de promoción para los colaboradores, ya que permite fidelizar el talento humano con la organización al permitir que las personas tomen responsabilidades de gran relevancia.

- Enfrentar nuevos desafíos corporativos que inciten el desarrollo de las personas y la organización.

- Capacidad de ganar capital de inversores externos que permitan enfrentar proyectos de mayor envergadura.

- La prosperidad de la posición de la agrupación en los mercados de capitales.

- Alcanzar una posición competitiva consolidada.

- Ocupar escalas de mercado que optimicen la competitividad de la compañía.

- Conservar la cuota de mercado en el caso de que el entorno en el que se opera esté en crecimiento (p.13).

Por otro lado, Néboa Zozaya González (2015) señala que el crecimiento empresarial se define como el incremento de la capacidad productiva de la entidad a través de determinadas inversiones en sus instalaciones, estructuras y recursos humanos que son financiadas por medio de recursos propios o ajenos (p.15).

La organización determina una primera ubicación para sus instalaciones de un determinado tamaño y capacidad. Luego, adquiere una posición relevante dentro del mercado en el que opera y de esta manera, surge naturalmente la necesidad de crecer y expandirse a nuevos mercados. Dicho crecimiento puede significar el aumento de capacidad o la deslocalización de algunas instalaciones. Es así, como el concepto de crecimiento hace referencia a incrementos o modificaciones de tamaño que provocan que ésta sea diferente de su estado original. De este modo, el crecimiento nace en función de los objetivos a medio y largo plazo $\mathrm{y}$, se torna en tendencia natural de la empresa (Zozaya, 2015, p.16).

Siguiendo esta misma línea, la elección de una estrategia de crecimiento que la organización puede emplear depende de las capacidades que dispone en determinado momento y de la predisposición que posee para afrontar riesgos. La innovación se convierte un factor clave en el desarrollo de la estrategia, debido a que es interpretado como el conjunto de ideas y actitudes compendiados en recursos que poseen el fin de crear, contrastar y perfeccionar 
productos, comercialización, diseño y gestión (La Comunidad de Madrid, 2017; Martinicorena, 2007 \& Zozaya, 2015).

Por esta razón, la empresa dispone de diversas estrategias para lograr alcanzar su objetivo de crecimiento. En primer lugar, el interno posee la estrategia de especialización que se enfoca en cómo la organización aumenta su actividad dentro de la misma línea de productos (Zozaya, 2015, p.17). Dentro de ésta tenemos 3 variables:

a) Penetración en el mercado: se busca aumentar las ventas de productos llegando a más clientes, mejorando la calidad del servicio, incrementando la inversión en publicidad o reduciendo precios.

b) Desarrollo de productos: se detectan necesidades en mercados no satisfechos. A esto se le denomina nicho de mercado y para ellos, se crean nuevos productos o adaptaciones de estos.

c) Desarrollo de mercados: se introducen o se adaptan productos a nuevos mercados geográficos en términos de características, precio, canal de distribución o publicidad.

Por otro lado, tenemos la estrategia de diversificación que se orienta a la búsqueda de nuevos mercados y productos para disminuir el riesgo de la empresa a largo plazo y permita disponer de excedentes financieros que generen mayor rentabilidad (Zozaya, 2015, p.17). Se subdivide en 3 categorías:

a) Diversificación horizontal o relacionada: busca ampliar la oferta de la empresa con nuevos y mejorados productos para atraer más clientes.

b) Diversificación o integración vertical: apropiación del proceso de fabricación, distribución de los productos y servicio post-venta. A su vez, posee dos variables: 1) hacia atrás: ingresa al mismo mercado de sus proveedores 2) hacia adelante: ingresa al mercado de sus clientes.

c) Diversificación heterogénea o conglomerada: los productos y los mercados son distintos y no se encuentran del todo relacionados tecnológicamente. Es considerada la estrategia más arriesgada porque la entidad ingresa en un ambiente competitivo nuevo. 
Tabla 1: Tipos de especialización y diversificación

\begin{tabular}{|c|c|c|}
\hline & Actuales & Nuevos \\
\hline Actuales & Penetración de Mercados & Desarrollo de productos \\
\hline Nuevos & Desarrollo de Mercados & Diversificación \\
\hline
\end{tabular}

\section{Fuente: Zozaya, 2015, p.17}

\subsubsection{La fusión como una estrategia arriesgada}

Forsythh, sostiene que las fusiones y adquisiciones empresariales son consideradas como operaciones arriesgadas, debido a que puede presentar fracasos ligados a diversos motivos (Forsythh, 2011, p. 45). Por ejemplo, puede ser provocado por omitir o efectuar tardíamente una diligencia, por tener un insuficiente estudio de la organización objetiva o target, por postergar determinadas "toma de decisiones" por no contar con una definición clara sobre las responsabilidades luego de la F\&A, por darle una mayor dedicación al logro de la misma F\&A y no a la integración de empresas, por poseer infracciones de leyes antimonopolio, por mantener una comunicación (tanto interior como exterior) deficiente, por dilatar la provisión de un líder reconocido en la organización; así como una larga lista de fracasos que involucran numerosos factores y particularidades inherentes a cada acción (p. 46-47). Bajo esta premisa, un gran porcentaje de fracasos son ocasionados por la mezcla de varios de los descuidos mencionados con anterioridad (Forsythh, 2011, p. 48).

Asimismo, toda fusión y adquisición revela un complejo reto institucional que tiene riesgos que pueden ser aminorados por medio de una adecuada evaluación, planificación y ejecución de una determinada acción (Devogue \& Spreier, 2000, p. 56). Por lo cual, si es que existe un preciso conocimiento de los objetivos que manejan la F\&A, el establecimiento de una correcta estrategia, la planificación de la fase de integración, una sólida implementación de la operación, la apreciación de las sinergias, la producción de procesos de doble diligencia y la conciliación de las diversas culturas organizacionales; se podrá concretar la creación de valor a través de la operación (p. 57-59).

Por último, Mascareñas (2005) sostiene que uno de los temas de mayor relevancia en la fase de implantación de F\&A se torna en las diferencias culturales entre las organizaciones 
involucradas, ya que las tensiones y conflictos culturales son causados por dificultades vinculadas a la integración de estas (p. 31). De este modo, es de suma importancia tener en consideración en la etapa previa a la adquisición o fusión, los factores culturales y la gestión adecuada de las diferencias culturales con el fin de poder conducir la operación con éxito (Laniado \& Beltrando, 2003, p. 78).

\subsubsection{Efectos de las fusiones sobre las variables empresariales}

Como se ha mencionado a lo largo del capítulo, irremediablemente, las fusiones y adquisiciones, producen consecuencias de sobre las variables empresariales en efectos de la empleabilidad, el poder del mercado, la productividad, el rendimiento tecnológico, la tasa de crecimiento, el precio de las acciones y el beneficio/rentabilidad (Martinicorena, 2007, p. 78).

En cuanto al empleo, Laniado \& Beltrando afirman que el impacto de una F\&A sobre la demanda de trabajo se torna en un efecto ambiguo. Esto es porque, por un lado, al producirse sinergias empresariales y compartirse áreas laborales, clientes y proveedores; se reducirá el empleo de manera inmediata (2003, p. 35). Por otro lado, esta sinergia permitirá el incumplimiento de los contratos laborales establecidos con anterioridad que dificultaban el despido de los colaboradores (2003, p. 36).

Por otro lado, cuando hablamos de poder del mercado, las F\&A producen, posibilitan y refuerzan el aumento de precios en la empresa resultante y competencia directa (Martinicorena, 2007, p. 49). Devogue \& Spreier (2000) manifiestan:

Los accionistas de las empresas competidoras implicadas en fusiones horizontales consiguieron retornos positivos en un entorno de comunicación de las fusiones (p. 77).

De acuerdo con Laniado \& Beltrando (2003), las organizaciones que mantenían una productividad mayor al promedio previa a la fase del cambio logran tener una mayor productividad al permutar de propietarios, así como también, sucede con las plantas que poseen mayor tamaño el no emplear de manera eficiente, sus recursos antes de la operación 
(p. 36). De la misma manera, Devogue \& Spreier (2000) sostienen que no se produjeron mejoras en la productividad en cuanto a los activos de dichas instituciones que desde un inicio eran menos eficientes y luego, se fusionaron (p. 48). Por último, el aumento en productividad se incrementa cuando las F\&A son de forma parcial en contraposición a las F\&A que son de manera completa (Mascareñas, 2005, p. 76).

En relación con la calidad de la mano de obra, las organizaciones implicadas en procesos de F\&A tuvieron mayor incremento de la calidad del capital humano en cuanto a la obtención de mejor educación laboral y experiencia (Mascareñas, 2005, p. 67).

Además, si hablamos del precio de las acciones, una gran cantidad de estudios evidencian que existe aproximadamente un $25 \%$ de ganancias para los accionistas de la institución adquirida luego de la operación (Devogue \& Spreier, 2000, p. 87). Asimismo, Martinicorena (2007) sostiene que el retorno de las operaciones financiadas con efectivo en las F\&A alcanza mejores resultados que las empresas financiadas con intercambio de valores (p. 79).

Bajo esta misma línea y estableciendo un análisis de las consecuencias de las fusiones en relación con el beneficio/rentabilidad, se determina que no existe una evidencia certera acerca de si es que éstas incrementan los beneficios laborales con respecto al modo previo a la operación. Sin embargo, múltiples estudios demuestran que existe una baja rentabilidad en el proceso (Laniado \& Beltrando, 2003, p. 58).

\subsubsection{El conflicto cultural en las fusiones}

Las estrategias de fusiones y/o adquisiciones producen un gran reto cultural. Esto se debe, a que dos organizaciones que, por lo general, no poseen una historia en común; deben negociar, interaccionar, actuar y trabajar conjuntamente en un reducido lapso (Iborra, 2002, p.33).

Según DeVogue y Spreier (2000), las diferencias existentes entre dos culturas empresariales en el desarrollo de la fusión o adquisición y el modo de gestión de ambas suelen convertirse en factores cruciales que determinan el éxito o el fracaso del proceso (p.57). 
Existen diversas definiciones sobre la palabra cultura; sin embargo, Buono y Bowditch (2003) señalan que es "everything that encompasses morality, art, knowledge, custom, law, belief and any other habit or capacity acquired by a person who is part of society" [todo aquello que abarca la moral, arte, conocimiento, costumbre, ley, creencia y cualquier otro hábito o capacidad adquirida por una persona que forma parte de la sociedad] (p.78).

La cultura organizacional está constituida por los modelos de creencias, valores, principios ideológicos, habilidades, presunciones compartidas y clima que poseen los miembros de una determinada empresa, y los rige por medio de reglas de comportamiento dentro de la institución (Iborra, 2002, p.45).

Por lo general, durante el proceso de negociación se suele prestar poca atención a ciertas diferencias culturales o sobre todo, llegar a un mutuo acuerdo sobre cuál es la cultura ideal luego de la fusión o adquisición de la institución. A esto se le suma, la dificultad para resolver conflictos culturales se traduce en que la cultura no es tan simple de definir, diagnosticar, entender, analizar y manejar (DeVogue y Spreier, 2000, p. 56).

Sin embargo, las organizaciones que poseen más éxito son las que atraviesan por un proceso minucioso de identificación de las culturas requeridas para impulsar la empresa ya fusionada y de las principales barreras u obstáculos que se han de superar (p.57).

Por otro lado, Castro (2003) manifiesta la cultura representa uno de los ejes centrales en el proceso de fusión, ya que trata de integrar los nuevos cambios con la cultura ya existente con el fin de que la organización funcione de manera adecuada. Pese a ello, a esto se le suma la resistencia al cambio, la asimetría de poder, el grado de hostilidad, la distancia cultural, el grado de integración y el alcance de la integración (p. 265).

El cambio no es más que cualquier situación en la cual, se adquieren determinados comportamientos, procedimientos y estructuras; alejándose de los propios con el único fin de poder adaptarse al contexto empresarial y así, llegar a tener una estabilidad que permita establecer acciones oportunas y de mejor calidad. Esto, a su vez, puede generar resistencia colectiva al ser considerado como un fenómeno psicosocial que se evidencia en la reacción de los colaboradores, el grado de importancia que la empresa concede al cambio, el nivel de 
apertura con el mismo, el temor que se produce y el grado de afectación o adaptación (Retamal, 2002, p. 67).

Amorós (2007) sostiene que la resistencia al cambio se puede evidenciar de dos formas distintas: a) abierta: que se expresa a través de sabotaje, huelgas, trabajo defectuoso, menor productividad y b) encubierta: que se manifiesta por medio del aumento del ausentismo laboral, incremento de denuncias, demoras, pérdida de motivación, tasas de accidentes, moral más baja y errores más altos (p.56).

Asimismo, este acontecimiento proviene de dos fuentes. En primer lugar, la resistencia individual al proceso de cambio. El personal de la organización presenta determinadas características que marcan el estilo de ejecutar las tareas de la empresa, por lo que así es más difícil aceptar los cambios del nuevo entorno al presentarse estilos diferentes de hacer determinadas cosas. Además, otra característica es la personalidad dogmática con la que se muestran ciertos rasgos de inflexibilidad con sus creencias y pensamiento cerrado. Otro factor es el temor a lo desconocido, ya sea por la incertidumbre sobre el futuro, por las consecuencias que esta acción va a generar, por razones económicas, profesionales o personales (p.57).

En segundo lugar, está la resistencia organizacional frente al cambio que se presenta cuando los intereses previamente definidos peligran por el equipo y los departamentos de la entidad. Existen diversos factores que intervienen en la forma en que una empresa se resiste o acepta el cambio. Uno de ellos es el diseño organizacional, en donde se debe tratar con cuidado, debido a que si es que es muy autoritario o rígido existirá mayor dificultad en la aceptación de las nuevas ideas o procesos. Otro punto relevante es que los principios y valores que manejan el actuar profesional de las entidades se encuentran tan radicados que en el momento en el que las nuevas ideas o formas de hacer las cosas se integren, existirá una gran resistencia al cambio (Amorós, 2007, p.58). 
Figura 11: Riesgo cultural: factores culturales con relación a los factores estratégicos

\section{Factores de riesgo}

Factores culturales y de poder

\section{Factores estratégicos}

- Distancia cultural

- Asimetría de poder
- F/A amistosa vs hostil

- Grado de integración
- Alcance de la integración

- Riesgo cultural

\section{Procesos de riesgo}

- Conflicto cultural

- Privación relativa

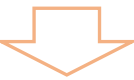

Resultados postadquisición

\section{Factores de riesgo}

- Rutinas organizativas de aprendizaje organizativo

- Rutinas organizativas para desarrollo de una cultura compartida

- Rutinas organizativas para neutralización de la privación

Fuente: Castro, 2003, p. 57

3. Las fusiones empresariales en empresas de mejoramiento del hogar en Perú

\subsection{Las empresas de mejoramiento del hogar en Perú}

Según el Diario Gestión, el sector de mejoramiento del hogar en el Perú posee un acelerado crecimiento y una constante reestructuración desde las últimas dos décadas. Actualmente, cuenta con 20 años en el mercado y continúa atendiendo las necesidades de una fuerte demanda insatisfecha (2005, p.12).

Ernesto Aramburú, Director - Gerente de la empresa chilena dedicada al estudio e investigación de mercados: Inversiones y Asesorías Araval, sostiene lo siguiente:

A principios de los años 90, el mercado de los home center no estaba muy bien definido porque el país presentaba una pronunciada crisis económica $\mathrm{y}$, además, existía poca apertura de comercios en general. Por un lado, se encontraban las ferreterías más importantes que abastecían pinturas y quincallería tales como: "La Piamontesa" y "La Sirena". Por otro lado, operaban empresas con un perfil orientado 
a la parte eléctrica como "Matusita". En cuanto a los comercios de griferías, sanitarios y mayólicas, estaban Cassinelli, Labrouse y Mateco; existían tiendas de equipos y electrodomésticos como Hiraoka y, por último, como clúster de productos ferreteros, se encontraban las avenidas como Tomás Marsano, Las Malvinas y Grau (2015).

Años más tarde, producto del crecimiento de la economía del Perú, el crecimiento del mercado inmobiliario, los cambios forjados por la confianza de los inversionistas y el retorno de capitales a nuestro país; a mediados de los años 90, la noción de tiendas por departamento, cines, comida rápida, entre otras, se vuelven grandes formatos empresariales. Lo mismo sucede con el rubro de mejoramiento del hogar (Diario Gestión, 2005, p.12).

De esta manera, en 1994 se apertura la primera tienda de la franquicia americana, Ace Home Center en la Avenida Caminos del Inca. En sus inicios, presentaba el formato de las ferreterías de las cadenas americanas, contaba con una oferta del 100\% de mercancía importada de Estados Unidos y estaba orientada a un público que deseaba adquirir herramientas americanas u otras categorías de productos como juguetes infantiles. Con los años, el formato y la oferta de Ace Home Center tuvo que cambiar para estar en sintonía con el público local. (Web Maestro Home Center, 2018).

En el año 1997, el Centro Comercial Jockey Plaza abrió sus puertas y renovó todo el escenario del retail en nuestro país. Con ello, la cadena aprovechó el contexto y aperturó el segundo local con un formato de 4,000 $\mathrm{m} 2$ y con un surtido de productos mucho más amplio. Un par de años después, Ace Home Center abre un nuevo local en Minka de 2,800 m2. Luego, aperturan tiendas comerciales en La Molina y Plaza San Miguel (Web Maestro Home Center, 2018).

Alrededor del año 2006, la compañía de mejoramiento del hogar chilena: Sodimac, llega a nuestro país a través de formatos tipo power center junto con el supermercado Tottus. De este modo, aperturan locales en Canta Callao y la avenida La Marina (Aramburú, 2015, p.2).

De esta manera, en el mismo año, el fondo de inversión: Enfoca, decidió adquirir las acciones de la empresa Ace Home Center y cambió su razón social a Maestro Home Center. Fue así 
como la compañía se nacionaliza y la ferretera logró quintuplicar sus ventas (Web Maestro Home Center, 2018).

En marzo del 2008, el formato de home center empezó expandirse a provincias y, en esa instancia, empezaron a formar parte del crecimiento de los centros comerciales del Perú (Aramburú, 2015, p.2).

En el año 2011, bajo el contexto de desarrollo que había en el mercado nacional, ingresa un tercer competidor: la empresa de mejoramiento del hogar del Grupo Intercorp: Promart. Ésta estaba enfocada en la mujer de la clase media con una oferta orientada al servicio y se convirtió en el complemento a su oferta de banca, centros comerciales, supermercados, cines y centros de estudio. Para lograr su propagación, Promart aprovechó las ubicaciones del mall del grupo: Real Plaza y ciertas locaciones de Plaza Vea (Aramburú, 2015, p.3).

En setiembre del 2014, se produjo una recomposición del mercado de mejoramiento del hogar cuando Sodimac adquirió el 100\% de las acciones de Maestro a un precio de S/. 1,404 millones, logrando así, obtener el $44.81 \%$ del mercado, Sodimac el $38.71 \%$, Promart el $11.76 \%$ y Cassinelli el 4.61\% (Equilibrium, 2017, p. 8).

Según el Diario Gestión (2015), durante el periodo del 2015, el número de tiendas de las cuatro principales cadenas (Maestro Perú y Sodimac -ambas empresas son parte del Grupo Falabella-; Promart -parte del grupo Intercorp- y Cassinelli) se incrementó a 89 en su totalidad. De los cuales, 41 de las tiendas se encuentran ubicadas en Lima y 48 en provincias: Piura (siete), Ica (seis), Chiclayo (cinco), Trujillo (cinco), Arequipa (cuatro), Cajamarca (tres), Pucallpa (tres), Cusco (tres), Huancayo (dos), Huacho (dos), Chimbote, Huánuco, Tacna, Puno, Moquegua, Jaén, Cañete y Talara (p.1).

Asimismo, en dicho año, se registró una menor cantidad de aperturas de locales. En total, solo seis nuevas tiendas en comparación al número de locales inaugurados en el 2014: ocho tiendas y en el 2013: 19 nuevas tiendas (Diario Gestión, 2015, p.1).

En la actualidad, el formato de home center en nuestro país posee un bajo nivel de penetración en relación con otros países. Esto se debe, a que el Perú cuenta con 89 locales y 
tiene acerca de 31 millones de habitantes. Mientras que Chile posee 155 locales con una población de poco más de 18 millones de habitantes (Equilibrium, 2017, p. 8).

Además, las tiendas de mejoramiento del hogar se encuentran ubicadas en centros comerciales con el fin de aprovechar sinergias positivas en cuanto a la seguridad, flujo de público, estacionamientos, entre otros. De esta manera, Sodimac cuenta con al menos ocho tiendas dentro de los malls Open Plaza y Mall Aventura Plaza, en donde el Grupo Falabella posee participación en estos centros comerciales. Del mismo modo, Promart tiene al menos 16 tiendas instaladas en los centros comerciales Real Plaza, ya que forman parte del Grupo Intercorp. Por otro lado, Maestro y Cassinelli cuentan con tiendas stand alone ubicadas en locales con puerta a la calle (Equilibrium, 2017, p. 9).

Figura 12: Homecenters: Evolución $n^{0}$ de tiendas

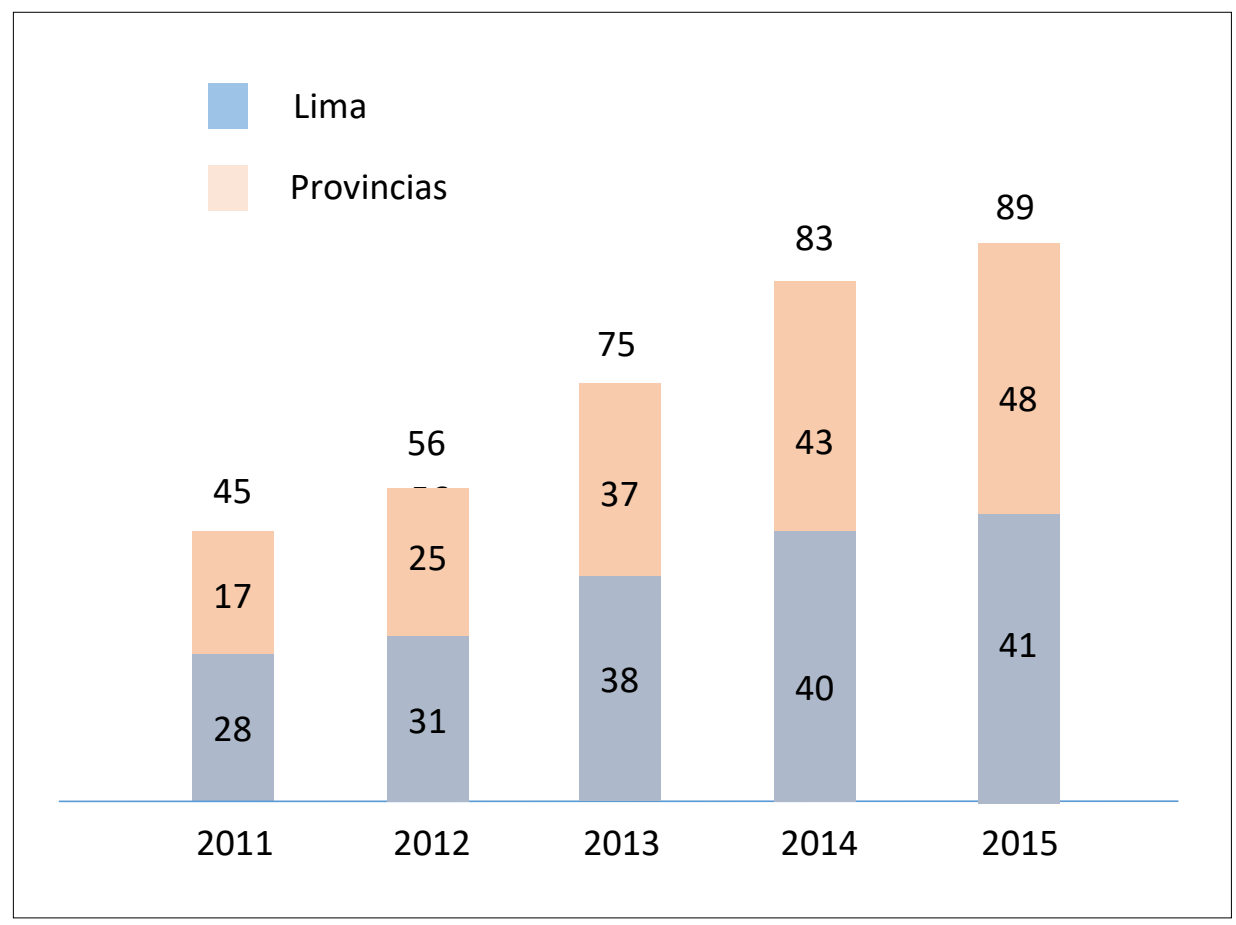

Fuente: Empresas - Estudios Económicos Scotiabank 


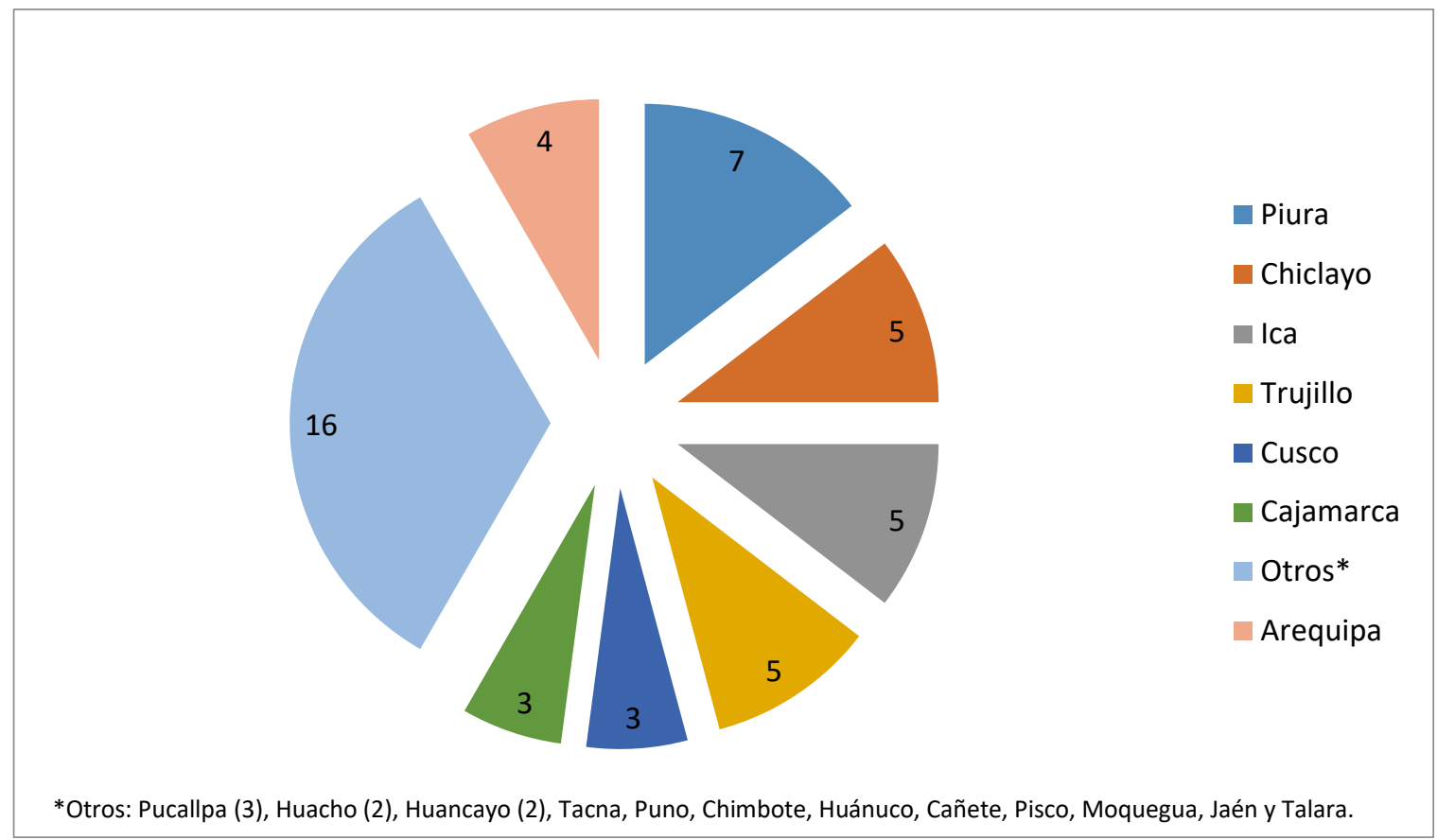

Fuente: Equilibrium, 2017, p. 8.

La totalidad de la participación de mercado que viene ganando el canal moderno dentro del rubro de mejoramiento del hogar, se debe tanto a los servicios de asesoría especializada y a la diversidad de productos que poseen, ya que no solo ofrece materiales de construcción, sino que también, griferías y sanitarios, productos de electricidad e iluminación, pinturas, pisos, muebles y decoración, maderas, revestimientos cerámicos, entre otros. A esto, le debemos añadir la venta de productos on-line de algunas empresas, debido a que presentan plataformas e-commerce dentro de su oferta comercial (Aramburú, 2015, p.3).

Según la Clasificadora de Riesgo, Equilibrium, en su estudio de mercado "Análisis del Sector Retail: Supermercados, Tiendas por Departamentos y Mejoramiento del Hogar”, el mercado de productos para el mejoramiento del hogar y ferretería factura aproximadamente alrededor de US\$ 6,000 millones anuales. Sin embargo, dicha cifra es bastante referencial, ya que la mayor parte del mercado tiene presencia de comercio informal (Equilibrium, 2017, p. 9). 


\subsubsection{Estructura y composición del mercado}

En América Latina, existe un panorama de baja penetración en el crecimiento del sector retail. En el Perú, no se logró superar el 5\% al término del año 2015. Esto se debe, a que existe una fuerte debilidad de la moneda local, un aumento en el nivel de endeudamiento en las familias y por último, un leve incremento de alimentos por factores climáticos (Apoyo Consultoría, 2017, p. 1).

De acuerdo con la Cámara de Comercio de Lima (2017), nuestro país ha disminuido su posición en el ranking de los 30 países con proyección a la inversión minorista. En este estudio, el Perú supera a Colombia y México gracias a su cautivador mercado de 48.9\%, una saturación de $58.6 \%$, riesgo de negocio y país de $49.3 \%$ y un $51.8 \%$ en el indicador de tiempo oportuno para ingresar. Pese a ello, nuestro país ha descendido del puesto 10 al puesto 16 en el año 2015 (p.34).

Además, Oxford Business Group sostiene:

The cities of Cusco and Arequipa have been growing notably, even above Lima. In 2013, 94\% of the investment in shopping centers was outside our capital. [Las ciudades de Cusco y Arequipa han ido creciendo notoriamente, inclusive hasta por encima de Lima. En el 2013, el 94\% de la inversión en centros comerciales se dio fuera de nuestra capital] (p.87).

Según Arellano Marketing (2016), este potencial está ligado a la autoconstrucción, ya que hasta el 2015 el 24\% de hogares en provincia efectúo alguna actividad de remodelamiento o mantenimiento de sus viviendas (p.56).

Este mercado está diseñado para determinados clientes que desean realizar mejoras en su hogar, remodelaciones de vivienda y ampliaciones internas o externas. Hoy en día, los principales y casi únicas empresas dedicadas a este rubro son Maestro Perú y Sodimac Perú, parte del grupo Falabella; Promart, propiedad del grupo Intercorp y por último, Cassinelli (Equilibrium, 2017, p. 11). 
En primer lugar, según Aramburú (2015), encontramos a Sodimac (Sociedad Distribuidora de Materiales de Construcción), que es una cadena chilena enfocada en categorías de mejoramiento del hogar, construcción y ferretería. Ésta pertenece al holding Falabella y se encuentra posicionada en Chile, Perú, Colombia, Uruguay, Argentina y Brasil (p.4).

En el año 2003, se fusionó con Falabella mientras que ésta ya contaba con una filial de construcción llamada Home Store, lo cual, significó un conjunto de 103 locales para ese entonces en Chile, Perú, Colombia y Argentina, permitiéndole tener una rápida internacionalización. Un año después, en el 2004, Sodimac llegó a nuestro país y permitió ampliar el negocio del grupo (Perú Retail, 2017, p.4).

Por otro lado, Equilibrium (2017) señala:

Hoy en día, en países como Chile y Perú el formato Sodimac como tal ha sido desplazado por el nuevo modelo Homecenter Sodimac que está orientado en artículos del hogar y ferretería, y Sodimac Constructor, enfocado a profesionales $\mathrm{o}$ especialistas de la construcción (p. 12).

En segundo lugar, tenemos a Maestro Perú, la primera entidad que desarrolló en nuestro país el concepto de tienda de gran formato especializada en el mejoramiento del hogar y la construcción. Se instauró en el Perú en el año 1978 y décadas más tarde, fue adquirida en su totalidad por Sodimac a un valor similar al nivel de sus ventas anuales, es decir, S/. 1400 millones (Diario Gestión, 2015, p.4).

Además, Aramburú (2015) afirma que la tercera empresa en este rubro es Promart, una cadena de tiendas de mejoramiento del hogar que pertenece a la una de las cadenas más grande del país, Intercorp. Ésta se especializa en materiales de construcción, decoración, organización, muebles, acabados, herramientas, iluminación, entre otros (p.5).

Por último, se encuentra Cassinelli el retail nacional especializado en revestimientos y mejoramiento del hogar que cuenta con más de 55 años en el mercado. Son especialistas en porcelanatos, cocinas, cerámicos, salas y griferías. Ésta posee una oferta diferenciada de sus demás competidores, ya que se enfoca en la moda y en las últimas tendencias del mercado (Perú Retail, 2017, p.1). 


\subsubsection{Los cambios recientes en las empresas de mejoramiento del hogar}

Como hemos mencionado en apartados anteriores, el canal de tiendas de mejoramiento del hogar o home center está compuesto por cuatro entidades principales: Sodimac, Maestro Perú, Promart y Cassinelli.

En el 2014, retail chileno, Falabella adquirió la firma Maestro Perú al 100\% de sus acciones y con ello, una participación de mercado de aproximadamente el $70 \%$ del canal moderno de mejoramiento del hogar (Perú Retail, 2017, p.6).

Asimismo, la misma fuente afirma que la mayor participación de mercado que está adquiriendo el canal moderno de dicho sector, corresponde a los servicios de asesoría especializada y a la gran variedad de su oferta, debido a que ofrece productos de electricidad e iluminación, materiales de construcción, línea ferreterra, pinturas, pisos, decoración, revestimientos cerámicos, muebles, griferías y sanitarios (Perú Retail, 2017, p.6).

Durante el periodo del 2016, la venta al por menor de artículos de pinturas, ferretería y productos de vidrio en almacenes especializados rodearían los S/.4,780 millones o US $\$ 1,427$ millones. De este modo, se evidencia un crecimiento cercano al 3\% en moneda local con relación al 2015 y una tasa de crecimiento similar al del 2014. Dichos resultados son superiores al crecimiento proyectado del sector construcción de $0.6 \%$ en el 2016, debido a la mejora de la confianza del consumidor que contribuye a la evolución positiva de las ventas de los home center e incentiva la adquisición de productos en la línea de mejoramiento del hogar (Arellano Marketing, 2016, p.57). 


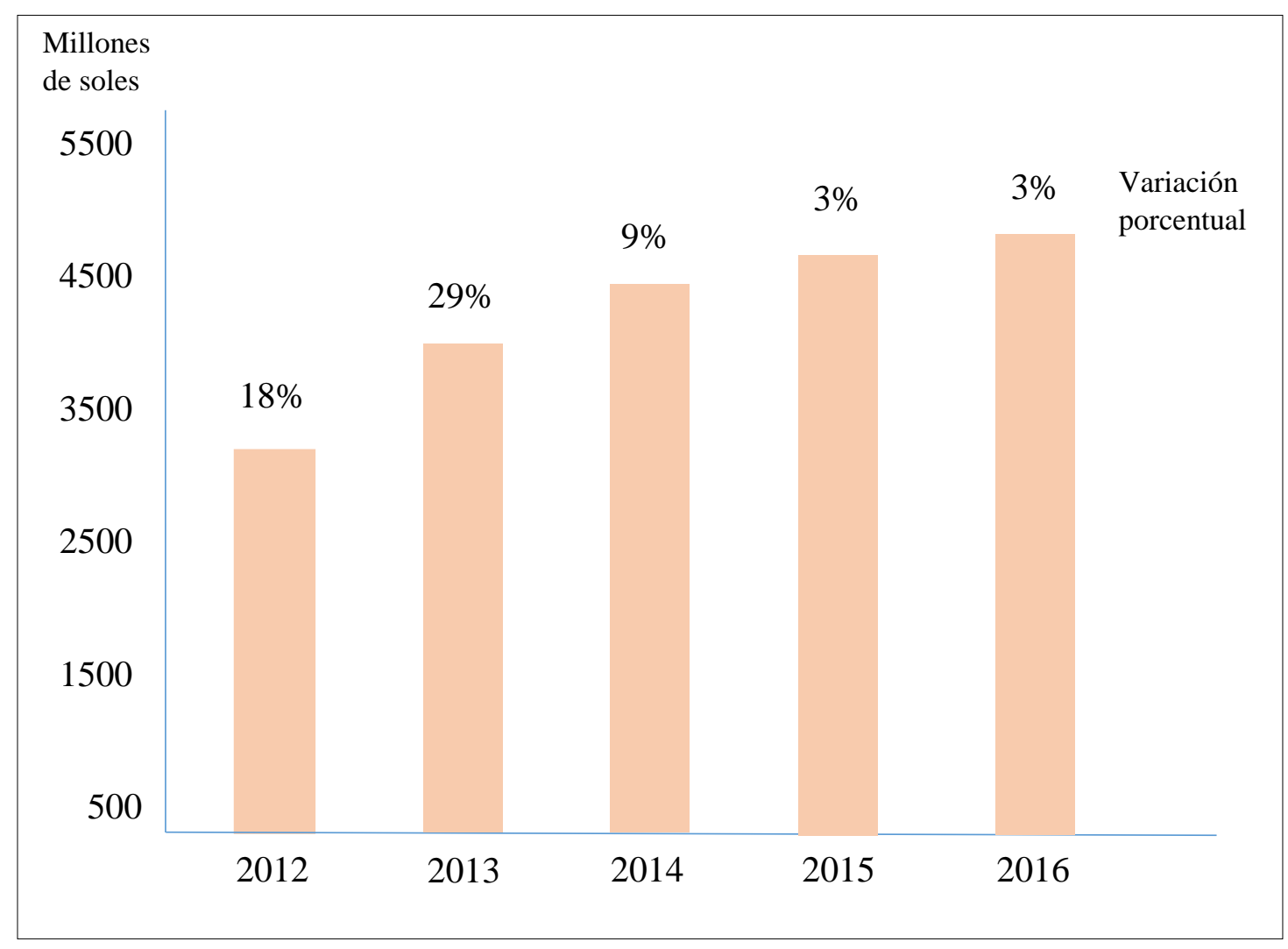

Fuente: Estudios Económicos Scotiabank

Asimismo, Apoyo Consultoría (2017) sostiene que existe una continua adquisición de nuevas viviendas y una constante apertura de nuevos locales, por lo que incentivan a generar mayor dinamismo en el mercado. Aseguran que el sector construcción está creciendo en un $3.9 \%$, sobre todo el segmento inmobiliario, debido a que existe una mayor venta de nuevas viviendas (p.3).

A esto, se le suma el aumento del impulso del consumo privado por el incremento del empleo formal gracias a la inversión privada, lo que origina una mejora proporcional en los ingresos de la población nacional (Perú Retail, 2017, p.7).

Por otro lado, pese a la expansión de las tiendas de mejoramiento del hogar o home center en el Perú, el canal de retail moderno solo posee un $22 \%$ de participación frente al tradicional (informales y ferreterías) que representa el 78\% del mercado (Semana Económica, 2014, p.11). 
Arellano Marketing (2016) manifiesta:

En este rubro se dan dos tipos de compra: a) el 'hágalo usted mismo' y b) el de productos acabados. Asimismo, encontramos la incursión de algunas organizaciones en la venta de productos on line a través del comercio electrónico o e-commerce. Si bien es cierto, existe un gran porcentaje de personas que aún prefieren visitar puntos de venta físicos, esto ha ido evolucionando con forme pasa el tiempo, debido a las diversas opciones que brinda la tecnología, al poco tiempo con el que se cuenta y al creciente tráfico.

De esta manera, los consumidores pueden navegar por medio de diversos canales en el proceso de compra. Esto incentiva la necesidad de ampliar los servicios minoristas con el fin de crear múltiples canales para evaluar las preferencias del cliente y poder brindarle productos de la manera más apropiada (Diario Gestión, 2015, p.8).

Por esta razón, es necesaria la integración de las tiendas físicas y sus plataformas online porque permite a las marcas al ser percibidas como una sola y no como partes divididas. También, los canales electrónicos ofrecen al público una información útil en tiempo real, ya sea en términos de las combinaciones de piezas de ropa más populares, los productos más vendidos, entre otros; por lo que pueden ayudar con el incremento del nivel ventas en las tiendas físicas (Perú 21, 2013, p.10).

Equilibirum (2017) menciona que existen tres subsectores más relevantes en nuestro país: los Supermercados, las Tiendas por departamento y el Mejoramiento del hogar (p.23). A continuación, presentaremos los grupos con su participación de mercado peruano.

\section{Supermercados:}

- Grupo Cencosud (38\%)

- Supermercados Peruanos (35\%)

- $\quad$ Hipermercados Tottus $(27 \%)$

\section{Tiendas por departamento:}

- Saga Falabella (57.6\%)

- $\quad$ Ripley $(37.1 \%)$

- $\quad$ Paris $(5.3 \%)$ 


\section{Mejoramiento del hogar}

- $\operatorname{Sodimac}(50 \%)$

- Maestro $(37 \%)$

- $\quad$ Promart (5\%)

- Cassinelli (5\%)

Hablando en términos de transformación digital en empresas de Retail, es uno de los que más está siendo impactado, ya que las empresas no solo piensan en publicidad en tiendas físicas, sino que también en desarrollar estrategias omnicanal que permitan hacer el análisis de Consumer Decision Journey con el objetivo de poder construir una estrategia integrada entre sus diferentes touch points tales como tener una presencia y participación muy bien trabajada, así como también, contar con un ecommerce (Arellano Marketing, 2016, p.19).

En el caso puntual de las tiendas de mejoramiento del hogar, Sodimac cuenta con un ecommerce desde el año 2014, así como adicionalmente, lo tiene Promart a partir del 2015. Pese a ello y a la alta competencia en el mercado, Casinelli y Maestro poseen solo páginas web informativas más no una plataforma de comercio electrónico. Asimismo, los home center como Sodimac y Promart cuentan con una buena versión para los dispositivos móviles en formato responsive (Arellano Marketing, 2016, p.19).

\subsection{El proceso de fusión en empresas de mejoramiento del hogar en Perú}

\subsubsection{Introducción}

En los últimos años, el mercado de Fusiones y Adquisiciones ha tenido una evolución significativa en nuestro país y se observa un crecimiento en cuanto al número de F\&A como al volumen de las transacciones gracias a que el Perú es muy atractivo para las empresas extranjeras o inversionistas que desean aumentar el valor de sus empresas. En los años 2013 y 2014, el mercado de F\&A en Perú tuvo un récord en transacciones monetarias, ya que se llegó al monto de US\$13,000M en los sectores de energía, industrial, materiales y financiero. Posteriormente, en el 2015, esta cantidad de transacciones disminuyeron en número y volumen; en cierta medida, por el plano económico a nivel mundial y, también, por las incertidumbres y expectativas que atravesaba el contexto político peruano. PricewaterhouseCoopers (2015) realizó una investigación sobre las fusiones y adquisiciones 
en nuestro país y reveló que las transacciones que se realizaron en dicho año apuntaban a obtener activos estratégicos con el fin de no comenzar una operación desde cero, generar sinergias y realizar eficiencias operativas (p.64). Un año después, en el 2016, notamos una gran recuperación, debido a las operaciones representativas de Backus-Sab Miller Perú y AB Inbev.

Figura 15: Evolución de mercado de fusiones y adquisiciones periodo 2010-2016

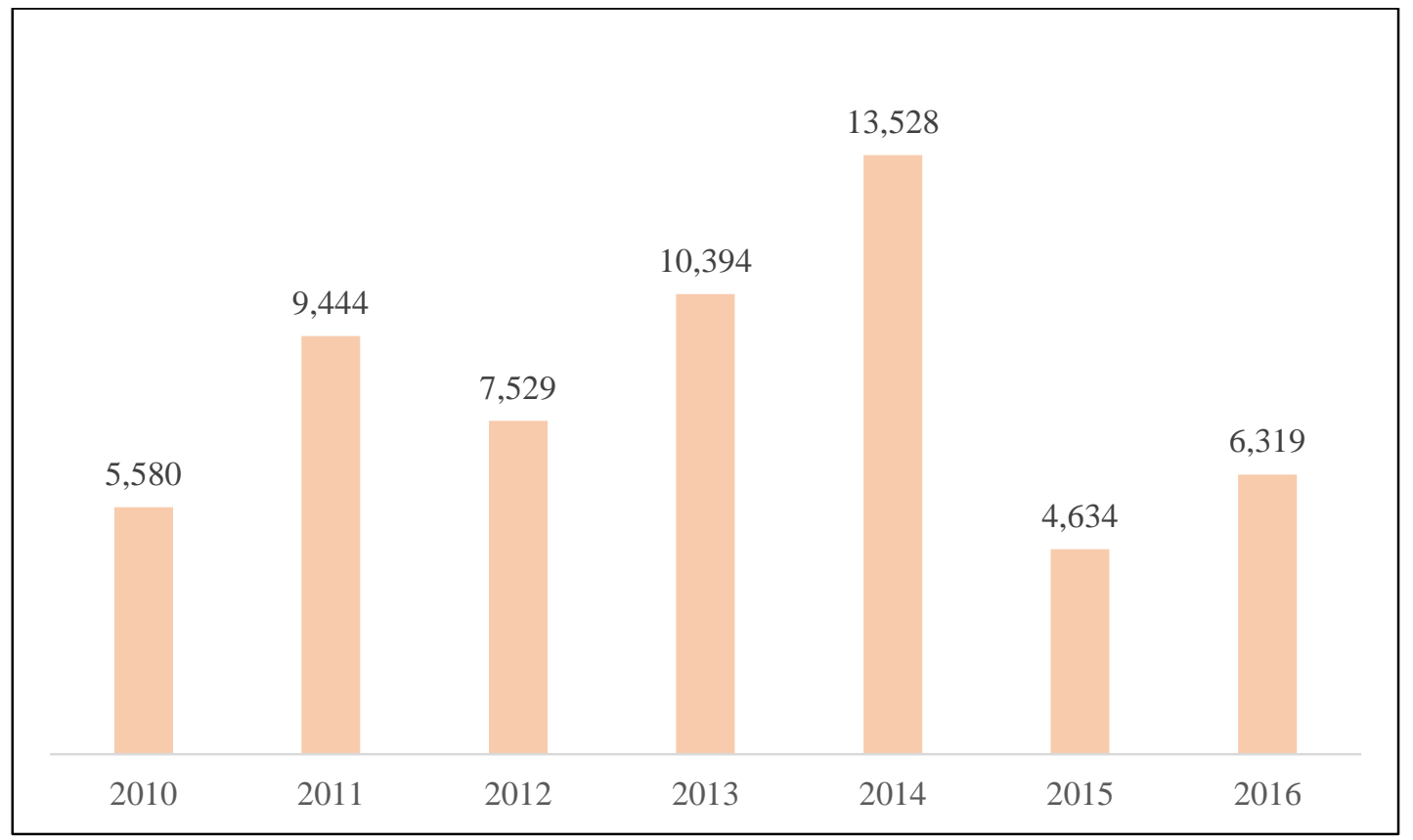

Nota: volumen en USD MM Fuente: PricewaterhouseCoopers (2017), p. 5 
Figura 16: Evolución de mercado de fusiones y adquisiciones periodo 2010-2016

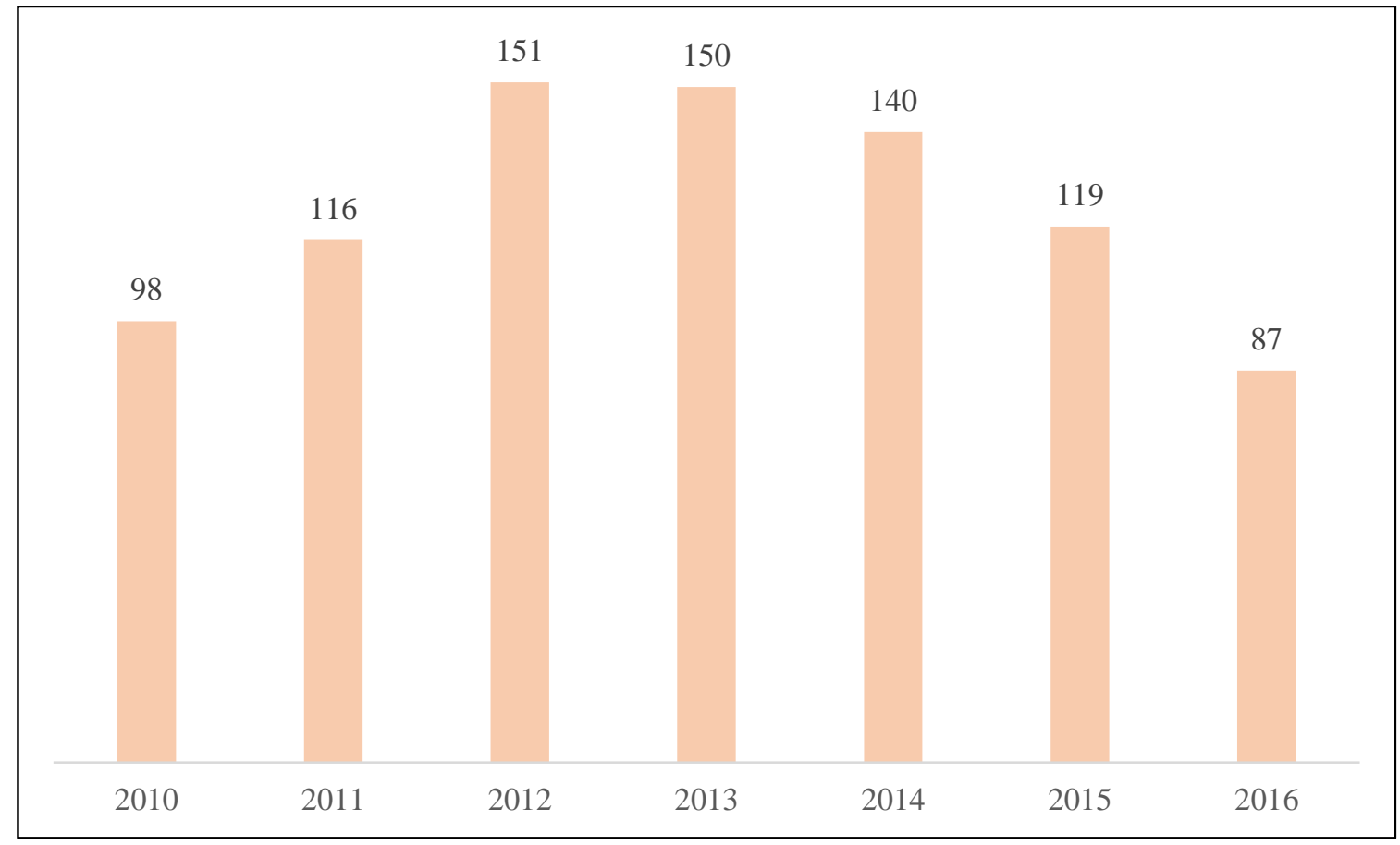

Nota: número de transacciones Fuente: PricewaterhouseCoopers (2017), p. 5

Entre el 2006 y el 2018, los principales grupos empresariales del sector retail moderno en nuestro país han efectuado diversos procesos de fusiones y adquisiciones con el fin de adquirir significativos activos estratégicos, logrando alcanzar más de US\$2,160 millones en su totalidad. Dentro de este sector, se agrupa un mix de formatos como las tiendas por departamento, de mejoramiento del hogar, los supermercados, los libros y periódicos, las cadenas de farmacias, los centros comerciales, tiendas de conveniencia y otros almacenes especializados de gran tamaño. Estos activos obtenidos de las F\&A reúnen el 88\% de las transacciones de cuatro grupos empresariales: Cencosud, Grupo Falabella, Grupo Romero e InRetail y en total dan un monto de US\$ 1,903 millones (Instituto de Economía y Desarrollo Empresarial - IEDEP, 2018, p. 6).

En el año 2007, la empresa chilena, Cencosud, compró la cadena de supermercados Wong por US\$500 millones en donde se efectúo el traspaso de activos inmobiliarios bajo la tutela de centros comerciales con 23 locales de supermercados operativos y 17 ubicaciones disponibles para próximos desarrollos de proyectos. Luego, en el 2016, el mismo Cencosud vendió la cadena compuesta por 47 farmacias ubicadas dentro de los supermercados Wong y Metro al grupo Quicorp, más específicamente, a Mifarma para continuar con su plan de 
adquirir activos no estratégicos. Posteriormente, en noviembre del mismo año, el grupo Crisol vendió su reconocida cadena de librerías a la entidad Derrama Magisterial por más de US\$20 millones. Ésta contaba con una participación de mercado del 51\% y además, se encontraba en 11 regiones de nuestro país. Luego, en el 2014, Sodimac Perú que es parte del grupo Falabella, compró el total de las acciones de la cadena de mejoramiento del hogar Maestro Perú del Grupo Enfoca por US\$470 millones (La cámara CCL, 2018, p. 9).

Años más tarde, en el 2018, se efectuaron dos transacciones relevantes. En primer lugar, Primax, del Grupo Romero, compró la cadena de grifos Pecsa y además, las tiendas de conveniencia Viva por aproximadamente US\$350 millones, logrando convertirse en cadena de estaciones de servicios más grande del Perú. Por otro lado, Inkafarma adquirió la cadena de farmacias Mifarma del grupo Quicorp, en donde Fasa y Arcángel también forman parte. Esta operación se realizó por un monto de US\$583 millones, permitiéndoles obtener una participación de mercado del 80\% entre las cadenas de farmacias (La cámara CCL, 2018, p. $10)$.

Tabla 2: Fusiones y adquisiciones en el rubro de retail 2006 - 2018

\begin{tabular}{|c|c|c|c|c|c|}
\hline $\begin{array}{c}\text { Grupo } \\
\text { vendedor }\end{array}$ & $\begin{array}{c}\text { Empresa } \\
\text { fusionada }\end{array}$ & Rubro & $\begin{array}{c}\text { US\$ } \\
\text { millones }\end{array}$ & $\begin{array}{l}\text { Comprador } \\
\text { estratégico }\end{array}$ & Año \\
\hline Grupo Wiese & $\begin{array}{c}\text { Sociedad: compra } 50 \% \text { de } \\
\text { acciones }\end{array}$ & Centros Comerciales & 13 & Parque Arauco & 2006 \\
\hline Grupo Wong & Supermercados Metro & Supermercados & 500 & Cencosud & 2007 \\
\hline Gruo Enfoca & Maestro & Mejoramiento del hogar & 470 & Grupo Falabella & 2014 \\
\hline Los Portales & Strip Centers del Perú & Centros Comerciales & 19 & Parque Arauco & 2015 \\
\hline Cencosud & Farmacias Wong y Metro & Farmacias & 0 & Quicorp & 2016 \\
\hline Grupo Crisol & Librerías Crisol & Librerías & 20 & Derrama Magisterial & 2016 \\
\hline $\begin{array}{c}\text { Corporación } \\
\text { Pecsa } \\
\end{array}$ & $\begin{array}{c}\text { Cadena de grifos Pecsa y } \\
\text { tiendas Viva } \\
\end{array}$ & $\begin{array}{c}\text { Combustible y tiendas } \\
\text { de convivencia }\end{array}$ & 350 & Grupo Romero & 2018 \\
\hline \multirow[t]{2}{*}{ Quicorp } & Botica Mifarma & Farmacias & 583 & Inretail & 2018 \\
\hline & Total sector Retail & 1,955 & & & \\
\hline
\end{tabular}

Fuente: Base de datos IEDEP. Elaboración: IEDEP

El Instituto de Economía y Desarrollo Empresarial (2019) menciona que las F\&A son entendidas como una herramienta de decisión estratégica corporativa y que si éstas están diseñadas correctamente, pueden obtener una mejora en la productividad, eficiencia y competitividad empresarial. Asimismo, crean valor a los accionistas y abren posibilidades con mejores beneficios a la colectividad, en términos de productos y servicios (p. 11). 
También, César Peñaranda, director ejecutivo del IEDEP- CCL, declaró que:

Con esta evolución, hay la perspectiva de mayores fusiones y adquisiciones en los próximos años considerando los acuerdos comerciales vigentes que abren oportunidades de ventas y el potencial del mercado nacional por la presencia de la clase media, además dichas operaciones son una fuente de atracción de inversión extranjera directa y tecnología de punta (Diario Gestión, 2018, p. 12)

En este contexto, el Instituto de Economía y Desarrollo Empresarial (2019) señala que hay una imprescindible necesidad de ahondar el proceso de fortalecimiento y modernización empresarial de Indecopi, bajo la obtención de una mayor profesionalización y autonomía para poder efectuar la defensa de la libre competencia y sancionar de manera severa el abuso de cualquier entidad que posea dominio en el mercado peruano (p. 11).

Figura 17: Perú: Evolución del Mercado F\&A

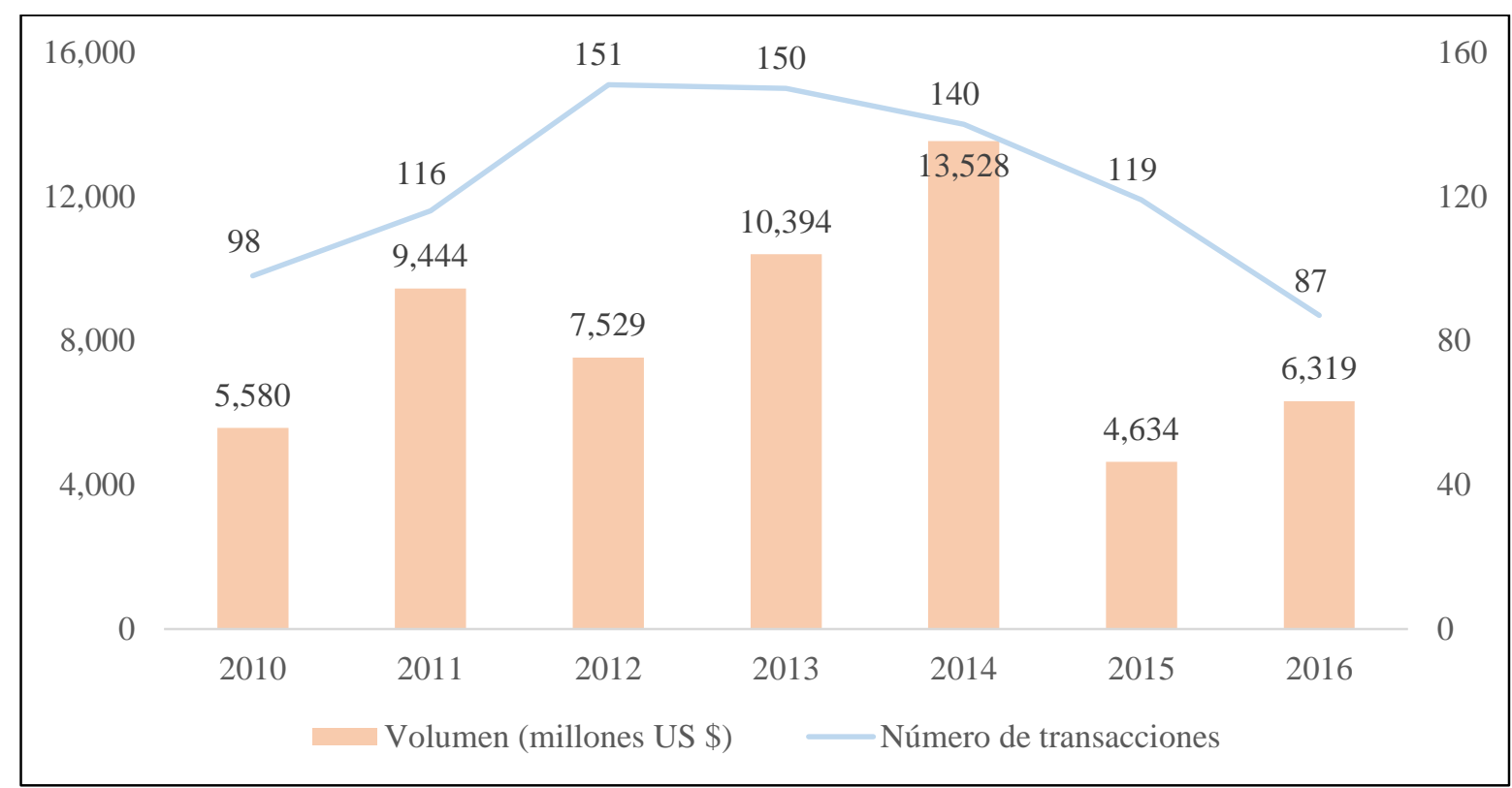

Fuente: Dealwatch. Elaboración: IEDEP 


\subsubsection{Las fusiones en empresas de mejoramiento del hogar en Perú}

La primera empresa que pasó por el proceso de fusión fue Sodimac, la cadena especializada en el mejoramiento del hogar más grande de Latinoamérica. Hoy en día, se encuentra en diversos países como Chile, Perú, Argentina, Brasil, Colombia y Uruguay y, cuenta con una fuerza laboral de 20,000 colaboradores aproximadamente (Perú Retail, 2017, p.8).

Los inicios de Sodimac radican en la década del 40 cuando un pequeño grupo de empresarios expertos en el rubro de la construcción, fundaron la organización Sogeco en el puerto de Valparaíso que estuvo enfocada en la creación de un sistema eficaz de distribución (Perú Retail, 2017, p.8).

Años más tarde, tras la Segunda Guerra Mundial y el profundo desabastecimiento que provocó en Chile; la Cámara Chilena de la Construcción exigió urgentemente la formación de una cadena nacional que pueda distribuir materiales de obra gruesa a precios asequibles para poder proveer al grueso de la sociedad necesitada. Fue así, como en el año de 1952 se fundó Sodimac con una estructura empresarial constituida por diversas sucursales a lo largo del país (Semana Económica, 2014, p.11).

Según Equilibirum (2017), en los 80's, Chile atrasaba por un panorama de recesión e impactó directamente en esta cooperativa al punto de llegar a la quiebra. En el año 1982, José Luis Del Río Rondanelli aprovechó el contexto y adquirió el control total de Sodimac S.A. a partir de ese momento, se inició una nueva etapa de desarrollo y crecimiento (p.34).

Pero en el 2003, Falabella tenía una filial de construcción llamada Home Store por lo que se interesó por la cadena Sodimac S.A. Ese mismo año, adquirió la firma y se sumó al conjunto de tiendas de mejoramiento del hogar con presencia en Chile, Perú, Colombia y Argentina. De esta manera, la cadena chilena de grandes almacenes, Falabella y el conjunto de tiendas especializado en construcción, Sodimac, anunciaron su fusión de manera oficial con transacciones de 2.500 millones de dólares. La firma formó parte de la propiedad de Falabella con un 22,4\% de participación gracias a la fusión y una compra de acciones. Esto le permitió tener una internacionalización empresarial más rápida y, además, en convertirse en la segunda empresa de América Latina de ventas al por menor (Arellano Marketing, 2016, p.20). 
Por otro lado, Equilibirum (2017) sostiene que Maestro Perú estaba en crisis: no contaba con ninguna apertura de tiendas programada para dicho año, tenía baja liquidez empresarial y poseía tendencia negativa en los márgenes. Llegó a tal punto en que la situación crediticia era preocupante y los rumores de su probable venta se esparcían por el mercado peruano (p. $35)$.

Sin embargo, el éxito de Sodimac estaba por las nubes, ya contaban con grandes proyecciones de crecimiento y de potenciar sus tiendas en los mercados latinoamericanos; por lo que en septiembre de 2014 adquiere las acciones de Maestro Perú por S/. 1,404 millones, una de sus principales competidoras en el mercado de mejoramiento del hogar (Equilibirum, 2017, p35).

Desde ese momento, el rumbo de la cadena de mejoramiento del hogar toma un giro prometedor, debido a que el mercado aceptó el proceso de adquisición y compra, por lo que tiempo después, las acciones de Maestro Perú ascenderían de 3.15 centavos de dólar a 98.25 centavos de dólar (Equilibirum, 2017, p.35).

En marzo del 2015, la cadena ferretera, Sodimac, apertura su primera tienda en Uruguay; en marzo de ese mismo año, inaugura su primera tienda en Brasil y en abril del 2016, informan su llegada a México junto con Soriana, la cadena local de supermercados (Arellano Marketing, 2016, p.19).

Otra fusión relevante que surgió en el sector fue la de Cassinelli - Sanihold y el grupo Celima - Trébol en julio del año 2015. Ambos retailers están dirigidos a dos segmentos económicos diferentes. En primer lugar, Cassinelli está orientado al NSE "B" y, por otro lado, la Corporación Celima-Trébol se encuentra enfocada al NSE “C y D”. Este proceso se inició en julio de dicho año con la llegada del colombiano Sergio Cárdenas, el nuevo gerente de la compañía. La Corporación Celima - Trébol realizó formalmente el proceso de fusión administrativa con Cassinelli, retail que compró dos años atrás. Sin embargo, hasta el primer semestre del 2015, ambas empresas operaban independientemente (Apoyo Consultoría, 2017, p.12). 
Luego de la fusión, las cosas no estaban muy claras dentro de la organización Cassinelli y los colaboradores sentían un clima de inestabilidad laboral. Entre el 2015 y el 2016, hubo una fuerte ola de recorte de personal, debido a que algunos cargos se duplicaban y otros colaboradores, fueron reubicados en otros cargos (Diario Gestión, 2015, p.9). A inicios del 2017 se logró concretar este proceso y la reestructuración administrativa empezó con fuerza sus laborales para ambas empresas (p.9).

\section{La Gestión Empresarial}

\subsection{Concepto de Gestión Empresarial}

La gestión de la comunicación es una práctica basada en la forma articulada y reflexiva por medio de una gran cantidad de niveles acerca de la actividad comunicacional dentro de una determinada organización. De esta manera, se torna relevante estudiarla, ya que debe darse en todos los niveles existentes en una empresa desde los rangos de puestos más bajos hasta los más altos (Ramírez, 2009, p.33).

Siguiendo la misma línea, Martínez (2011) afirma que es un proceso utilizado para guiar los objetivos de la empresa que se transforma al final, en un instrumento para evaluarla. Sin embargo, sostiene que existen ciertas discrepancias entre los ideales clásicos y modernos del control de gestión. En primer lugar, es aquella que contiene de forma única al control operativo y que lo despliega a través de un sistema de información vinculado a la contabilidad de costos. Po otro lado, la segunda engloba muchos más elementos y avista una continua interacción entre todos ellos. Es decir, enfoca su atención en la planificación y control de manera equitativa, y, además, determina una orientación estratégica que genere sentido alguno a sus figuras más operativas (p.71).

Prieto (2011) menciona:

Es una técnica gerencial cuyo proceso permite a la entidad a ser proactiva en cuanto al planteamiento de su futuro. La proactividad hace referencia a estar pendiente de los sucesos que se suscitan en el entorno con el fin de rescatar los mejores resultados con recursos disponibles como herramienta principal de gestión. En otras palabras, es la manera de perfil el futuro y encargarse de que esto suceda (p.47). 
Además, el enfoque tradicional de la gestión empresarial se basa en el estudio de la estructura de la empresa y precisa los papeles de los colaboradores en la misma. Por ello, la contribución más relevante de esta perspectiva es la definición y el análisis de las tareas que son imprescindibles para establecer y potenciar una organización (Koontz \& O’Donnell, 2004, p.76).

Martínez (2003) señala que la gestión empresarial es cuando las entidades comienzan a darse cuenta de que una división departamental rígida conlleva fácilmente a la omisión de ciertas responsabilidades y no permite enfrentar una mejora de los procesos de la organización a profundidad (p.36).

De igual forma, consiste en alterar determinadas cosas en un grupo de individuos con el único fin de conseguir resultados de la manera más efectiva y económica posible. La gestión empresarial intenta seleccionar las acciones en función al resultado esperado y a los bienes que se disponen para explotar óptimamente los recursos. Por lo tanto, toda empresa requiere un sistema de planeación y supervisión que logre distinguir la visión, misión, objetivos, valores, presupuestos, políticas, estrategias, programas y procedimientos con un foco estratégico (Luna, 2014, p.16).

\subsection{El Plan de Gestión Empresarial}

Saniz (2015) sostiene que hoy en día, las empresas no pueden subsistir haciendo solo un buen trabajo, sino que, por el contrario, deben hacer un excelente trabajo si es que buscan obtener gran éxito en un mercado caracterizado por un rápido crecimiento y una fuerte competencia a nivel global. Actualmente, las empresas y los consumidores se encuentran expuestos a una gran diversidad de ofertas con relación a la calidad, costo o valor al momento en que buscan satisfacer sus necesidades. Señala, además, que la clave de la rentabilidad de las organizaciones se enfoca en el conocimiento y la satisfacción del público con ofertas $100 \%$ atractivas y competitivas (p.60).

Muchas veces los clientes son afectados por diferentes situaciones de cambios, contextos, características e intensidades que establecen el mundo actual de los negocios. Estas modificaciones en la estructura organizacional, la cultura de calidad, los nuevos sistemas de 
dirección y la búsqueda de la excelencia se traducen en nuevas estructuras de negocio, desarrollo de la innovación tecnológica, reconocimiento de la responsabilidad de la empresa y la importancia de servicio al cliente. Las entidades, para que puedan obtener mayor éxito en el valor diferencial de la ventaja competitiva, adaptan sistemas de mayor contenido de forma tal que compatibilice la ideología del servicio en conjunto con las exigencias que propone entorno (Saniz, 2015, p.61).

Según Santos, estas son las fases que conforman el plan de Gestión empresarial:

Fases del Control de Gestión: resulta importante, para poder realizar un diagnóstico de la situación del Sistema de Control de Gestión de una organización, destacar un grupo de aspectos que definen el nivel o grado de complejidad y conformación de los sistemas de control de gestión atendiendo a un grupo de características:

- Calidad y con fiabilidad en la contabilidad, cultura organizativa. Complejidad de la actividad, posibilidad de formalización del proceso, características del entorno, tipo de estructura.

- Especialización de la actividad y de los centros de responsabilidad, un mayor peso en factores de carácter estratégico como planes, presupuestos, proyectos, entre otros (Santos, s.f.)

\subsection{Otros niveles de Gestión en una organización}

Saniz (2015) menciona que la eficiencia en el desarrollo de los procesos y el cumplimiento de las metas de una compañía dependen de los niveles de gestión y planeación de su sistema logístico y de funcionamiento interno. La planeación es un proceso diseñado para alcanzar los objetivos determinados. Implica tener claros tantos los objetivos que se persiguen como las acciones necesarias para alcanzarlas (p.33).

La planificación en una organización es el proceso que lleva a tomar las decisiones para conseguir el futuro que se quiere, para ello se debe tener en cuenta las condiciones actuales de la compañía y los factores externos e internos que pueden influir directamente para alcanzar las metas establecida (Santos, s.f.). 
Prieto (2011) menciona que un sistema de planeación y gestión integrado y balanceado se puede gestionar en tres niveles principales: el estratégico, el táctico y el operacional. Cada integrante de la compañía pertenece a uno de los tres de acuerdo con la posibilidad de tomar decisiones que se le permita, a sus funciones y al rango de tiempo para el cual está proyectado su trabajo (p.58).

Los siguientes son los tres niveles presentes en un sistema de planificación y gestión robusto dentro de una organización:

\section{a) Nivel estratégico:}

Corresponde a la planeación que se orienta a lograr los objetivos de la organización y su fin es establecer los planes de acción para el funcionamiento de la compañía. Se basa en decidir los objetivos de la empresa, definir los recursos que se usaran y las políticas para obtener y administrar dichos recursos (Prieto, 2011, p.78).

El nivel estratégico es conducido por la gerencia y los directores de la organización, es el encargado de establecer el marco de referencia general, pero no detallado, para el funcionamiento de la compañía, suele cumplir periodos de tiempo largos y su principal fin es la efectividad (Prieto, 2011, p.78).

\section{b) Nivel táctico:}

Desarrolla detalladamente la planeación del funcionamiento de cada una de las áreas de la empresa a partir del marco de referencia elaborado en el nivel estratégico. Elabora la directiva para emplear los recursos asignados a cada área de la forma más efectiva posible para alcanzar los objetivos esperados (Prieto, 2011, p.79).

Este nivel es dirigido y ejecutado por los ejecutivos y jefes de mediano nivel en la compañía y comprende las áreas específicas de trabajo por las cuales está conformada la empresa, coordina la utilización de los recursos y su fin principal es la eficiencia (Prieto, 2011 p.79).

La diferencia básica con el nivel estratégico es que el primero se refiere a la gestión de toda la empresa y se extiende en el tiempo, mientras que la segunda se refiere a la planeación de 
los productos y servicios específicos que ofrece la organización con tiempos y plazos determinados (Prieto, 2011, p.79).

\section{c) Nivel Operativo:}

Corresponde a la asignación de las tareas puntuales que debe realizar cada colaborador de la organización en cada una de las áreas de trabajo que componen la compañía. Se desarrolla a partir de los lineamientos proporcionados por los niveles de planeación estratégico y táctico (Prieto, 2011, p.80).

Este nivel es dirigido y ejecutado por los jefes con menor rango jerárquico en la empresa. Cumple con tareas muy específicas, tales como producción y operación de productos y servicios. Los encargados siguen procedimientos y acatan reglas definidas con precisión por parte de los otros dos niveles y sus actividades cubren periodos de tiempo específicos de acuerdo con cada proceso (Prieto, 2011, p.80).

Los niveles de planificación en la organización hacen parte fundamental del Balance Scorecard, una herramienta para alinear a todas las integrantes de una organización hacia la consecución real de las estrategias de negocio definidas, todo esto por medio del seguimiento de objetivos medidos a través de indicadores puntuales (Prieto, 2011, p.80).

\subsection{La política empresarial}

Política es una de las palabras más utilizadas por los directivos, ejecutivos y el personal de las empresas a nivel mundial. Por lo general, escuchamos decir: "Falta política en la sociedad, en la universidad, en el Estado, en la casa, etc.” (Bermúdez \& Rodríguez, 2013, p.92).

Según, Bermúdez \& Rodríguez (2013), la política debe jugar un rol importante y fundamental en las organizaciones; sin embargo, a veces se deja en un segundo plano. Ésta, posee determinados principios orientadores como la concentración y la innovación (p.96).

Las políticas y los objetivos empresariales dirigen el pensamiento crítico y el accionar, sin embargo; los objetivos previamente planteados facilitan la toma de decisiones de manera 
oportuna en los roles administrativos. Esto, lo vemos reflejado en el punto de vista de la dirección, el aprovechamiento adecuado de los recursos, la solución inmediata para las decisiones o la ley administrativa interna que administra las labores de los colaboradores bajo determinados criterios que guían sus labores (Prieto, 2011, p.81).

\subsection{Factores condicionantes de la Gestión Empresarial}

Prieto (2011) menciona que existen dos factores para la gestión empresarial las cuales son:

Internos: Sentimientos personales, puntos de vista, conocimientos, experiencia, hechos, fuentes, comprensión, interpretación, ambiente y la gente (p. 67).

Externos: Opinión pública, Estado, publicaciones, asociaciones profesionales, situación internacional, economía, sociedad y asuntos políticos (p. 67).

\subsection{Ventajas de la Gestión Empresarial}

Ortega (2008) menciona que las ventajas de la gestión empresarial son (p.49):

- Permiten apreciar el punto de vista en la administración en campos específicos de la compañía.

- Suministran un marco referencial que permite actuar rápidamente

- Fijan los límites y alcances de la toma de decisiones.

- Anticipan situaciones y condiciones para superar las crisis

- Mantienen un clima laboral favorable y estimulan el mejoramiento continuo.

- Garantizan el equilibrio entre datos, hechos, intuición y el instinto.

- Establecen las bases para el seguimiento de la ejecución.

- Fomentan la comunicación, participación y coordinación entre los miembros de la organización. 


\subsection{Etapas de la Gestión Empresarial}

Prieto (2011) menciona que las etapas de la gestión empresarial son (p.77):

\section{a) Elaboración:}

\section{Investigación:}

- Determinar el objetivo

- Reunir la información

- Comparación externa

- Consulta a expertos

\section{Ejecución:}

- Aplicación de la política escogida

- Procedimiento por seguir

- Asignación de responsabilidades

\section{b) Aprobación}

- Verificar la gestión de la empresa

- Buscar una opinión técnica

- Obtener aprobación del Consejo de Dirección

- Escuchar la opinión de los interesados

\section{c) Comunicación}

- Realizar la difusión de la gestión

- Designar los mensajeros de la gestión

- Atender las sugerencias a la gestión

\section{d) Aplicación}

- Asegurar la factibilidad de operación de la política

- Asignar responsabilidades de evaluación de la política

- Coordinar la aplicación integral

\section{e) Revisión}

- Detectar los desvíos de la política y corregirlos 
- Revisar periódicamente la política de la empresa

- Vigilar y evaluar la aceptación de la política

- Hacer replanteamientos oportunos

- Asumir los cambios inherentes a la política

\subsection{Niveles de la gestión empresarial}

\subsubsection{Indicadores}

Son elementos informativos del control de que evalúa el funcionamiento una determinada actividad. Esto se debe a que, hacen referencia a ciertos parámetros estables que son empleados para la comprobación del funcionamiento de ésta misma. Son los componentes básicos de las técnicas de control de gestión (Ortega, 2008, p.34).

La utilidad y fiabilidad del control de gestión está ligado de manera directa a la utilidad y fiabilidad de los indicadores. Una vez elegidos los indicadores, se imputan sobre ellos ciertas técnicas de seguimiento tales como: organigramas, precios de coste, ratios y presupuestos. Es decir, formulados los objetivos, se determinan mediciones cuantitativas y/o cualitativas que permitan establecer con el mayor grado de precisión los resultados de la planeación. Por ejemplo, encontramos: la estrategia, ejecución, control, registro, relacionados: KPI, Operativos, Control y eficiencia y, por último, la eficacia Dato / información (Ortega, 2008, p.34).

Control: Es un proceso cíclico y repetitivo que está compuesto por ciertos estándares (Ortega, 2008, p.34):

Establecimiento de estándares: es la primera etapa del control, que constituye los estándares o criterios de evaluación o comparación. Se determina un estándar a la norma o un criterio que sirve de base para la evaluación o comparación de una cosa específica (Ortega, 2008, p.34).

Existen tres tipos de estándares; los cuales se exponen a continuación: 
- Estándares de cantidad: Como volumen de producción, cantidad de existencias, cantidad de materiales primas, números de horas, entre otros (Ortega, 2008, p.35).

- Estándares de tiempo: Como tiempo estándar para producir un determinado producto, tiempo medio de existencias de unos productos determinado, entre otros (Ortega, 2008, p.35).

- Estándares de costos: Como costos de producción, costos de administración, costos de ventas, entre otros (Ortega, 2008, p.35).

Eficiencia: es la relación entre los recursos aplicados en un proyecto y los logros obtenidos por el mismo. Ésta, se manifiesta cuando se disponen menos recursos para conseguir un mismo objetivo. $\mathrm{O}$, viceversa, cuando se llegan a más objetivos con los mismos o menos recursos (Prieto, 2011, p.80).

Información: está constituida por un grupo de datos previamente controlados y ordenados. La información admite la resolución de problemas y la toma de decisiones, debido a que su beneficio racional se traduce como la base del conocimiento. Por ello, la información es un recurso que concede de manera inmediata, un significado o sentido a la realidad (Prieto, 2011, p.80).

Chiavenato (2009) sostiene que la información no es más que un conjunto de datos que consiguen un significado, de tal modo que reducen el margen de incertidumbre y aumentan el conocimiento de las personas (p.91).

Ferrell y Hirt (2002), por su parte, afirman que esos datos y conocimientos están estrechamente ligados a la mejora de nuestra toma de decisiones. Si un individuo se está bien informado sobre un determinado tema, lo más seguro es que su decisión sobre ello será más acertada que otra persona que no lo esté (p.74). 


\subsubsection{Procesos}

Según Bermúdez \& Rodríguez (2013), se denomina "Procesos" al conjunto de actividades vinculadas o que interactúan entre sí que convierten puntos de entrada, ya sea en productos o servicios. Esto, genera resultados eficientes solo cuando los recursos y las actividades se tramitan como un proceso (p.39).

Asimismo, Saniz (2015) sostiene que un término muy ligado al "Proceso" es el de "Sistemas", debido a que éste es la sumatoria de procesos (p.47). Por ello, presentamos los significados a continuación:

Sistemas: Es el conjunto de procesos que se encuentran estrechamente relacionados o que, de alguna manera, interactúan con un fin común. Por eso, para garantizar la eficacia y eficiencia de una organización en cuanto al logro de sus objetivos, es crucial identificar, entender y gestionar los procesos vinculados como un sistema (Saniz, 2015, p.48).

- Procesos: Se denomina proceso a cualquier actividad o conjunto de actividades que disponen de recursos para transformar puntos de entrada y los convierte en resultados. Acá, se considera la estrategia, el control, la ejecución y el registro que están ligadas a los sistemas, procesos y actividades (Saniz, 2015, p.48).

- Actividad: Es la acumulación de acciones que se deben realizar con el fin de cumplir una determinada operación. Se basa en la ejecución de determinadas tareas a través del uso de los recursos humanos, técnicos, materiales y financieros que son realizadas por una unidad administrativa (persona) como parte de una actividad/tarea asignada (Saniz, 2015, p.48).

\subsubsection{Documentación}

Prieto (2011) manifiesta que todas las organizaciones deben tener registrados y documentados todos sus procesos para conservar controles internos que darán una mejor gestión y desempeño por parte del personal operario y administrativo de cada área de la empresa. Esto permitirá que la Gerencia General, Gerentes y Jefes puedan emplear 
indicadores de gestión, control y de resultados con el fin de evaluar el desempeño de los colaboradores que están bajo su cargo. Todo ello, se establece en base a relación, estrategia, control, ejecución y registro (p.49). Además, éstas se encuentran vinculadas con los siguientes conceptos:

Manual: Es el documento clave en donde se presenta la estructura completa del sistema.

Éste, debe exponer de manera clara todas las actividades requeridas para poder administrar de la forma óptima, los procesos con el fin de alinearlos a las estrategias de la Alta Gerencia (p.49). Asimismo, da continuidad en el sistema de gestión cuando existen situaciones de cambio en la empresa (p.50).

Prieto (2011) afirma que este documento debe proporcionar información sobre el sistema de gestión y debe especificar lo siguiente (p.50):

Procedimientos: Son una forma detallada y minuciosa de llevar a cabo un determinado proceso. Cuando un procedimiento está documentado, se emplea frecuentemente los conceptos "procedimiento escrito" o "procedimiento documentado". Éstos son los encargados de describir y explicar de manera específica, el cómo cumplir con una serie de tareas para lograr de la mejor manera, un fin específico en orden cronológico con el objetivo de controlar las posibles variantes del proceso. De esta manera, se establecen a los responsables de la ejecución de cada una de las actividades a realizar (p.51).

Las políticas: Regulan el alcance y el fin de una cierta actividad de la compañía que es diseñada y ejecutada dentro de un procedimiento o instrucción de trabajo. Las políticas son cruciales en las organizaciones, ya que establecen reglas claras de operación; sin embargo, no precisa procedimientos. Por tanto, deben ser claras y entendibles por los colaboradores de la empresa (p.53).

Los instructivos: Son guías o instrucciones de operación que se administran a un nivel de ejecución y relatan tareas o eliminan la ambigüedad del término "cómo hacer". Estas guías pueden ser empleadas para determinar operaciones, tareas o procesos que detallan y orientan 
cierta información de referencia que contienen ilustraciones, visuales, catálogos, entre otros (p.53).

- Los registros: Sobrellevan un sistema de información para dar a relucir el cumplimiento de las actividades/tareas indicadas en procedimientos o preceptos de trabajo. Dicha información debe ser considerada para proponer indicadores y proceder en la toma de decisiones de una manera óptima y objetiva. Además, debe ser legible, estar firmada y aprobada por el encargado que ejecuta o supervisa dicha actividad (p.54).

- El formato: Es el esqueleto de una solicitud de información, en la cual, se establece un registro que se considera una evidencia documental de que efectivamente, se están realizando las actividades correspondientes según los requisitos e instrucciones de trabajo establecidos (p.54). El registro generado para evidenciar una determinada actividad o incidencia provocada fuera de la programación junto con la solución de ésta, se denomina bitácora (p.52).

Por último, Bermúdez \& Rodríguez (2013) sostienen que para que las empresas operen de manera eficaz, deben identificar y gestionar los procesos que interactúan y que están estrechamente interrelacionados (p.26). Asimismo, afirman que el resultado de un proceso está vinculado a la entrada del siguiente proceso. Todo lo mencionado anteriormente, se denomina "enfoque basado en procesos" y se plasma en la gestión sistemática e identificación de los procesos realizados en la empresa, sobre todo si existen interacciones entre dichos procesos (p.56).

\section{La Gestión Comunicacional}

\subsection{Comunicación Corporativa}

Para iniciar este apartado, es necesario precisar que existen notables diferencias entre la Comunicación Corporativa y la Comunicación Organizacional. La primera, es la mezcla de todas las maneras posibles de expresión que posee determinadas categorías de investigación y planificación previamente definidas, mientras que, por el contrario, la Comunicación 
Organizacional parte su estrategia por la construcción de diversos procesos en cuanto a la Comunicación Interna y Comunicación Externa de la compañía (León, 2009, p.34).

Asimismo, Dupuy (2001) afirma que el sistema de comunicación y el sistema de organización corporativa poseen una diferencia abismal, ya que los actos cotidianos que se manifiestan en el comportamiento de una entidad se tornan en actos comunicativos (p.5).

Del mismo modo, el concepto de Comunicación Organizacional se denomina de tres posibilidades:

Según Carlos Collado (2005), la comunicación es un fenómeno natural en todas las organizaciones y todos los grupos que existan en el mundo y que se desarrollen en sociedad sin determinar tipos o tamaños. Bajo el concepto de que la comunicación es un proceso natural y, por consiguiente, social y que ha permitido el desarrollo no sólo de la cultura sino también de la civilización, partimos de que la comunicación organizacional es el "conjunto total de mensajes que se intercambien entre los integrantes de una organización, y entre esta y su medio" (p. 30).

Estos mensajes son intercambiados de diferentes maneras, ya sea a través de memos, circulares, carteleras, mensajes electrónicos, medios de comunicación, circuito cerrado, canales interpersonales, boletines, tableros, entre otros. Éstos, se dan de manera vertical u horizontal traspasando las barreras jerárquicas de la institución, pero todas ellas se establecen dentro de un complejo panorama denominado: Comunicación Organizacional (Collado C., 2005, p. 30).

En segundo lugar, encontramos a la comunicación como una materia que tiene como objetivo principal el estudiar la manera de cómo se presenta la comunicación dentro de las empresas y con el medio mismo (Collado C., 2005, p.31).

Por último, Carlos Collado sostiene que la comunicación no es más que un conjunto de actividades y técnicas que mediante una investigación previa, orientan a la empresa a facilitar y agilizar los flujos comunicacionales que se dan entre todos los agentes de la organización, ya sea internos como externos. Asimismo, contribuye en todas las estrategias 
que permiten el cambio de percepciones, actitudes y opiniones que pueden tener sobre ésta, con el fin de ayudar en el cumplimiento de los objetivos organizacionales (p. 30).

Por otro lado, Joan Costa (2001), afirma que "toda organización se encuentra en comunicación consigo misma y, directa o indirectamente, con su entorno, irradiando una determinada imagen, identidad y cultura" (p.276).

Carlos Fernández (2005), manifiesta que, dentro de la comunicación, es importante tener en cuenta lo siguiente:

La Comunicación Corporativa Integral se conforma por: Comunicación Interna, conjunto de actividades efectuadas para la creación y mantenimiento de buenas relaciones con y entre sus integrantes, a través del uso de diferentes medios de comunicación, políticas y programas; Comunicación Externa, conjunto de mensajes emitidos por cualquier organización hacia sus diferentes públicos externos (accionistas, proveedores, clientes, distribuidores, autoridades gubernamentales, medios de comunicación, etc.) encaminados a mantener y mejorar sus relaciones con ellos, además de proyectar una imagen favorable y promover sus productos o servicios (p.12).

Del mismo modo, Sergio Guzmán (2011) afirma que la comunicación organizacional cumple un rol fundamental dentro de toda empresa, ya que ésta permite que los procesos, tanto internos como externos, sean cada vez más efectivos, eficientes y beneficiosos para las instituciones. Además, sostiene que los medios por los que la organización da a conocer su cultura interna a los agentes externos se dan a través de los empleados, accionistas, proveedores, clientes, entre otros (p.24). Asimismo, manifiesta que cada empresa posee una identidad que la hace diferente las demás organizaciones, por lo que su comunicación corporativa también debe ser diferenciada y debe tener concordancia con el tipo de clientes, entorno, proveedores y otros factores que formen parte de su universo empresarial (p.25).

Por otro lado, Guzmán sostiene que, bajo la condición de una dimensión deontológica, la naturaleza de la comunicación en las empresas se expresa a través de su propia esencia. Es decir, el capital humano es entendido como un acto producto de la comunicación social, por lo que conlleva a tener actividades en común como los métodos, objetivos, procesos, acciones, propósitos y resultados de todos los colaboradores (p.24). Por otro lado, bajo la condición de la dimensión teleológica según el marco de la comunicación organizacional, la 
corporatividad, como unidad de la identidad colectiva, es pensada como un sistema autónomo vinculado al propio entorno de su dimensión social (Guzmán, 2011, p.25).

\subsection{Identidad Corporativa}

La identidad corporativa es la parte visual de la organización y que, a través de ésta, se transmiten y destacan las características o rasgos esenciales de la institución. Es decir, la empresa necesita un nombre y una razón de ser, con el fin de generar un gran impacto visual y poder diferenciarse de su competencia directa existente en el mercado a cuál esta va dirigida (Catherine Fishel, 2000, p.81)

Asimismo, Joan Costa (2007), expone que la identidad corporativa es la unión de los signos visuales que son percibidos por los públicos y son memorizados de manera instantánea. Esto quiere decir, que el impacto visual que ejerce en el usuario logra obtener un cierto grado de recordación de la marca gracias a los conceptos gráficos visuales que se dan en el desarrollo de la identidad de la comunicación (p.32).

El conglomerado de estos signos, trabajan en conjunto al momento de comunicar, debido a que se desarrolla un concepto consolidado que se apoya en las texturas, colores, tipografías, signos, entre otras características; permitiendo que resalte en términos de alcance y pueda ser utilizado en campañas de lanzamiento o campañas de intriga (Bourriaud, N., 2009, p.57).

Además, Magdalena Mut Camacho y Eva Breva Franch (2005) señalan, que, de partida, si no existe un buen concepto y desarrollo de identidad, la identidad corporativa puede perder fuerza frente a la competencia del mismo rubro, debido a que al momento de que el cliente realice una elección de compra (ya sea de un producto, un servicio, un bien tangible o intangible), la identidad visual es la encargada de generar ese impacto al momento de tomar una decisión (p.62).

\subsubsection{Importancia de la Identidad Corporativa}

La imagen e identidad corporativa para la organización se torna de crucial importancia, debido a que es la primera impresión que tendrá el cliente en cuanto a la empresa y, además, podrá verse influenciado en la toma de decisión de compra. Hoy en día, existen empresas 
que poseen un buen sistema organizacional; sin embargo, su identidad e imagen no está muy bien desarrollada. Esto, puede significar falta de interés o simplemente, por no saber a quién acudir o simplemente por desconocimiento del tema (Bourriaud N., 2009, p.43).

Desde su aparición, los seres humanos han buscado la comunicación por medio de diferentes medios, transmitir mensajes y así, darse a notar de grupos sociales. Es por esta razón, que el término o concepto de identidad no es nada nuevo. Podemos observar en todas las épocas los miles intentos por parte de las personas por hacerse reconocer a través de símbolos, ya sea por la marca de un producto, las imágenes que hay alrededor de una institución o hasta por un tatuaje corporal (Mut Camacho M. y Breva E., 2005, p.73).

Asimismo, Christian Regouby comenta que la identidad corporativa se define como todo aquello que contiene la carta de presentación de la empresa y dentro de su sistema de identidad visual se encuentran diversos elementos constitutivos de la identidad, tales como la historia de la institución, sus estructuras, su evolución, los servicios, la dinámica estratégica y la percepción por los diferentes públicos (Arguello, 2005)

Dentro de la Identidad Corporativa nos habla de imagen visual que proyecta la empresa. Para Regouby Christian la identidad corporativa es la representación de la organización, es determinar la filosofía corporativa la cual se ve refleja en ella y 7a su público o mercado, teniendo como objetivo el impacto como primera vista hacia ct67lientes que no nos conocen y para los que ya son nuestros clientes transmitir lo que la empresa significa, lo que conlleva a que las empresas necesiten una imagen corporativa que respaldo su servicio.

Del mismo modo, dentro del libro: "Imagen Corporativa, el origen de los primeros indicios de la identidad corporativa" de Joan Costa (2002), se puede encontrar la historia del comercio, en donde en primera instancia, fue vital identificar y diferenciar los productos entre sí, logrando iniciar las primeras fases de la marca comercial (p.33). Según Joan Costa, dicho proceso semiótico, se clasifica en dos tipos de signos (p.35):

- Marca icónica: Proveniente de la acción "marcaje", en donde sus primeras manifestaciones se detectaron en ciertos restos arqueológicos de la Europa del siglo VIII a.C. que se encontraban en contenedores de transportación de productos. El 
marcaje nació dada la necesidad de poder reconocer el encargado de los productos de exportación, debido a la gran frecuencia de robos en los almacenes y en altamar.

- Logotipo: Tuvo sus inicios gracias a la aparición de la imprenta, las artes gráficas y la creación de los tipos de imprenta con las letras enlazadas. De esta manera, se reflejaba en el papel, letras ligadas que se volvían lo que hoy en día se conoce como logotipo. La diferencia con la "marca icónica” es que ésta sí puede ser leída y, por el contrario, el logotipo es para ser visualizado, pero ambos tenían el rol de ser marca diferenciadora o como una forma primitiva de identidad.

Catherine Fishel (2000) afirma que la primera manifestación del concepto de identidad corporativa se hizo presente tras el auge de la revolución industrial con dos grandes manifestaciones: a) la primera, en el año de 1890, cuando Gottlieb Daimler diseñó la estrella de tres puntas de la marca Mercedes Benz y b) la segunda, cuando los hermanos Michelin crearon la mascota "Bibendum" con el fin de publicitar su marca de neumáticos (p.42).

Asimismo, Joan Costa (2007) comenta que existe otro momento histórico, el cual se exhibe en Europa a principios del siglo XX, con diversas innovaciones instauradas en diferentes empresas. La primera ella fue la compañía alemana, Allgeneine Elektricitäts Gesellschaft (AEG), que en el año 1908 empleó el diseño en términos de concepción gráfica y, además, lo expandió a otros aspectos de la organización. Para lograrlo, contrató a dos profesionales: a) Peter Behrens, quien fue arquitecto y artista gráfico que se encargó de la aplicación de una concepción unitaria en productos e instalaciones de diversa índole, tales como oficinas, fábricas, establecimientos comerciales y de comunicaciones. En ellos, empleó dicho principio y conceptualizó la creación de marcas, logotipos, carteles, anuncios folletos y catálogos; b) por otro lado, se encontró Otto Neurath, quien fue psicólogo de profesión y fue el encargado de unificar en un solo procedimiento las relaciones humanas y las comunicaciones con el mercado (p.63).

De este modo, Joan Costa afirma en su libro: "100 años de juventud: identidad corporativa", lo siguiente:

"Con Behrens y Neurath, el diseño en sentido global y la sociología de la comunicación entraban en el mundo de la empresa. Por primera vez, tanto como se 
pensaba en los productos, la calidad y el negocio, una organización industrial pensaba en la institución como un todo. Incluido su estilo que impregnaba todas sus manifestaciones; su estética distintiva y su cultura, así como sus interrelaciones humanas internas y externas, y la imagen de la empresa" (p.35).

Con ello, esta idea integradora se convirtió en anticipo de la futura estrategia para la competitividad. El resto del mundo lo hizo 50 años más tarde. Hoy en día, ninguna compañía actúa sin un concepto corporativo ni estrategia bien desarrollada (Costa, J., 2003, p.36).

Por otro lado, años más tarde, en el año 1928, la empresa italiana Olivetti ideó un servicio de publicidad que luego de tres años, se convirtió en el departamento de Desarrollo y Publicidad. En 1946, creció y se transformó en la oficina Técnica en Publicidad y, diez años después, esta área fue asumida por Renzo Zonzi, quien integró las relaciones culturales, el diseño industrial, las relaciones internas y externas, la comunicación, publicidad y promoción. De esta manera, se incluyó un nuevo rol dentro de la empresa: el Director de Comunicación (DIRCOM) (Bourriaud, N., 2009, p.55).

En el artículo "De la identidad corporativa a la identidad visual corporativa" de Magdalena Mut Camacho y Eva Breva Franch (2005), se menciona que los aportes realizados las empresas mencionadas con anterioridad sumados con la evolución de las teorías de la comunicación, dan como resultado el "dotar de valor simbólico a la organización, operando, no sólo sobre el producto físico, sino sobre discursos” (p.32). Asimismo, Joan Costa (2007) sostiene:

"Las innovaciones desarrolladas en AEG y Olivetti fueron exportadas a Estados Unidos por el alemán Walter Landor, quien las simplificó, las redujo al campo de diseño gráfico y las bautizó bajo el nombre de identidad corporativa, causando una disociación entre el diseño industrial y el diseño gráfico. Si Europa creó el concepto y estableció los primeros desarrollos, los USA le dieron nombre (necesitaban una marca para este producto), lo envolvieron en un buen packaging y lo reexportaron a Europa y al mundo" (p.57). 


\subsubsection{El Valor De La Identidad Corporativa}

El valor de la identidad corporativa reside en la claridad con que la institución se muestre, ya sea con mensaje comprensivo de cara a sus propios empleados o simbolizando los valores éticos y cultura o su forma de trabajo para que todos los colaboradores puedan transmitir esos valores, los puedan comunicar hacia sus propios compañeros o a terceros (Ind, 2007, p.24).

Bajo la misma premisa, Nicholas Ind (2007) afirma la identidad del sujeto institucional o empresarial, forma parte de un complejo sistema de mensajes que puede presentarse en todos los componentes que implican los rasgos y valores de la entidad (p.24).

Por eso, la identidad encierra el historial de la empresa, sus directivos, sus colaboradores, sus creencias y su filosofía, la personalidad de sus dirigentes, sus estrategias y, sus valores éticos y culturales. De esta manera, puede proyectarse o comunicarse mediante los diversos programas de identidad corporativa (Ind, 2007, p.24).

\subsubsection{Signos esenciales en la Identidad e Imagen Corporativa}

\subsubsection{El nombre}

Saniz (2015), señala que en el proceso de la conceptualización de la identificación institucional, se manifiestan dos conceptos que se diferencia con gran notoriedad: a) Identificación en sentido estricto, que tiene relación con el proceso mediante el cual, la organización se asigna una serie de atributos que determinan el qué y cómo es ésta y, b) Denominación, que no es más que la codificación de la identidad previa de la institución a través de su asociación con determinados nombres que permitan tomar la decisión de quién es esa empresa (p.48).

Dichos nombres consiguen producirse a través de diversos mecanismos lingüísticos y adoptan una multitud de aspectos que se dividen en: Descriptivos, Patronímicos, Toponímicos, Simbólicos y Contracciones (Saniz, 2015, p.95). 
Sánchez, J. y Pintado, T. (2009), comentan que el nombre es la carta de presentación de la organización, debido a que, por éste, todos la pueden reconocer $y$, además, porque va asociada la imagen que el público tenga sobre ella (puede ser positiva o negativa) y por último, y el alcance que tengan a futuro (p.47).

\subsubsection{El logotipo}

El logotipo detalla simbólicamente la imagen que ha establecido la institución y con ello, empezará a aparecer en todos los elementos de marketing con el fin de reforzar la imagen de marca y e implantar ciertos vínculos entre la empresa y el público a través de fácil y rápida asociación del logotipo a la organización (Ramírez, 2009, p.56).

Por otro lado, Joaquín Sánchez Herrera y Teresa Pintado (2005) sostienen en el libro: "Imagen Corporativa" lo siguiente:

"Etimológicamente, la palabra logotipo procede del griego: logos ("palabra") y tupos ("golpear o grabar la piedra con un punzón"). En cierto sentido, ése es el objetivo del logotipo: grabarse en nuestra memoria visual -que es mucho más afectiva y permanente que la memoria verbal- para que recordemos el nombre de una organización. Por otro lado, el poder del logotipo está condicionado por las circunstancias de que "un símbolo corporativo siempre debe guardar relación con un determinado contexto (p.98)."

Con ello, se puede decir que un logotipo no es más que una palabra diseñada que tiene como característica principal la originalidad, un carácter único y distinto; en otras palabras, es la expresión de la "marca" que representa la abstracción de todo lo que es en sí la empresa o un producto (Sánchez \& Pintado, 2005, p.38).

Catherine Fishel (2000), sostiene en su libro "Rediseño de la Imagen Corporativa" que:

"Los clientes ven el mundo a través de dos ojos montados horizontalmente en su cabeza. Es como mirar a través del parabrisas de un coche. Para lograr el máximo impacto visual, un logotipo debería tener la misma forma del parabrisas" (p. 138).

De esta manera, el logo permite que la empresa logre ubicarse, de forma visual, junto con sus competidores y, además, posea una imagen más atractiva y profesional frente a los proveedores. Asimismo, existen logotipos de muchas formas y tipos como, por ejemplo, cuadrados, ovalados redondos, verticales, horizontales, entre otros; sin embargo, todas estas 
representaciones no suelen ser iguales ante los ojos de los consumidores (Neville, Bell \& Mengüc, 2005, p.82).

Para Prieto (2011), un logotipo es el conjunto de abreviaturas, letras, cifras o símbolos de forma unificada dentro de un solo bloque que permite proporcionar una composición tipográfica. En otras palabras, es la firma de la institución que es aplicable en todo el material visual o impreso de la misma. Es decir, puede aplicarse en carteles, papelería, señales, transporte, dípticos o en otro material que muestre la presencia de la organización. Además, se puede incorporar en medios audiovisuales como en la radio y televisión o en la prensa (p.43).

\subsubsection{El Imagotipo}

Sánchez \& Pintado (2009) sostienen que la utilización del nombre y del logotipo suelen estar añadidas a un signo no verbal que cumple la función de optimizar las condiciones de identificación a través de la ampliación de los medios (p.78).

Estas imágenes, conservan una apariencia estable que alcanzan la atracción visual por las cuales fueron realizadas y, además, logran poseer una identificación que no requiere lectura en cuanto al sentido verbal de la terminología (Saniz, 2015, p.68).

Ramírez (2009) afirma que los imagotipos suelen acoplar múltiples características, debido a que su rol principal es brindar memorabilidad y capacidad de diferenciación frente a las demás marcas (p.34).

\subsubsection{Componentes de la identidad corporativa}

Según Neville, Bell \& Mengüc (2005), la identidad corporativa es el conjunto de símbolos que una institución emplea para ser identificado frente diversos grupos de personas. En otras palabras, es la expresión visual de la empresa. Por ello, considera que los componentes que conforman la identidad corporativa son los siguientes (p.69):

a) Logo: Attribute that integrates and determines the brand. [Logotipo: Atributo que integra y determina la marca].

b) Colors: Express corporate colors. [Los colores: Expresan los colores corporativos]. 
c) Symbol: It is characterized by a vector drawing that has one or two colors. [Símbolo: Es caracterizado por un dibujo vectorial que lleva uno o dos colores].

d) The slogan: An aggregation component that intends to display an idea and that, by simply displaying the logo, the client can remember the statement automatically. [El slogan: Componente de agregación que pretende exhibir una idea y que, con solo visualizar el logotipo, el cliente pueda recordar el enunciado de manera automática].

Estos elementos se deben adecuar dependiendo del medio de comunicación en el que se empleen y, además, deben ser uniformes en cuanto a la gama cromática, debido a que no deben realizarse cambios en cuanto a uso de las tipografías, dimensiones, ubicaciones, jerarquía, orden, entre otros. Para ello, se debe adecuar al soporte y seguir estrictamente el Manual de Identidad Corporativa, con el fin de no presentar cierta sensación de inestabilidad y desbalance en la marca (Ramírez, 2009, p.58).

Para Prieto (2011), la Identidad Corporativa se torna en un concepto estratégico para posicionar a una determinada entidad, por lo que exige identificar y definir los atributos de identidad, con el fin de unificarlos y conllevarlos a la estrategia previamente establecida de una manera más congruente (p.25).

Dicha identidad se transmite a través de cualquier acción comunicacional por parte de la organización. Por esta razón, es crucial tener una estrategia definida, ya que permite acrecentar las garantías de que ésta percibida de la mejor manera por parte del cliente. Todo ello, puede ser logrado solo si la identidad corporativa se torna como una guía principal para todas las actividades de la entidad, ya que propicia una relación armoniosa entre todas las actividades comunicacionales de la misma. Es decir, que todo que la organización hace, dice y comunica, puede ser entendido como una amplitud de su identidad, ya sea consolidándola o debilitándola (Sánchez \& Pintado, 2009, p.57).

En el mismo sentido, Saniz (2015) manifiesta que la Identidad Visual es un componente de la Identidad Corporativa que se constituye a partir de gran cantidad de características que requieren una clasificación y estructuración, a partir de la filosofía, la orientación y la comunicación (p.35). Asimismo, un programa de identidad corporativa es una herramienta de gerencia que permite identificar y operar de manera sistemática, los temas, las estructuras y la personalidad de una empresa. 
Por otro lado, Sánchez \& Pintado (2009), Ramírez (2009) y Retamal (2002) detallan que los elementos intangibles son los componentes de naturaleza inmaterial, carácter no monetario y ausencia de sustancia física; producto de transacciones o acontecimientos pasados como, por ejemplo, la compra, la producción o cualquier otro medio de adquisición (p.46, 78, 53).

De mismo modo, los autores sostienen que la diferencia entre activos y elementos intangibles radica en que el primero, son todas las inversiones de naturaleza intangible que pueden ser evidenciadas y manifestadas en el balance desde el ámbito de la contabilidad y; el segundo, se torna en un concepto mucho es más amplio, debido a que los elementos intangibles pueden contener aspectos que harían resaltar las exigencias de las normas contables o, en caso contrario, las rebajarían. Por tanto, no entra en la denominación de activos intangibles (Sánchez \& Pintado, Ramírez \& Retamal, 2009, p.46, 78, 53).

De esta manera, se percibe que para el recurso intangible es crucial el stock o valor actual en un determinado lapso y que, además, es presentado o no en términos financieros. Por otro lado, las actividades intangibles involucran la asignación de recursos para la adquisición de nuevos compendios, con el fin de aumentar el valor de estos y también, para evaluar y controlar los resultados alcanzados. Es así, como se puede un carácter estático a los recursos mientras que las actividades se les asigna un carácter dinámico (Sánchez \& Pintado, Ramírez \& Retamal, 2009, p.46, 78, 53). A continuación, se puede visualizar la visión dinámica y estrategia de los intangibles: 
Figura 18: Visión dinámica y estratégica de los intangibles

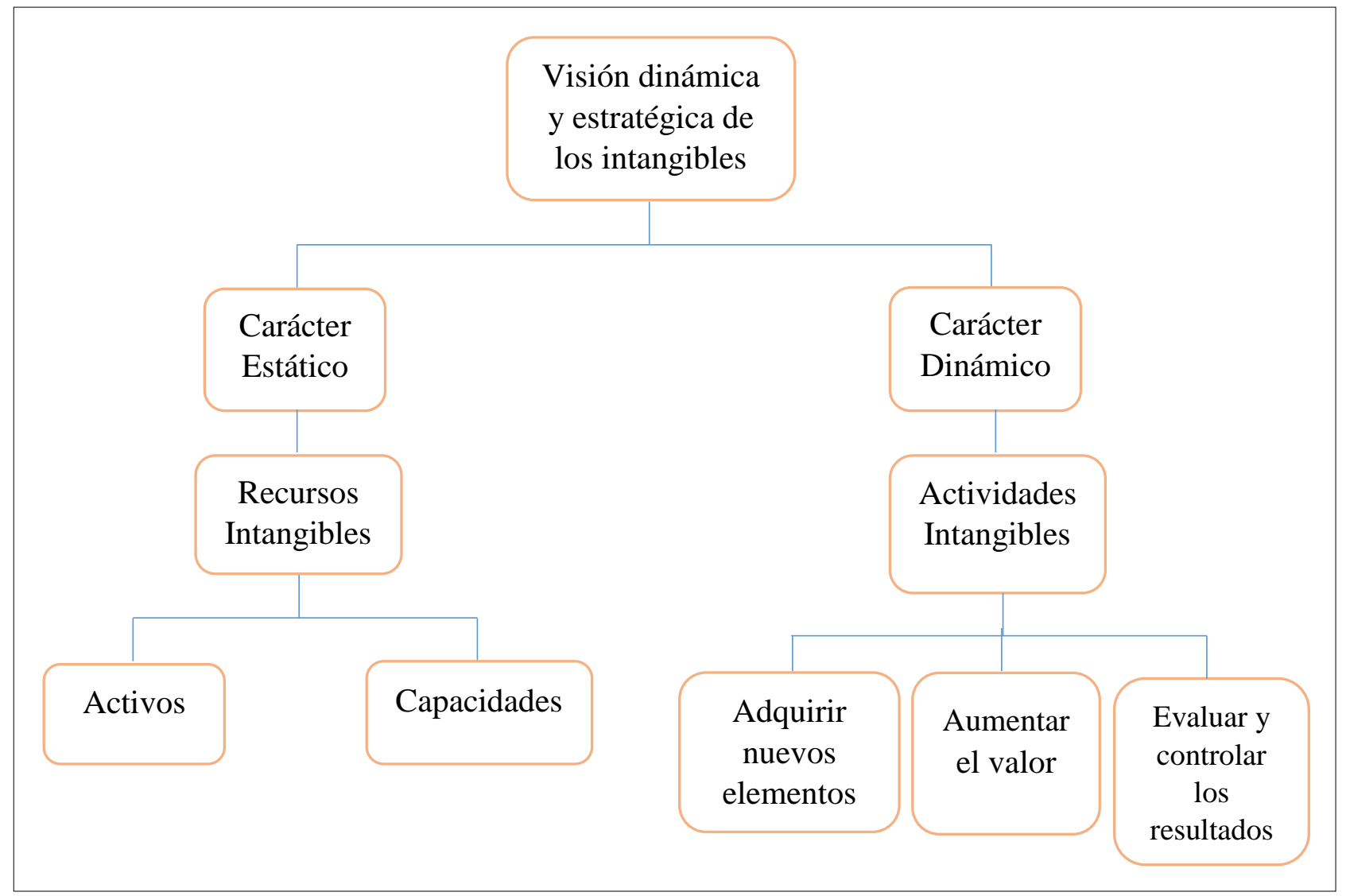

\section{Fuente: Cañibano (2007)}

Bajo el mismo precepto, se concluye que la integración de los recursos y las actividades intangibles crean un valor adicional en la empresa (Sánchez \& Pintado, 2009, p.63). Por ello, se presenta el cuadro con los conceptos mencionados con anterioridad: 


\section{Figura 19: Marco conceptual de los intangibles}

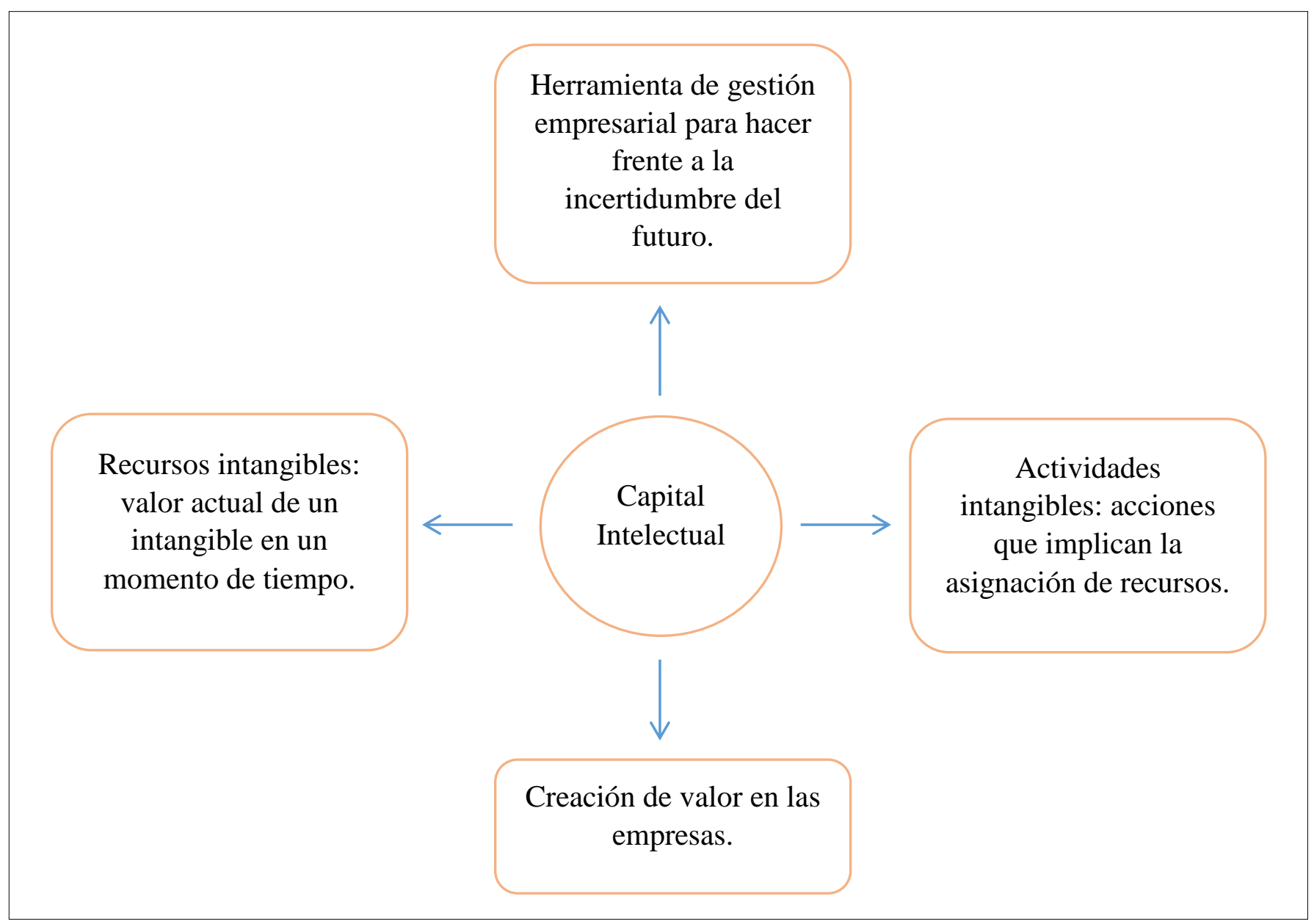

Fuente: Cañibano (2007)

Como podemos observar, Cañibano (2007) diferencia los recursos intangibles de la entidad de las actividades que permiten fusionar dichos elementos de manera eficiente. De este modo, plantea que la creación de valor en las empresas se produce gracias a la combinación de recursos y actividades intangibles y no necesariamente a la consideración que posee de manera independiente (p.67). Producto de la unión de todos los intangibles creadores de valor, se manifiesta la creación del capital intelectual de la institución que puede ser empleado en el mercado como herramienta de gestión empresarial para contrarrestar la incertidumbre del futuro económico (p.68).

Bajo el mismo parámetro, Tejedo (2011) sostiene que los elementos intangibles son el reflejo del fondo de comercio o goodwill y por esta razón, es que su valor se establecerá de forma indirecta en el mercado bursátil (p.33). Zhang (2013), afirma que el fondo de comercio se 
encuentra confirmado por elementos intangibles desconocidos en los estados financieros, dado que las organizaciones deben reconocer un fondo de comercio positivo con el fin de que tengan mayor rentabilidad, liquidez, y apalancamiento para los que todavía no conocen a la empresa (p.87).

Asimismo, Tejedo (2011) señala que la creación de valor puede ser materializada en la entidad por medio de la generación de elementos intangibles y patrimonio a largo plazo. Es así, como los recursos, las capacidades y los compromisos de los colaboradores son los factores clave para la creación de valor en la empresa. También, indica que existen varios puntos clave que colaboran con la maximización de la creación de valor de la institución, por ejemplo, el conocimiento, el uso de sistemas para mejorar estas competencias individuales, el apoyo a los clientes, el aprendizaje que nos proporcionan los clientes, la integración de sistemas y procesos o la utilización de nuestra capacidad para atender la demanda, el desarrollo de competencias individuales y, el uso de las competencias de proveedores y clientes para mejorar nuestros productos (p.56).

También, la atribución a la creación de valor se da por parte de las organizaciones a diversos elementos intangibles tales como el capital relacional, estructural, la investigación, la experiencia y el desarrollo; gracias al afán de lograr resultados positivos, eficiencia y crecimiento (Ochoa, 2007, p.83).

Después de lo señalado anteriormente, Monclús (2004) afirma que los elementos intangibles tienen que ser identificados producto de la agregación de la información y el entendimiento de las actividades productivas de la empresa (p.77). Por otro lado, Zhang (2013) sostiene que los elementos intangibles se caracterizan por la complejidad de contabilización, de su rol fundamental en la generación de ventajas competitivas, de la reproducción por instituciones competidoras y por sus futuros beneficios para las entidades (p.26).

Para gestionar intangibles, el número recomendable de indicadores que deben ser empleados gira en torno a diez, acentuando la antigüedad de los colaboradores como el indicador más usado. De igual modo, la utilización de indicadores financieros y no financieros, tanto homogéneos como comparables, deben facilitar la interpretación de la importancia de los elementos intangibles con el fin de que accedan su gestión (Rodríguez, 2009, p.89). 
Por último, Ochoa (2007) indica que los indicadores fundamentales son la lealtad de los clientes, la satisfacción de estos, el establecimiento de relaciones duraderas con éstos y con los proveedores para que se puedan identificar dichos elementos intangibles y, además, se puedan controlar de manera más oportuna. También, señala que existe una segmentación de empresas en tres grupos: a) entidades comprometidas con la implantación de intangibles, b) escépticas a la implementación de dichos elementos y c) desconfiadas frente a la innovación de los intangibles (p.45).

\subsection{Imagen Corporativa}

Whetten \& Mackey (2002), sostienen que el elemento general de la imagen corporativa para la comprensión de los términos de identidad y reputación se extiende en una gran diversidad de conceptos que, por lo general, suelen ser confundidos entre estos dos términos. Esto es debido a que, dificultan el consenso de la descripción de la imagen impiden y perjudican el estudio de la relación entre dichas nociones (p.400).

Por otro lado, esta diversidad de significados ha facultado que su propia utilización dentro del terreno de la comunicación corporativa, también se vuelva muy complejo. Esto se ve reflejado en la gran variedad de conceptos establecidos en este campo y, además, se ve emitida en la literatura referente al tema (Capriotti, 2013, p. 15).

Neville, B., Bell, S. y Mengüc, B. (2005) afirman que este fenómeno origina que la conceptualización de imagen e identidad corporativa se confundan y que haya dualidades con la entidad por parte del cliente, gracias a la diversa cantidad de significados (p.1184).

Además, sostienen que el concepto de imagen se traduce como la primera instancia de percepción o contacto visual que sucede de persona a persona que hace evidente las diversas maneras y formas. Por ello, la imagen forma parte de la comunicación que se da por medio de las personas. Es importante resaltar, que ésta tiene variaciones según la percepción que posee cada individuo, ya que distinta una de la otra y por lo general, se torna a descontextualizar de manera radical el concepto de este (Neville, B., Bell, S. \& Mengüc, B., 2005, p.1184). 
Asimismo, las imágenes se pueden crear o generar a través de diversas herramientas, conceptos, acciones, momentos, entre otros. Incluso, por medio de nuestro cuerpo, por ejemplo, el lenguaje de las señas que mediante de señales gestuales que se efectúan mediante los gestos corporales, faciales o de las manos; los individuos se pueden comunicar y comprender sin problemas (Whetten \& Mackey, 2002, p.401).

Capriotti (2013) señala:

La Imagen Corporativa es la imagen que tienen los públicos de una organización en cuanto entidad. Es la idea global que tienen sobre sus productos, sus actividades y su conducta. La Imagen Corporativa es la estructura mental de la organización que se forman los públicos, como resultado del procesamiento de toda la información relativa a la organización (p. 29).

Como vemos, el concepto de imagen denota gran importancia y, además, añade valor a las compañías, productos, marcas y servicios. Al ser tan relevante, también, se vuelve un factor delicado, debido a que posee influencia de la percepción del público o consumidor en general o por la actitud que quiera reflejar como imagen corporativa (Belting H., 2007, 90).

\section{Tabla 3: Clasificación de conceptos de Imagen}

\begin{tabular}{|l|l|}
\hline Concepto & Descripción \\
\hline Imagen Construida & $\begin{array}{l}\text { Imagen construida externa: percepciones de los miembros de la } \\
\text { organización de cómo son percibidos por los elementos externos. }\end{array}$ \\
\hline Imagen Proyectada & $\begin{array}{l}\text { Imagen creada por la organización le gustaría que los miembros } \\
\text { que es comunicada a sus stakeholders. }\end{array}$ \\
\hline $\begin{array}{l}\text { Imagen Futura } \\
\text { Deseada }\end{array}$ & $\begin{array}{l}\text { Percepción visionaria que a la organización le gustaría que los } \\
\text { miembros internos y externos tuvieran de la organización en el } \\
\text { futuro. }\end{array}$ \\
\hline $\begin{array}{l}\text { Identidad } \\
\text { Corporativa }\end{array}$ & $\begin{array}{l}\text { Representaciones consistentes y dirigidas de la organización } \\
\text { resaltadas a través de los símbolos corporativos y logos, } \\
\text { autorepresentaciones planificadas estratégica y operacionalmente } \\
\text { aplicadas. }\end{array}$ \\
\hline $\begin{array}{l}\text { Impresión } \\
\text { Transitoria }\end{array}$ & $\begin{array}{l}\text { Impresión a corto plazo construida por el receptor a través de la } \\
\text { observación directa o de la interpretación de los símbolos } \\
\text { recibidos de la organización. }\end{array}$ \\
\hline Reputación & $\begin{array}{l}\text { Juicios colectivos de los miembros externos, relativamente } \\
\text { estables, formados a largo plazo a partir de las acciones y logros } \\
\text { de una organización. }\end{array}$ \\
\hline
\end{tabular}

Fuente: Giorgia, D., Schultz M. y Corley, K (2000) p. 63-81. [Traducción propia] 
Por último, Sánchez, J. y Pintado, T. (2009) declaran que hoy en día, se torna complicado definir la imagen corporativa, ya que afirman que absolutamente todo lo que engloba a una empresa o producto, hace referencia a su imagen. Por lo tanto, la correcta definición de dicho término es una representación mental que presenta cada individuo, creada por una suma de atributos con referencia a la entidad (p.101).

\subsubsection{Clases de imágenes}

Whetten \& Mackey (2002) manifiestan que las imágenes se pueden formar por medio de momentos, herramientas, acciones, conceptos, entre otros (p.401). Por ello, es imprescindible explicar las diversas clases de imágenes para comprender su impacto en las organizaciones:

- Imágenes visuales y conceptuales: hoy en día, nos encontramos inmersos en un panorama de creación de imágenes contantes, tanto visuales como conceptuales. Por un lado, encontramos las imágenes de la televisión, medios impresos y medios digitales. Por otro lado, tenemos las imágenes conceptuales como los múltiples conceptos corporativos, la imagen de una empresa o país, entre otros (Ochoa, 2007, p.83).

- Imagen Personal: se conceptualiza como un fenómeno visual que se enriquece, de manera paulatina, con otras experiencias. Un claro ejemplo es cuando se conoce por a una persona y la primera impresión se da por su imagen física y, posteriormente, por sus gestos, expresiones, ademanes, forma de caminar o hablar. Luego, el ser humano crea una percepción acerca de la conducta habitual, por lo que diseña mentalmente una imagen puntual de una persona (Ochoa, 2007, p.83).

- Imagen Institucional: así como las personas proyectan una determinada imagen que establece su personalidad; las compañías realizan el mismo ejercicio, ya que poseen una imagen que las identifica y las define a través de la opinión de sus diversos públicos, lo cual, constituye su personalidad. (Ochoa, 2007, p.84). Dentro este marco, la imagen institucional presenta a su vez, dos tipos de imagen: a) imagen objetiva que constituye la identidad desarrollada por la empresa en cuestión y b) imagen 
subjetiva que es aquella que manera en que el público percibe a la organización, en términos de imagen emocional y que es instituida por variables intangibles como las experiencias directas de los usuarios (Cañibano, 2007, p.68).

- Imagen corporativa: adquiere un rol fundamental, debido a que crea valor para la entidad y se establece como un activo intangible estratégico. Asimismo, permite ocupar un espacio en la mente de los diversos públicos de la institución y facilita la diferenciación de la empresa en el mercado con respecto a la competencia (Rodríguez, 2009, p.89).

\subsubsection{Componentes de la Imagen Corporativa}

Sánchez \& Pintado (2009) sostienen que la Imagen Corporativa posee diversos elementos que se listan a continuación (p. 16):

- La imagen principal: está compuesta por aquellos atributos ligados a la identidad de la institución y, a la percepción que posee dentro y fuera de la empresa. La imagen deriva de lo que la empresa es como tal y por eso, su fundamento se centra en la carta de identidad, como, por ejemplo, en la misión y visión (p. 16).

- La imagen esencial: procede de un acontecimiento determinante para la organización. Es decir, toda compañía opera en un ambiente preexistente y arduamente modificable. Por lo que, son las peculiaridades de este escenario las que fijan una determinada imagen contextual que depende estrechamente de la imagen del país o del sector en donde la institución realiza sus operaciones. Con ello, se puede precisar que imagen contextual está conformada por un marco político, legal, social, cultural, económico, tecnológico y medioambiental (p. 16).

- La imagen factual: Es producto de la conducta de la entidad. Si la imagen social y la contextual son imágenes en alguna medida previas, la imagen factual es necesariamente consecuencia de una actuación, de un comportamiento puede ser perfectamente premeditado o completamente espontaneo, lo cual se traduce en que parte de la imagen factual es controlada y otra parte no, en todo caso, la imagen 
factual es enormemente compleja pues tiene ramificaciones en un gran número de ámbitos diferentes: financiero, comercial mediático, social, interno, institucional (p. 17).

- La imagen conceptual: es la imagen ideada y difundida por la compañía por medio de los diversos canales de comunicación de que ésta dispone. En el mismo sentido, la imagen proporciona la percepción de un estilo empresarial y la forma particular de expresión que definan a la entidad y la diferencien de las demás. Con todo ello, las diferentes acciones comunicativas que constituyen la imagen conceptual pueden desarrollarse en los ámbitos sociales, comerciales, internos o sectoriales (p. 17).

\subsubsection{Fuentes de información para la construcción de la Imagen Corporativa}

Ramírez (2009) afirma que existen distintas fuentes de información que permiten la construcción de la imagen corporativa (p. 79). A continuación, se mencionarán las más relevantes para la presente investigación:

- Los medios de comunicación masivos: existen dos mensajes que deben ser distinguidos en esta sección: a) comerciales: son aquellas comunicaciones que están directamente controladas por la institución y b) noticias: son todas las informaciones que los púbicos contemplan propias del medio, por lo que el control sobre la información que las empresas pueden ejercer se torna variable. Bajo este contexto, los medios se han convertido en una fuente de información privilegiada que determina la imagen de las compañías (p. 79).

- La experiencia personal: en muchas oportunidades, se ha evidenciado que las relaciones interpersonales poseen mayor influencia en la información proveniente de imágenes que de los propios medios de comunicación, ya que refuerzan actitudes prexistentes. De este modo, es imprescindible destacar la influencia de los líderes de opinión y de los grupos de referencia porque en ocasiones, determinan o moldean las conductas de las personas en la medida en que éstas aceptan los mensajes como muestra de la realidad o porque emplean los valores grupales para aplicarlas como pautas normativas para su propio comportamiento o áreas específicas (p. 79). 
- La experiencia propia: posiblemente, sea este el modo de información más categórico en la formación de la imagen de una institución, debido a que brinda mensajes de primera mano. Sin embargo, puede que estén mediatizados por cualquiera de las anteriores fuentes de información definidas. Por ello, la experiencia propia puede clasificarse en dos grupos: a) directa: cuando se obtiene una relación no mediada con individuos que pertenecen a la organización o directamente con la misma. Un claro ejemplo es por medio del servicio de atención al cliente y b) indirecta: cuando dicha experiencia se encuentra vinculada con el uso o consumo de productos y servicios, luego de observar el comportamiento de la entidad en el ámbito del patrocinio (p. 80).

\subsection{4 ¿Imagen Corporativa o Identidad Corporativa?}

Para Ochoa (2007), es relevante que las empresas se diferencien una de otras y además, que destaquen sobre sus competidores. Por ello, es tan crucial tener una identidad construida cuidadosamente y tener un buen posicionamiento en el mercado, debido a que estos componentes generan un gran valor para la compañía y contribuyen con el éxito sobre la competencia (p. 56).

Además, Belting (2007) señala que existe una discrepancia entre el concepto Imagen Corporativa e Identidad Corporativa. Por un lado, se denomina Imagen Corporativa a la percepción que una determinada organización alcanza ante sus públicos. Por otro lado, el término Identidad Corporativa hace alusión a la imagen que una institución pretende adquirir y lograr, con el fin de forjar una buena reptación entre sus clientes. De esta manera, es relevante comprender ambos elementos, debido a que la imagen de una corporación puede acreditarse a través de la planificación de una buena gestión de identidad corporativa (p. 91).

Por tanto, la imagen corporativa es construida, en gran medida, por la identidad corporativa. Con ello, se puede afirmar que todas las organizaciones poseen una imagen corporativa, ya sea buena o mala, pero no todas tienen un plan de identidad corporativa previsto (Ochoa, 2007, p. 56). 
Además, Wessels (2003) sostiene que toda institución es única por ello, su identidad debe prosperar internamente desde las raíces de su personalidad, firmeza y debilidades (p. 75).

La identidad de una compañía debe ser tan evidente que se debe emplear como el parámetro de medición de sus productos, servicios, comportamiento y gestiones. De esta manera, la identidad no solo es un slogan o una recopilación de frases, sino que más bien, es tangible y transparente (Villafañe, 2004, p. 61).

El material impreso o digital de comunicación de la entidad, debe ser consistente con la imagen que se desea proyectar para que refleje las características y objetivos de la misma. Asimismo, estos materiales conforman el mix de identidad, por lo que deben ser rigurosos con su elaboración y planeación (Sabaté y Quevedo Puente, 2003, p.55).

Del mismo modo, Neville, Bell \& Mengüc (2005) afirman que los productos que realiza o comercializa la organización, la infraestructura, decoración, uniforme del personal, el trato hacia los colaboradores, proveedores o clientes etc., deben proyectar calidad y confianza, ya que también es una manifestación de su identidad (p. 82).

\subsection{Reputación Corporativa}

Ferguson, Deephouse y Ferguson (2000) definen el término "reputación" como el conocimiento de las auténticas características de una organización y las emociones que hacia ésta poseen los grupos de interés. Asimismo, afirman que el concepto es utilizado en numerosas disciplinas como teoría de juegos y sociología y en cada una de ellas, cuenta con una definición diferente de tal manera, en que no se encuentra un consenso global en la literatura sobre dicho término. Por tanto, estos autores manifiestan que la reputación es el reflejo que una entidad posee a lo largo del tiempo en sus influenciadores y cómo lo enuncian por medio de sus pensamientos y palabras (p.83).

Por otro lado, Mora V. y Montoro S. (2003) señalan que la reputación no es más que un factor de referencia para las características específicas de los socios que van a auxiliar y se refieren a la información de dominio público acerca de los socios, es decir, reconocidos por los demás agentes que intervienen en un establecido sector o actividad (p.156). 
Otros autores sostienen que existe un vínculo entre la creación de valor y reputación, debido a que se refuerzan mutuamente y además, influyen directamente una en la otra, permitiendo crear una situación que puede figurar como una espiral ascendente (Sabaté y Quevedo Puente, 2003, p.55).

También, Wessels (2003) puntualiza que los beneficios de una buena reputación se traducen en la eventualidad de reclamar un sobreprecio por el pago de precios más bajos en sus compras, los productos o servicios que brinda la entidad, mayor lealtad por parte de los clientes y colaboradores, una mayor estabilidad en los ingresos y la atracción de las personas más cualificadas en el mercado de trabajo.

\subsubsection{Pilares de la Reputación Empresarial}

Wessels (2003) detalla que la reputación se convierte en un santuario cuyos comientos son los seis componentes fundamentales de la reputación empresarial (p. 76):

- Aptitud financiera: riesgos de inversión, competencia, perspectivas de crecimiento y rentabilidad.

- Atracción emocional: apreciación, consideración y confianza.

- Visión y rol del líder: actitudes de dirección.

- Espacio de trabajo: clima laboral, cultura y ambiente.

- Responsabilidad social: responsabilidad social corporativa o empresarial.

- Productos y servicios: calidad, innovación y atractivo de los productos y servicios (p.45).

Con ello, no cabe duda de que, gracias a su alto grado de intangibilidad, la reputación de las organizaciones apenas facilita a una medición y valoración empírica.

5.4.2 Características de la Reputación Corporativa 
Del mismo modo, las características que conducen a la reputación vuelven más confuso su tratamiento (Sabaté y Quevedo Puente, 2003, p.55). A continuación, se detallarán estas características:

- La multidimensionalidad: la reputación posee una diversidad de dimensiones.

- Respeta su formación y lo deduce a un proceso social dificultoso.

- No se consigue en una zona temporal limitada, sino que es de pausada acumulación.

- Suele manifestarse o producirse en contextos únicos, por lo que hace es dificultosa su réplica.

- Es específica para cada entidad.

- Es dificultosamente manipulable por la propia entidad.

Por consiguiente, nos encontramos frente a un concepto muy delicado que, si llega a poseer un reflejo en la entidad, es crucial conocer sus dimensiones, cómo es que se logra el complejo proceso social, quiénes son los stakeholders que la conceden y, finalmente, cómo se obtiene la asignación de la clasificación de la reputación (Neville, Bell \& Mengüc, 2005, p.84). Ésta última se ha determinado bajo diversos parámetros basados en diferentes áreas de investigación:

- Economía: Perspectivas y afirmaciones por parte de los clientes sobre la calidad de los productos de una entidad.

- Sociología: Opinión masiva acerca de la que se tenga noción.

- Gestión Estratégica: Juicios almacenados por parte de los clientes de las organizaciones a lo largo del tiempo.

- Marketing: Reflexión de valor acerca de los atributos de una entidad producto de un sólido desempeño. 
Tabla 4: Definiciones de Reputación Corporativa por Stakeholder

\begin{tabular}{|l|l|l|}
\hline \multicolumn{1}{|c|}{ Fuente } & \multicolumn{1}{|c|}{ Definición } & \multicolumn{1}{|c|}{ Stakeholder } \\
\hline $\begin{array}{l}\text { Gray \& Balmer } \\
\text { (1998) }\end{array}$ & $\begin{array}{l}\text { Connota la apreciación de la compañía } \\
\text { por sus stakeholders. }\end{array}$ & Internos y externos \\
\hline Bromley (2000) & $\begin{array}{l}\text { El principal modo en que grupos de } \\
\text { interés externos y otra parte concernida } \\
\text { conceptualizan la institución. }\end{array}$ & Externos \\
\hline Davies (2001) & $\begin{array}{l}\text { Término colectivo refiriéndose a todos } \\
\text { los puntos de vista de las partes } \\
\text { interesadas de la reputación } \\
\text { corporativa, incluyendo la identidad y } \\
\text { la imagen. }\end{array}$ & Internos y externos \\
\hline $\begin{array}{l}\text { Whetten } \\
\text { Mackey (2002) }\end{array}$ & $\begin{array}{l}\text { Un modelo específico de } \\
\text { retroalimentación, tomado por una } \\
\text { entidad y sus grupos de interés, relativa } \\
\text { a la credibilidad de la empresa de } \\
\text { avisos de identidad. }\end{array}$ & Internos y externos \\
\hline Lewellyn (2002) & $\begin{array}{l}\text { Los juicios constituidos por los } \\
\text { observadores sobre una organización. }\end{array}$ & Externos \\
\hline Barnett (2006) & $\begin{array}{l}\text { Una percepción de la realidad de la } \\
\text { compañía en manos de grupos de } \\
\text { interés externos. }\end{array}$ & Externos \\
\hline
\end{tabular}

\section{Fuente: Walker, K. (2010). [Traducción propia]}

Como vemos, el $100 \%$ de los autores hace énfasis en los stakeholders externos de la organización. Asimismo, todos coinciden que la Reputación Corporativa no es más que el juicio de valor o la percepción que los grupos de interés tanto externos e internos (Villafañe, 2013, p.45)

Berens y van Riel (2004), manifiestan que la noción de reputación está asociada a tres clasificaciones principales: a) la satisfacción de las demandas sociales $(41 \%)$, b) la personalidad corporativa $(24 \%)$ y c) la confianza (11\%). Además, la destreza de una compañía para satisfacer las necesidades de sus stakeholders, tanto las técnicas o funcionales como las psicológicas o emocionales (24\%); esta primera clasificación empieza a trazar las proximidades del concepto moderno de reputación, integrando aspectos de gestión o habilidades técnicas con contenidos sociales o éticos (p.67). El concepto de la Reputación Corporativa (RC) lo podemos fraccionar bajo el enfoque de distintos autores; así tenemos los enfoques: 
- Perceptivo: el objetivo es fomentar la opinión y la definición de la RC se torna en la percepción de los stakeholders en base al comportamiento de la institución (Villafañe, 2004)

- Cognitivo: el propósito es la valoración, por tanto, la RC no es más que el reconocimiento que ejercen los stakeholders con referencia al comportamiento de la entidad (Villafañe, 2004)

\section{La Gestión Comunicacional en los Procesos de Fusión y Adquisición}

\subsection{Introducción}

Cuando dos empresas se fusionan, las complicaciones en dirección se focalizan en la manera de gestionar los diversos procesos, entre ellos, se encuentra la preocupación de la gestión de la comunicación interna en un proceso de fusión o adquisición (Cardona, Gómez, \& Londoño, 2000, p.56). Los cambios y las emociones no son perceptibles, por lo que pueden afectar de manera directa la efectividad de las comunicaciones internas (p.57). Bajo el mismo parámetro, la adecuada planificación e implementación de la estrategia comunicacional permite cooperar, en gran medida, a que la fusión se efectúe con éxito (Martín, 2010, p. 38).

Arriagada (2009), sostiene que la estrategia comunicacional interna se presenta cuando existe la necesidad de emplear todos los recursos monetarios de la entidad para poder efectuar los planes de la manera más objetiva posible (p.86). De esta manera, menciona un despliegue de actividades que se deben contemplar para lograr una oportuna gestión de la comunicación interna durante las fusiones y/o adquisiciones. Entre ellas: se debe ser abierto, riguroso, creativo y lógico para poder elaborar la estrategia de comunicación (p.87).

Asimismo, es importante tener en cuenta que la estrategia no posee valor sin los parámetros tácticos, debido a que un plan de comunicación puede ser muy sobresaliente, pero si no se sabe cómo efectuarlo se torna intrascendente. Por el contrario, si el centro de atención se encuentra solo en las tácticas y no en la estrategia, es posible de que se corra el riesgo de ejercer una mala gestión comunicacional. Es por esta razón, que la estrategia requiere máxima dedicación, tiempo y energía para cerciorar que las acciones que se lleven a cabo sean eficientes y efectivas (Martín, 2010, p. 40). Por tanto, es crucial desplegar una estrategia 
detallada y un plan táctico completo de comunicación interna, que deben implicar ciertos puntos fundamentales, tales como:

a) Compromiso de la gerencia: es crucial el compromiso que obtengan los gerentes con la estrategia y las tácticas de comunicación interna durante el proceso de fusión, ya que ellos son los principales emisores de la estrategia comunicacional, por lo que deberían empujar a la compañía por medio de este cambio. También, la accesibilidad y visibilidad de los gerentes servirá como herramienta para que los colaboradores puedan comprender y apoyar el proceso de fusión (p. 41).

b) Aliados comunicacionales: para que la tarea comunicativa sea eficaz, el área de comunicaciones necesita construir vínculos estables y duraderos con otras unidades relevantes de la entidad como legal, recursos humanos, relaciones públicas, etc.; con la finalidad de emitir mensajes oportunos, coordinados y coherentes con la comunicación establecida hacia afuera de la misma (p. 41).

c) Comunicación cara a cara: se ha comentado mucho sobre la relevancia que posee la comunicación uno a uno, pero se vuele más trascendente cuando una compañía que enfrenta un proceso de cambio tan relevante como la fusión o adquisición. Por esta razón, los gerentes y jefaturas deben estar preparados y entrenados para resolver las interrogantes de los colaboradores, ya sea de manera grupal o personal. Éstos, deben encaminar a los antiguos y nuevos equipos de trabajo, informando las decisiones, sugiriendo acciones, dirigiendo procedimientos, y motivando a los colaboradores (p. 41).

d) Sondear el ambiente o clima de trabajo: para elaborar y ejecutar el plan de gestión de la comunicación interna, se necesita monitorear, además, cómo los colaboradores han asimilado y comprendido el proceso de cambio. Con ello, el equipo de comunicaciones puede medir la estrategia y las tácticas de la manera más efectiva a través de los canales comunicacionales internos, como la intranet (p. 42).

e) Habilidad para administrar la participación de los colaboradores: los gerentes y jefaturas deben brindar la oportunidad a los miembros de la empresa de preguntar sobre los detalles de la fusión y/o adquisición y, de esta manera, responder de manera efectiva, creíble y consistente las interrogantes de éstos. Es crucial que el Departamento de Comunicación establezca las respuestas y que éstas estén correctamente elaboradas y gestionadas con data e información estratégica, con el fin de que se categoricen para 
tener conocimiento acerca de dónde deben focalizar los esfuerzos de comunicación (p. 42).

f) Compartir los puntos importantes con la alta gerencia: una exitosa comunicación interna durante los procesos de fusión y/o adquisición demandan perenemente que los temas más importantes sean compartidos de manera inmediata y oportuna con el equipo de alta dirección. Esto se debe, a que certifican una reacción mucho más rápida y además, ganan tiempo valioso para la gestión. Por ello, es que el proceso de toma de decisiones y respuesta activa deben ser parte de la estrategia de comunicaciones internas de la entidad (p. 42).

Con todo ello, Martín (2010) señala que, si la estrategia de comunicación es efectuada de exitosamente, se manifestará en los siguientes puntos (p.43):

- La función de comunicaciones internas deja de ser un modelo bidireccional para ser uno multidireccional, lo que establece un círculo permanente de información.

- Se origina una gestión integrada de la marca, estrategia, comunicación y cultura.

- La comunicación interna se constituye en el desarrollo de los perfiles de conducción entre gerentes y jefes.

- La estrategia de comunicación interna se convierte en una pieza primordial en la estrategia del negocio.

Siguiendo la misma línea, Jaramillo (2004) manifiesta que la comunicación interna es una parte de la comunicación organizacional que se encarga de temas relacionados a los mensajes, la cultura, los comportamientos, los valores, la motivación, los medios, etc.; por lo que será la encargada de intervenir y aportar estrategias en los procesos de fusión y/o adquisición (p.74).

Por otro lado, Ribes (2005) identifica dos momentos clave en los que la comunicación se torna en un factor decisivo para el éxito o el fracaso en procesos de fusión o adquisición (p. 46): 
- Pre-merger: se da cuando las empresas emergen en el mercado para captar a sus socios. En este punto, la compañía adquiriente suele demostrarles a los accionistas que la adquisición les agrega valor y no riesgo.

- Post- merger: la entidad que desea ser parte de una corporación de mayor tamaño debe comprobar que pretende mantener un proyecto propio si es que quiere cuidar la confianza y la moral de sus colaboradores. En este periodo, las propias compañías no tienen un panorama muy claro sobre el éxito de la fusión; por ello, es fundamental que los equipos de comunicación planteen tácticas de acción basándose en todos los escenarios posibles para dar a conocer una visión coherente del futuro de la empresa y descartar ciertas preocupaciones de los grupos de interés.

Para Ritter (2005), una vez que el merger ha sido comunicado, los equipos de comunicación deben canalizar sus esfuerzos en entregar el mensaje a los públicos prioritarios. Éste debe exponer las causas y consecuencias positivas de la fusión y/o adquisición (p. 38). También, argumenta que los estados necesarios en los mergers son presentar un aumento significativo, en términos de calidad y cantidad comunicacional. Por último, sostiene que en un merger lo correcto es comunicar primero los objetivos de la empresa para evitar provocar ambientes hostiles (p. 39).

Continuando con esta premisa, la definición del acompañamiento de la comunicación en el contexto de fusión permite la elaboración de una cultura y además, acredita los propósitos del negocio.

Los elementos necesarios en todo merger son un aumento significativo en la calidad y cantidad de la comunicación interna. Una vez que la operación tiene la conformidad legal y las dos entidades pueden iniciar su integración, empieza la fusión cultural. Para ello, el área de comunicación cuenta con un despliegue de herramientas a las cuales acudir. A la hora de comunicarse con los colaboradores, la alternativa ideal reside en las reuniones de personal. Pero cuando no se dispone de tiempo o prevalecen dificultades materiales, se pueden emplear videoconferencias, boletines impresos, e-mail y conferencias telefónicas. Con ello, se deja en claro cuál será la estructura y la esencia de la nueva institución. Es así, que se torna relevante el asegurarse de que todo el mundo se encuentre a favor del proceso y para ello, es relevante hacerles comprender la situación por la que se está atravesando (Ribes, 2005, p. 79). 


\subsection{Procesos de cambio de comunicación y de organización en fusiones}

Dentro del marco de las fusiones y/o adquisiciones, los integrantes de la empresa pasan por un proceso de cambio, comprendido como un conjunto de acciones dirigidas a contribuir con la entidad en el ajuste de nuevas estrategias y actitudes redirijan su labor para lograr la maximización de su desempeño y además, para certificar el cumplimiento de los objetivos. Por esta razón, es relevante que comprendan creencias, comportamientos previos y valores (Castaño \& Vélez, 2000, p. 37).

Por otro lado, Cruz (2004) afirma que las diversas experiencias que poseen relación con los cambios empresariales pueden detectar que, en diversas situaciones, las organizaciones afrontan determinados procesos disgregados de estrategias comunicacionales. Es así, como los procesos de cambio dentro de una entidad involucran ciertas transformaciones en los hábitos de conducta (p. 68).

En términos generales, se puede afirmar que existen diferentes umbrales de aceptación y reacciones ante al cambio. Por un lado, encontramos a los que no quieren el cambio, debido a que se están conformes con el statu quo de la organización y; por otro lado, tenemos a los que no suponen en qué los beneficiará, por lo que están a favor del cambio solo de manera intelectual, pero no aceptan los primeros pasos a seguir por pensar que son traumáticos para los colaboradores (Cruz, 2004, p. 70).

Castaño \& Vélez (2000) mencionan que la comunicación anticipada de los valores posee un rol primordial en todo cambio organizacional. Por ello, cuando un cambio no es comunicado visiblemente, genera incertidumbre, entropía, pérdida de confianza, patologías comunicacionales y una baja de la productividad (p. 38). De esta manera, todo cambio podrá hacerse efectivo si la empresa puede proyectar, mediante sus valores, la visión prevista (p. 39).

Es así, como surge una herramienta empleada en diversos procesos de fusiones y/o adquisiciones: los agentes de cambio, que no son más que facilitadores o intermediarios de la comunicación que se encuentran en el equipo Gestión Humana o de Comunicaciones. Este 
proceso solo se puede efectuar por medio de las personas, debido a que el velar por el mejoramiento de éstas, involucra el desarrollo del talento humano (López, 2006, p. 56).

Ribes (2005) indica que cuando comienza la fusión y/o adquisición y se origina la integración cultural, es crucial poner atención en las identidades internas que alcanzan el proceso de fusión:

Las culturas de trabajo son siempre un marco de seguridad lleno de simbolismos que cada empleado conoce y comparte con los demás. A esa cultura empresarial se ha incorporado y en ella aprendió a sobrevivir. Frente a una fusión y al surgimiento inevitable de una nueva identidad corporativa, códigos nuevos y desconocidos reemplazan a estos guiños familiares, produciendo incertidumbre y temor. El rol principal de los equipos de comunicación en esta etapa consiste en aclarar la situación de cada uno de los empleados y en facilitar la relación entre los dos grupos de inmigrados. El talón de Aquiles de las comunicaciones suele ser la lucha por la supremacía: si las identidades corporativas que deben integrarse son fuertes, los conflictos no se hacen esperar. (p. 54).

Tras lo mencionado en líneas anteriores, Montoya (2000) detalla algunos errores que no deben cometer los líderes de las organizaciones al momento de comunicar las estrategias planteadas para resolver problemas en momentos de fusiones y/o adquisiciones (p. 53). Entre ellos se encuentran:

- La desinformación e incomunicación: los colaboradores de las entidades deben ser conscientes sobre lo que hay que cambiar y saber el por qué lo deben hacer para evitar la resistencia al cambio. Por ello, lo fundamental en toda fusión es que se comunique todo el panorama que se está suscitando, con el fin de que el personal no se escude en decir que no posee conocimientos de lo que está sucediendo (p. 53).

- No lograr convencer de que lo mejor es el cambio: el líder debe encargarse de persuadir a todos, manifestando que es preferible cambiar a quedarse como están. Es decir, los colaboradores deben darse cuenta de que con este cambio las cosas se tornarán mejores para que logren estar motivados a realizarlo (p. 53).

- Si no se visualiza un efectivo sentido de urgencia, no existirá un cambio (p. 54).

- No lograr una planificación adecuada: en momentos de transición y ejecución es importante reducir la discordancia entre las tecnologías de información y la ausencia de una dirección en un mismo sentido (p. 54). 
Con el paso de los años, diversos fracasos en el mundo de los negocios responden a problemas tanto en los sistemas de información como en los soportes de la toma de decisiones. Una gestión que involucra la fusión debe comprenderse, por lo general, como una experiencia positiva, debido a que los participantes exploran un nuevo mundo de autenticidad y vínculos libres del control habitual. Por esta razón, es que los integrantes de las empresas se consideran dueños de una visión compartida, en donde están involucrados emocionalmente y además, poseen creativas soluciones a problemas existentes desde tiempo atrás (Castaño \& Vélez, 2000, p. 38).

Siguiendo este contexto, Ribes (2005) revela los principios más relevantes durante el proceso de fusión organizacional:

- Microcosmos del todo: el acto de fusión comprende un microcosmos particular del sistema organizativo destacado, incluyendo a todos los grupos que cuentan con un determinado interés en los ejes sujetos en cuestión (p. 55).

- Ceder el control: los gestores habituales deben conceder el control en caso haya un número específico de personas que estén efectuando actividades facilitadas (p. 55).

- El conocimiento del grupo: el acto de fusión congrega las experiencias personales y laborales de distintas personas, por lo que tienen un enorme conocimiento sobre la organización y la situación real a comparación de los expertos, facilitadores o consultores (p. 55).

Frente a los agentes del cambio organizacional que hacen más fácil o difícil el ambiente del negocio, se encuentra el proceso de fusión que es un factor muy cambiante, impredecible y complejo. Por lo general, los procesos de cambio procedentes de las empresas conciben en las personas reacciones variadas que, si son analizadas a profundidad, resultan claramente comprensibles, tales como: el temor, incertidumbre, nostalgia por el pasado, angustia, tensión son solo algunas de ellas (Cruz, 2004, p. 72).

Montoya (2000) señala que las consecuencias que provienen de dichas respuestas al cambio repercuten no solo en los individuos, sino que también en el clima laboral de la organización, ya que facilitan el surgimiento de conflictos intergrupales e interpersonales y además, una 
baja productividad al disuadir la atención del trabajo para enfocarse en la situación que se vive en dicho momento (p. 57). Por esta razón, el nivel de resistencia obedecerá al grado de incertidumbre que promueva y a la magnitud de la transformación que procure llevar a cabo (p. 58).

Los arriesgados cambios culturales, el temor de especulación accionaria en torno a las alianzas, la reducción de estructuras y los posibles despidos que puede involucrar una fusión y/o adquisición, no permiten un considerable accionar en cuanto a la ejecución de estrategias pre - fusión y por tanto, la comunicación interna estaría en función a presentar una información por etapas únicamente (Ribes, 2005, p. 80).

Bajo este contexto, el clima organizacional se torna como un elemento fundamental durante el proceso de las fusiones y/o adquisiciones, debido a que admite dar a conocer las percepciones que colaborador posee acerca de los procesos y estructuras que acontecen en un medio laboral (López, 2006, p. 57).

Castaño \& Vélez (2000) indican que el desarrollar estudios que accedan a determinar los puntos críticos que afectan a los colaboradores son elementos básicos para que éstos obtengan mejores logros basados en sus objetivos y se modifiquen ciertos factores que puedan afectar su desempeño o motivación a lo largo del tiempo (p. 39).

Por ello, es sustancial que los sistemas de información sistematizados o computarizados que admitan tener una oportuna percepción del clima laboral sean implementados en cada entidad, con el fin de mejorar la forma de trabajo para volverse más competitivos y poder comprender lo que más inquieta a los trabajadores para lograr exitosa integración (Cruz, 2004, p. 73).

Por último, Ritter (2005) sostiene que la comunicación en procesos de cambio es una parte fundamental de la comunicación interna, ya que se centra en la determinación de elegir la manera más adecuada de canalizar los mensajes que intercambian los agentes individuales o colectivos que constituyen la entidad en un entorno cambiante, rodeado de gran incertidumbre y de gran propagación de canales informales. Por lo que comunicar una 
realidad en tránsito producto de un proceso de reestructuración, adquisición o fusión resulta complejo (p. 40).

\subsection{Herramientas de comunicación en las fusiones}

Adicionalmente a los instrumentos habituales de comunicación propias de una organización resultante de una fusión, se encuentran las desarrolladas por otras ciencias como la psicología, las comunicaciones y la administración. Por ejemplo, está la encuesta de Predicción del impacto del cambio (PIC) que tiene como objetivo determinar en qué medida los colaboradores asimilan o no el cambio sin evidenciar su comportamiento disfuncional. Asimismo, pretende calcular los elementos expuestos en la siguiente tabla para poder examinar: a) los elementos positivos en las empresas tales como el potencial, voluntad, comprensión, papel del líder y emociones; b) componentes de riesgo como las circunstancias de trabajo, conocimientos, cantidad, restitución del status quo y alcance; y c) los inhibidores como la comprensión del negocio, impacto personal, poder e influencia, comportamientos y tiempo para definir las herramientas de intervención y plasmarlas en un plan de acción (Correa, 2011, p. 53).

Tabla 5: Factores para pronóstico del impacto del cambio en la organización

\begin{tabular}{|c|c|}
\hline Factor & Definición \\
\hline Cantidad & Número de modificaciones en la manera de trabajar. \\
\hline Alcance & Previsto para la implantación. \\
\hline Tiempo & Si los motivos de implantar Ser Uno - Concretos son claros y entendibles. \\
\hline Comprensión & Conocimiento previo o percepción de la forma como me afectará Ser Uno - \\
Concretos
\end{tabular}




\section{Fuente: Correa 2011, p. 4.}

Por lo general, los planes de comunicaciones que acompañan los procesos de fusiones y/o adquisiciones son producto de los resultados de las herramientas como la encuesta de Predicción del impacto del cambio (PIC) y se elaboran por medio del enfoque participativopersuasivo. Éste se orienta al entendimiento y está basado en la evidencia recogida por el área de gestión del cambio con foco en que no se genere un entorno mediático, brindando información sobre las novedades de la fusión y pensando en mitigar los impactos establecidos en la promesa (Cruz, 2004, p. 74). De la misma manera, existe otra herramienta que está presente en las comunicaciones en procesos de fusión: la curva de la resistencia al cambio versus el tiempo, encargada de dirigir el proceso informativo por las diversas etapas para brindar conocimiento acerca del proyecto en cuestión, con la finalidad de ayudar a los colaboradores a asimilar la integración con la nueva empresa (Correa, 2011, p. 54). 
Figura 20: Vivencia de procesos de cambio

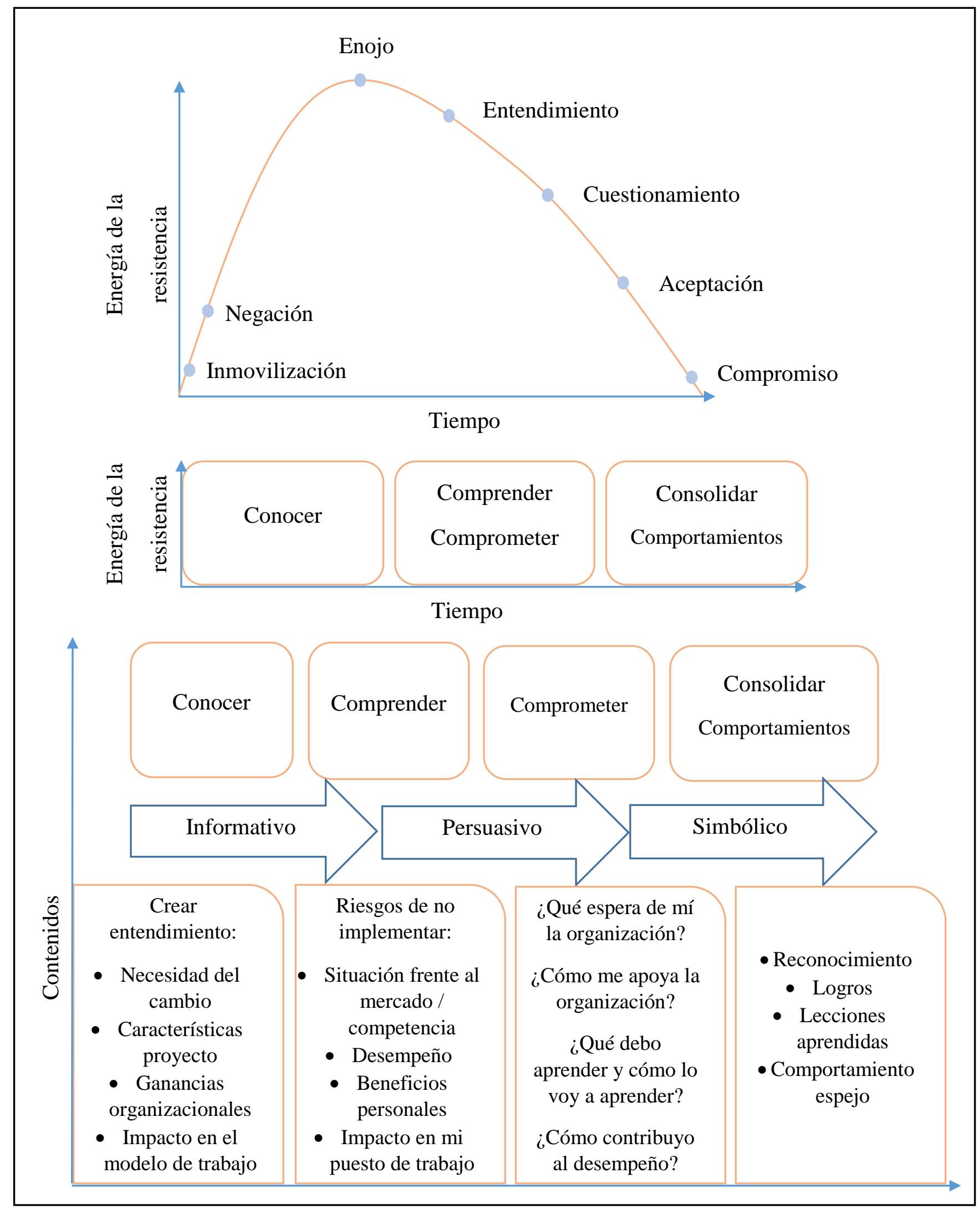

Fuente: Correa, 2011, p. 10. 
Dennis T. Jaffe y Cynthia D. Scott se centraron en el modelo del proceso de cambio organizacional y lo dividieron en cuatro etapas: negación, resistencia, exploracióncompromiso. De esta manera, crearon el modelo de la curva del cambio que no es más que una herramienta planteada para guiar a los individuos, grupos y empresas a comprender, administrar y aceptar el proceso de cambio. Principalmente, se utiliza en las etapas tempranas de la fase de cambio o cuando se presenta una resistencia significativa. El público ideal para este instrumento son los individuos sometidos a un cambio que ellos mismos no empezaron (Correa, 2011, p. 10).

Este modelo aplicado en procesos comunicacionales radica en cuatro etapas: negación, resistencia, exploración y compromiso que, por lo general, suelen darse secuencialmente. Pese a ello, puede suceder que el orden se vea alterado o que incluso se manifieste un retroceso. Además, la velocidad de este cambio torna a ser variable y posee como objetivo final el lograr la etapa de compromiso (Correa, 2011, p. 11).

Por lo general, los instrumentos de acompañamiento para las fusiones y/o adquisiciones pretenden tener énfasis en la comunicación directa y así, ejecutar una serie de acciones segmentadas con el fin de llegar a los usuarios identificados de la manera más efectiva. Bajo la misma línea de mapeo de procesos, es crucial el aprovechamiento de los medios internos de la empresa e identificar los criterios de intervención con los colaboradores para poder saber lo que se les quiere comunicar, lo que quieren saber, qué esperan sentir cuando conozcan esa información y por último, qué cambios espera la entidad que ellos realicen (Correa, 2011, p. 11).

Por otro lado, también se manifiestan determinados errores en los procesos de comunicación de F\&A tales como: informar con el silencio, comunicar tarde, desconocer el pasado y el presente, no segmentar, ignorar los sentimientos y las percepciones, convencer en lugar de motivar, enfatizar en el futuro, desconocer los modelos mentales previos, etc. (Correa, 2011, p. 12).

Según Ribes (2005), en una situación de cambio es relevante tener en consideración las siguientes directrices comunicativas: 
- Solidificar espacios de comunicación e informar al 100\% de los colaboradores (p. 81).

- Auxiliar en la comprensión sin provocar ciertas expectativas que no se pueden hacer efectivas (p. 81).

- Comunicar todo, también las dificultades (p. 81).

- Comunicar poca convicción y determinación para no tener que reconsiderar frecuentemente las decisiones o emitir mensajes cruzados en sentidos diversos ( $\mathrm{p}$. 82).

- Transformar la problemática, inquietud o negación en compromiso, determinación, impavidez y esperanza (p. 82).

- Recodar que comunicar no solo se traduce en informar, sino que es importante certificar que la información es entendible y fácil de asimilar (p. 82).

Para lograr esto, es necesario instaurar espacios sólidos y seguros que permitan la generación de vínculos en donde los colaboradores puedan asimilar, de manera efectiva, el proceso de cambio empresarial (Ribes, 2005, p. 82).

Adicionalmente, Cruz (2004) sostiene que existen otras herramientas que contribuyen a la comunicación interna para informar procesos de cambio durante la fusión y/o adquisición, ya sea en una comunicación ascendente, descendente u horizontal. Estos son los siguientes: periódicos, revistas, intranets, campañas internas, boletines y otras que pueden ser integradas por:

- Ambientes de conversación: sirven para dirigir reuniones reglamentadas de comunicación con individuos representativos de las múltiples colectividades de la empresa. De manera tal, que consigan almacenar sus opiniones y puedan estar en el acompañamiento de la gestión de cambio (p. 75).

- Labor sobre resistencias: en los comités de comunicación se determinan las herramientas que estimulan la colaboración de los colaboradores (p. 75).

- Medios de acompañamiento: elementos para focalizar las incertidumbres del proceso de cambio (p. 76).

- Anticipación: es sustancial disponer del plan de comunicación interna antes de empezar el proceso de cambio (p. 76). 
Con todo ello, se puede decir que la comunicación interna en F\&A debe ser gestionada como un enfoque sistémico y multipropósito con la ayuda de las herramientas que permitan mejorar la relación entre jefes y equipos, difundir la visión del negocio, buscar una armonía entre las diferentes áreas y, además, potenciar la cultura e identidad corporativa para llevar de manera eficiente el proceso de cambio (Cruz, 2004, p. 77).

En el caso de las empresas estudiadas, Cassinelli y Celima - Trébol, se realizó un exhaustivo análisis sobre los medios de comunicación empleados durante el proceso de fusión. En primera instancia, se encuentra el blog interno que se emplea para difundir noticias del mercado de mejoramiento del hogar, eventos internos (fiesta de aniversario, día del padre, día de la madre, fiesta de fin de año, etc.) y noticias del resto de empresas del retail (Celima - Trébol, Hipermercados, Cassinelli y Proyecta). Asimismo, las redes sociales corporativas difunden los nuevos ingresos del personal, los cumpleaños del mes, las fechas festivas a nivel nacional, los próximos eventos de la empresa y algunos "retos o juegos" para la interacción entre el personal.

Por otro lado, utilizan frecuentemente el email para anunciar nuevos ingresos del personal, los cumpleaños del mes y próximos eventos de la empresa. Sin embargo, los correos corporativos los manejan por separado (@ cassinelli.com y @hmcceramico.com). También, emplean las videollamadas para realizar coordinaciones o reuniones importantes entre áreas, grupos de trabajo o empresas (Cassinelli y HMC). De la misma manera, recurren al chat interno para efectuar conversaciones en torno a las labores de áreas o funciones puntuales.

Además, realizan de manera constante reuniones personales o grupales de las cuales, algunas son de carácter obligatorio; con el fin de mantener un contacto físico entre los diferentes colaboradores y coordinar determinadas labores o comunicar anuncios referentes a las áreas o el grupo de empresas retail (Celima - Trébol, Hipermercados, Cassinelli y Proyecta).

De igual manera, los colaboradores del área de Recursos Humanos realizan encuestas anónimas una vez al año entre los trabajadores para sondear el clima laboral y la cultura. Por último, poseen un buzón de sugerencias, en donde receptan comentarios, consejos o quejas sobre la empresa o jefaturas directas. Sin embargo, no se utiliza con reiterada frecuencia. 


\section{CAPÍTULO III: METODOLOGÍA}

En el presente apartado, explicaremos la metodología que se llevará a cabo para recaudar la información esencial que nos permita lograr los objetivos planteados en esta tesis.

\section{Universo}

\subsection{Población}

La población del presente estudio se conforma por los 57 casos de entidades constituidas como sociedades anónimas que han sido partícipes de un proceso de fusión y/o adquisición en el Perú durante el año 2015 (EY, 2016, p.12).

\subsection{Muestra}

Está constituida por el caso de dos empresas organizadas como sociedades anónimas que han formado parte de un proceso de fusión y/o adquisición en el Perú en el 2015. Se trata de la unión de Cassinelli y Celima-Trébol.

Para la selección de esta muestra, se ha realizado un muestreo no probabilístico, debido a que establece un procedimiento de selección orientado a los objetivos que persigue la investigación, más no por un criterio estadístico en general (Hernández-Sampieri \& Mendoza, 2018, p. 191).

\subsection{Unidad de Análisis}

Se encuentra compuesta por las compañías organizadas como sociedades anónimas que han sido parte de un proceso de fusión y/o adquisición en el Perú durante el año 2015 y que fueron seleccionadas previamente en la muestra, como es el caso de Cassinelli y CelimaTrébol. 


\section{Métodos Estadísticos}

\subsection{Tipo de Estudio}

De acuerdo con el objetivo y el diseño de esta investigación, el tipo de estudio es descriptivo - explicativo. Dado que, por un lado, el foco se torna en la descripción y recolección de determinadas situaciones, manifestaciones o eventos que pretenden especificar ciertas conductas relevantes de un grupo de personas; con el fin de medir o evaluar diversos componentes, aspectos o dimensiones de un determinado problema a investigar (Bocanegra, 2000, p. 68). Por otro lado, es explicativo dado que pretende encontrar y responder las posibles causas del problema que generan un proceso, fenómeno o comportamiento en un grupo de personas (Hernández-Sampieri \& Mendoza, 2018, p. 191). Esto, con el objetivo de validar la presencia o ausencia de una gestión comunicacional en las empresas peruanas, Cassinelli y Celima-Trébol para poder así, comprobar la hipótesis de la investigación.

\subsection{Diseño de Investigación}

Para la exploración del problema, se empleó el diseño no experimental - longitudinal de tendencias, debido a que es un método transversal que se aplica según la naturaleza de los datos: cualitativo o cuantitativo. Asimismo, este método se encarga de la recolección de datos a través del tiempo en periodos o momentos específicos para forjar inferencias con respecto al cambio de una muestra representativa, sus causas y consecuencias. Por ello, el propósito consiste en describir ciertas variables y analizar su interrelación e incidencia en un periodo establecido (Bocanegra, 2000, p. 68). Dicho esto, el diseño se efectuó en base al análisis de las variables de indagación presentes en tres momentos definidos:

\author{
Antes de la fusión \\ y/o adquisición
}

\section{Después de la fusión y/o adquisición}

Actualmente, con la fusión y/o adquisición 
Para la realización de la presente investigación, se ha recurrido al estudio cualitativo para entender a profundidad el comportamiento humano y la percepción de los colaboradores de Cassinelli, con el fin de conocer los motivadores de los usuarios tanto en nivel emocional como racional. Creswell (2007) sostiene que las metodologías cualitativas comprenden la observación y el análisis de la información en entornos naturales para examinar diversos fenómenos, resolver los problemas y contestar las preguntas (p. 46). Es por esta razón, que son interpretativas y de carácter inductivo porque su objetivo es el de predecir, describir, explorar y explicar el "porqué" de la naturaleza con relación a la información no estructurada (p.48).

Asimismo, se empleó la metodología de investigación cuantitativa para analizar diseños descriptivos o causales de las actitudes o conductas de los empleados de la empresa de manera numérica. Bajo la misma línea, Rodríguez Peñuelas (2010) sostiene que el método cuantitativo se concentra en las causas o hechos del fenómeno social, más no por los estados subjetivos de la persona. Por lo que, se emplean los inventarios, cuestionarios y análisis demográficos que al final, se traducen numéricamente y pueden ser analizados con estadística con el fin de comprobar, verificar o rechazar ciertas relaciones que pueden surgir entre las variables definidas (p.32). Por otro lado, Tamayo (2007) afirma que es la antítesis de las teorías que ya existen a partir de un conjunto de hipótesis que surgen de ésta, por lo que se torna necesaria la obtención de una muestra de manera discriminada o aleatoria, pero representativa de un fenómeno o una población objeto de estudio para determinar ciertos patrones de comportamiento y tratar teorías (p.67).

Para lograr este propósito, se emplearon entrevistas en profundidad aplicada al personal administrativo de las áreas: Contabilidad, Logística, Marketing, Compras, Operaciones y RRHH (08) y, al personal de ventas de las tiendas de Lima Metropolitana: San Miguel, Ate, Surquillo, Independencia y Surco (07) para obtener información de primera mano sobre la fusión empresarial y sus posibles impactos en los principales activos intangibles a nivel interno. La muestra fue seleccionada en base a la diversidad de características sociales y culturales: 22 a 56 años con nivel socioeconómico B, C y D. 
Finalmente, se realizaron 100 encuestas a un público representativo de colaboradores de las empresas Cassinelli y HMC (perteneciente a Celima-Trébol), con el objetivo de reconocer los factores positivos o negativos que podrían influir en la nueva cultura organizacional tras la ausencia de una gestión comunicacional en el proceso de fusión empresarial. El perfil de nuestra muestra se concentra en las áreas: Contabilidad, Logística, Marketing, Compras, Operaciones, RRHH, Ventas, Tesorería, Producto, Finanzas y Postventa y, poseen un perfil entre los 18 y 64 años, pertenecientes a los niveles socioeconómicos A, B, C y D. El 50\% de los colaboradores laboran en el área administrativa y el resto, corresponden a la fuerza de ventas de las tiendas de Lima Metropolitana de los distritos: San Miguel, Ate, Surquillo, San Juan de Miraflores, Independencia, San Juan de Lurigancho y Surco.

\subsection{Procedimiento y Análisis Estadístico de Datos}

\section{Diseño de la encuesta dirigida a los cargos administrativos y de ventas de las tiendas de} Lima Metropolitana: Adaptación de la herramienta IMCOC (Instrumento para Medir Clima en Organizaciones Colombianas)

En primera instancia, se realizó una adaptación del modelo de encuesta IMCOC del docente de Administración de la Universidad del Rosario, Carlos Méndez Álvarez, que pretende obtener mejoras significativas en los indicadores de gestión de clima organizacional. De esta manera, se aplicaron 100 encuestas a una muestra representativa de empleados de Cassinelli y HMC, con el objetivo de medir el impacto de clima y cultura a partir de las variables: Objetivos, Liderazgo, Cooperación, Relaciones Interpersonales, Toma de Decisiones y Motivación en el personal de las empresas fusionadas. Siguiendo esta misma línea, se realizaron ciertas modificaciones en determinadas preguntas para poder así, cumplir con el objetivo de esta investigación. En la sección de anexos se puede visualizar el modelo adaptado de la encuesta.

\section{Trabajo de campo}

Las 100 encuestas aplicadas a los colaboradores de las áreas administrativas y fuerza de ventas de las entidades en cuestión se efectuaron en las instalaciones de Cassinelli y HMC ubicadas en los distritos de San Miguel, Ate, Surquillo, San Juan de Miraflores, Independencia, San Juan de Lurigancho y Surco. En las próximas líneas, se podrán observar los datos recolectados y resultados obtenidos a partir del trabajo de campo realizado. 


\section{Análisis de datos}

Luego de la aplicación de las encuestas, se procedió a realizar la tabulación de las mismas y se efectuó una ponderación por pregunta, variable y totalidad de preguntas, con el fin de encontrar manifestaciones o señales de cambios relacionados al clima y cultura organizacional después del proceso de fusión.

Una vez que se obtuvieron los resultados de las encuestas, se analizaron los datos derivados de la herramienta IMCOC y se homogenizaron las calificaciones, debido a que el máximo valor de las puntuaciones en la encuesta adaptada era 5 y la de IMCOC era 7; por ello, se recogió el dato final de la ponderación limitada por la variable y se dividió entre 7 para establecer el porcentaje final del enunciado. De igual manera, se realizó con las variables de las empresas fusionadas pero esta vez, se dividió entre 5.

De este modo, se consolidaron las respuestas provenientes de las entrevistas y encuestas para analizar algunos juicios rescatados y poder así, contrastar con la hipótesis planteada en la presente tesis. A continuación, se presentan los hallazgos y resultados obtenidos. 


\section{CAPÍTULO IV: HALLAZGOS Y RESULTADOS}

\section{Resultados producto de las entrevistas}

Para contextualizar el escenario de la fusión, es importante recalcar que la Corporación Cerámica S.A. o bajo el nombre comercial: el Grupo Celima - Trébol, posee varias empresas dentro del mercado peruano. Entre ellas tenemos: Celima, Trébol, Centro Cerámico Las Flores (Hipermercado Cerámico), Camelias, Oriente, Improsa, Comexa y hace 3 años, Cassinelli.

En la Memoria anual de la Corporación Cerámica S.A. (2014), se resalta que la empresa fue establecida el 15 de diciembre del 1967 bajo el nombre de "Inmobiliaria Los Robles, S.A.". En el año 1968, la denominación cambia por "Inmobiliaria Cipreses S.A.” y luego, en 1994 se nombra "Corporación Cerámica S.A".

La organización tiene como propósito institucional la "fabricación de manufactura y comercialización de sanitarios con la industria concentrada de cerámica (p. 12). Además, en la página web se menciona que posee como misión de negocio: "el mejoramiento de la calidad de vida de las personas ofreciendo sanitarios y griferías comprometidos con el cuidado del ambiente" (Trébol, 2017). Asimismo, su visión se alinea a "ser la referencia de eficiencia y calidad en los rubros donde nos encontramos sobre la costa del Pacifico de Sudamérica" (Trébol, 2017). Del mismo modo, en la web de Celima - Trébol (2017) se señala que cuenta con una participación en el mercado peruano desde el año 1982, permitiendo aperturar diversas tiendas en 21 países gracias a la calidad y precios competitivos que posee.

A lo largo de los años, la Corporación Cerámica S.A. ha logrado con éxito una serie de estrategias comerciales con el fin de diversificar su cartera de productos y unificar el mercado sin canibalizarse (p. 13). Por ejemplo, en el 2014 logró la integración de Cerámica Lima S.A., una entidad destinada a la producción, distribución y comercialización de cerámicos y pegamentos. También, en el 2017 logró la alianza estratégica con la empresa Cassinelli dedicada al rubro de cerámicos, revestimientos, griferías y sanitarios con la idea de integrar la cadena de valor aprovechando los centros de venta de Cassinelli orientados a los segmentos socioeconómicos A y B (p. 13). 
Dentro de este contexto y para el desarrollo de este apartado, se realizaron 15 entrevistas a los colaboradores de las empresas de estudio; de los cuales, 09 pertenecían a Cassinelli y 06 formaban parte de Centro Cerámico Las Flores (Hipermercado Cerámico - HMC).

Las entrevistas se aplicaron a empleados administrativos de las áreas: Contabilidad, Logística, Marketing, Compras, Operaciones y RRHH (08) y al personal de ventas de las tiendas de Lima Metropolitana: San Miguel, Ate, Surquillo, Independencia y Surco (07), con el fin de obtener información de primera mano acerca de la fusión empresarial y sus posibles impactos en los principales activos intangibles a nivel interno.

A continuación, se presentarán los resultados que responden a los objetivos de la investigación:

- Objetivo específico 1: Identificar los componentes en el acompañamiento de la gestión comunicacional para los procesos de cambio por fusión en dos empresas peruanas: Cassinelli y Celima-Trébol durante el lapso de un año.

\section{Durante el proceso de fusión, no hubo una adecuada estrategia comunicacional.}

En primer lugar, los colaboradores mencionaron en repetidas oportunidades que, en el año 2015, no se les comunicó nada referente la fusión empresarial que se aproximaba (Celima Trébol y Cassinelli). Fue en el 2016 que se enteraron de que los colaboradores de Hipermercado Cerámico venían a instalarse en las oficinas de Cassinelli, debido a que era una empresa con demasiadas tiendas y no podían ser controlados por el pequeño grupo administrativo que tenían a cargo.

Por esta razón, es sumamente importante contar con un Plan Comunicacional que establezca los canales y medios por donde se brindará la información a los públicos internos, planteé los mensajes a difundir en el momento correcto y anticipe posibles situaciones de riesgo producto del proceso de fusión. Dicho esto, se responde la hipótesis de la tesis. 


\section{Al principio, no se contaba con funciones claras y se retrasaba el trabajo.}

Bajo la misma línea, determinaron que antes de que HMC lleve la Contabilidad, se llevaban todas las operaciones contables de Cassinelli y cada uno tenía sus funciones en base a ello. Cuando HMC se instaura en Cassinelli, tuvieron que hacer una redistribución de tareas para organizarse y equilibrar ambas empresas. Al principio costó debido a que el primer mes, HMC no estaba del todo claro con sus funciones porque decía "hago primero Cassinelli o Hipermercados". Por ejemplo, sostuvieron que en el primer mes que fue el cierre contable para ambas instituciones, fue complicado y denso. Esto se debe a que el equipo se quedó hasta tarde para poder terminarlo por la magnitud y complejidad que tenía incluir ambas organizaciones. Luego, meses más tarde, en febrero y marzo, el personal de HMC se ordenó. Fue duro y complicado, pero al final del 2017, algunas áreas como Contabilidad y Logística ya estaban involucradas indirectamente. Por ejemplo, los pagos los hacía la Tesorería de Celima y la Contabilidad también la manejaron hasta diciembre del 2017.

Por ello, es crucial contar con una buena gestión comunicacional para informar sobre los cambios en los procesos de fusión, crear vínculos entre los colaboradores de las entidades unificadas y además, garantizar el éxito en función a los objetivos y lineamientos de la nueva empresa.

\section{La estrategia de Publicidad y el Marketing se unificó, pero se trabajaron de manera diferenciada para ambas marcas.}

Además, los entrevistados indicaron que, en cuanto a temas de publicidad, una sola agencia ve las dos marcas y la estrategia publicitaria se réplica para ambas empresas. En la actualidad, HMC posee un Fanpage en Facebook (promociones), Web (consulta de facturas electrónicas) y publicidad radial, pero, por ejemplo, HMC decía "cómo me voy a enfocar a la parte industrial si solo tengo que producir". Como el Grupo Celima - Trébol no le daba el foco a una empresa con 28 tiendas (HMC), por eso, deciden entregárselo a Cassinelli porque ese foco sí era lo suyo. De este modo, sostuvieron que HMC le traspasó los clientes a Cassinelli, ya que no tiene la condición de constructora, por el contrario, Cassinelli comercializa para usuarios finales de acuerdo con cada sector, Celima se especializa en cerámicos y porcelanato y Trébol fabrica grifería y sanitarios. 
No existe una adecuada gestión de Comunicación Interna entre ambas marcas.

Del mismo modo, mencionaron que en cuanto a la comunicación interna, aun manejan el tema de los correos por separado (@cassinelli.com y @hmcceramico.com). Además, no poseen logos en sus firmas, sino que en la parte superior tienen un texto que dice: Cassinelli - Hipermercado. Lo cual, genera mayor alineación por parte de ambas marcas, ya que se autodenominan "retail" pero siguen el personal sigue siendo diferenciado dentro de la misma empresa. Por eso, no sienten que haya una integración al 100\% entre instituciones. Por lo que comentan los colaboradores, HMC aún no se siente identificado como parte del grupo, pero sí valoran al retail (Hipermercados, Cassinelli y Proyecta). Es más administrativo en una línea de gerencia, pero jerárquicamente lo ven como retail.

Lo planteado anteriormente, es resultado de una deficiente estrategia comunicacional y de llevar a cabo este tipo de labores sobre la marcha del proceso de cambio. Lo cual, genera incomodidad y un impacto negativo en la percepción por parte de los colaboradores de ambas instituciones.

- Objetivo específico 2: Determinar los principales activos intangibles a nivel interno que surgieron en el proceso de fusión empresarial de Cassinelli y Celima-Trébol como consecuencia del acompañamiento comunicacional.

\section{Preocupación de los colaboradores por la canibalización de productos entre ambas entidades.}

Además, el personal entrevistado sostuvo que, a la larga, Cassinelli e Hipermercado Cerámico (HMC) pueden llegar a canibalizarse, debido a que ambos comercializan productos para el mejoramiento del hogar tales como: mayólica, porcelanato, grifería y sanitarios. Muchos de los productos que ofrecen son fabricados por el Grupo Celima Trébol, por lo que comparten el concepto de comercio industrial.

Esto responde a nuestra hipótesis, debido a que hubo muy poca comunicación con respecto a las nuevas funciones de trabajo en este proceso de fusión, por lo que provocó una cierta desconfianza al percibir el entorno de la empresa como inestable y cambiante. 


\section{Incomodidad por parte del personal de HMC por traslado a oficinas de Casinelli.}

Por otro lado, afirmaron que el verdadero choque entre ambas empresas se dio en diciembre del 2017 cuando se realizó una fusión a nivel administrativo, pero solo en ciertas áreas no al 100\%; sin embargo, a partir del 2 de enero del 2018, Cassinelli tomó el control al 100\% de la parte administrativa de todas las áreas. Lo que causó que el personal de HMC pasara de estar situado en una oficina ubicada en Ricardo Palma - Miraflores a las oficinas de Cassinelli. Por lo que, les cedieron ciertas zonas para las personas que quedaron seleccionadas luego de la reducción de personal que hubo en la parte administrativa. En ese momento, se generó un ambiente un poco tenso porque la gente no sabía si iba a pertenecer a Cassinelli o a Hipermercados. A esto se le sumó, que los altos directivos de la compañía prefirieran, en la mayoría de los casos, optar porque el personal de Cassinelli se quedara en la empresa porque tenían la experiencia de trabajar en una compañía más grande.

- Objetivo específico 3: Establecer la relación causa-efecto de la presencia o ausencia de la dimensión comunicacional en el proceso de cambio por fusión empresarial de las empresas Cassinelli y Celima-Trébol.

\section{Fricción y reducción de personal entre altos mandos.}

Por otro lado, señalaron que cuando pasó HMC a Cassinelli, se encontraban algunos Gerentes: el Gerente que veía constructoras de HMC, la Gerenta de Procesos, la Gerenta de Inteligencia de Negocios, la Gerenta de Proyectos, el Gerente Retail y los Jefes de Operaciones (5) pero hubo mucha fricción porque se duplicaban las funciones. Por esta razón, ningún Gerente de HMC continuó trabajando, por lo que se quedaron los de Cassinelli, debido a la buena toma de decisiones anteriores.

\section{Rápido proceso de unificación de marcas y de funciones, pero más carga laboral.}

Asimismo, luego de la fusión y del traslado del personal a las nuevas oficinas, se contaba con dos marcas (Cassinelli e Hipermercado Cerámico), por lo que se decidió unificar las labores de los colaboradores y hubo una reducción previa. Con ello, vino la sobre carga de trabajo, debido a que el personal tenía doblegar las funciones bajo el mismo salario, lo cual, 
como confirmaron los entrevistados, generaron desmotivación y renuncias en determinadas áreas de la empresa.

\section{Nuevas gestiones de Comunicación Interna para HMC.}

Al año siguiente, afirman que el clima fue mejorando, debido a que RRHH de Cassinelli constantemente los motivaba haciendo actividades como, por ejemplo, el Día del Vendedor (en donde Benavente les mandó un saludo), el Día de la Mujer (trajeron a Marco Grande para tomarse fotos y el equipo de RRHH los esperaba con chocolates y rosas) y el Día del Trabajo (en donde les daban un desayuno y un presente). Por eso, por más que de alguna forma les haya chocado el cambio y fusión, Cassinelli hizo lo posible para valorar al personal y para reconocerlo. De este modo, una de las acciones resaltantes fue desestimar uno de los proyectos más importantes de la empresa: regalar un viaje todo pagado al equipo con mejor proyecto, debido a que, no era justo que premien también a HMC si es que habían entrado recién a mitad de año, por lo que el personal de Cassinelli decía "vas a preferir a uno y al otro no". Los colaboradores sostuvieron que en la fiesta de la empresa ha habido sorteos de camisetas, televisores, cines y teatro. "Dentro del sorteo, ganó un señor que tiene 30 años en HMC en el área de almacén y algunos del personal de ventas de Cassinelli también salieron sorteados". Mencionaron, además, que, en el 2017, se sintió más preferencia hacia el equipo de Cassinelli, ya que cada persona andaba con su grupo.

\section{Mejores oportunidades para el personal de HMC y más preocupación por su bienestar} laboral.

Otro punto importante que resaltaron fue que cuando Cassinelli toma el mando, la Asistenta Social empezó a ir a las tiendas de HMC para ver la realidad. Desde el mantenimiento, el baño, lo que sentían ellos, qué les faltaba. Por esa preocupación por parte de Cassinelli en las tiendas de HMC ha provocado que tengan la percepción de que la empresa sí está preocupada por ellos. Eso ha ayudado a que el clima mejore.

De este modo, manifestaron que, en la actualidad, el personal de las tiendas se siente más calmado e identificado con la empresa porque antes ellos tenían un Jefe de Operaciones y un Jefe Zonal, pero a pesar de que existían, las tiendas estaban muy descuidadas. Desde 
exhibir productos que no había en stock o la incongruencia de la publicidad (en medios y en tiendas). Eso disminuía el ánimo de trabajo. Sin embargo, señalan que la gente ahora se identifica más con su marca, se sienten más respaldados, a gustos y reconocidos. Antes, el equipo de HMC no tenía esos reconocimientos que Cassinelli les otorgó. Además, los vendedores no eran premiados cuando llegaban a su cuota, pero posteriormente, este panorama cambió radicalmente. De este modo, en este último año, HMC ha incrementado sus ventas porque existe mayor orden en las tiendas, la gente se encuentra más motivada, identificada, además, hay un mejor mix de productos, campañas financieras, mejor merchandising y vendedores más capacitados.

\section{Arduo proceso de adaptación de HMC en términos de un nuevo ambiente laboral, nuevos} roles y funciones, nuevos jefes y compañeros de trabajo.

También, señalaron que en la etapa de la inserción del año 2017 fue un poco complicada, ya que era una etapa de conocimiento entre ellos y de adaptación a un nuevo ambiente y grupo. El equipo de HMC sentía que estaban alojados en un lugar que no les pertenecía, por lo que no había un buen clima. Por más que haya un trato cordial (de buenos días), no había esa simpatía o conexión como equipo porque cada uno veía sus cuentas en esa época. En el 2017 , Cassinelli empieza a llevar un poco más el control e igual le chocó el equipo de HMC porque pensaban "tú te estás metiendo en mis funciones", "por qué me estás preguntando", "por qué te están dando a ti mi perfil", "tú vas a aprender lo que yo sé para que luego tú me saques". Al principio, fue un poco chocante para varios de los colaboradores. Indicaron que algunos de HMC decidieron irse porque no estaban a gusto de que se compartan las funciones. El personal entrevistado sostuvo que fue un clima tenso e incierto.

Bajo este contexto, se reafirma nuestra hipótesis, debido a que fue necesario emplear una buena gestión comunicacional para abordar los nuevos roles, áreas, compañeros y ambiente laboral, con el fin de que los públicos internos estén al tanto del proceso y además, sientan confianza en el manejo de la fusión. 


\section{Reducción masiva del personal de HMC versus el de Cassinelli.}

Pese a ello, el personal entrevistado mencionó que actualmente, queda el $20 \%$ de colaboradores de HMC porque la parte administrativa de Cassinelli contaba con más personal. "Por ejemplo, en HMC, el área de RRHH era de 5 personas, en cambio, en Cassinelli habían 12. Entonces, la interrogante fue "o sacan a 12 o sacan a 5". En ese momento, se quedó una Asistenta Social y dos Asistentes de Personal de HMC, pero ellos, con el tiempo decidieron irse porque no se sintieron cómodos. Actualmente, en RRHH y en Compras queda 1 persona de HMC. En Contabilidad y en Marketing no hay ninguna persona. En el caso de RRHH, fue parte de una estrategia porque las personas ya tenían el histórico de HMC y debían tomar decisiones en base a préstamos, hacer seguimiento al personal, reclamos del personal, analizar evaluaciones y ver sus planillas. Señalan que en las tiendas ha habido cambios constantes de personal. En el lado de Almacén es siempre rotativo, debido a que el control por parte de HMC en 28 implica harta labor. Esta persona de HMC conoce a los administradores y personal de tiendas, por lo que tiene más llegada. Mencionaron que era más complicado que una persona de Cassinelli se adapte a esta labor.

En cuanto al área de Tesorería y Contabilidad, Celima controlaba todo, luego, le hizo el traspaso a Cassinelli. Ahora, el equipo asume dos empresas. Por lo que manifiestan que todo un reto porque al principio la gente lo veía como una carga laboral pero también era algo nuevo porque era otra forma de trabajo y la empresa los ha ido apoyando, reconociendo y alentando porque el trabajo es difícil, sobre todo en la parte administrativa que no lo controló de a pocos, como otras empresas. En el 2016, algunas áreas tenían el control parcialmente pero luego, en el 2018, pasan a manos de Cassinelli dos áreas: Tesorería y Contabilidad, áreas fundamentales por lo que era más que seguro que la gente podía tener dos respuestas: 1) no, me voy o 2) no, esto es una sobre carga laboral. Pese a ello, sostienen que Cassinelli ha venido trabajando un buen clima a lo largo de los últimos años, por lo que la reacción del personal ha sido muy buena. Esto ha generado nuevas oportunidades y retos para HMC, ya que los colaboradores estaban por aprender algo nuevo, controlar algo más y evaluar si Cassinelli estaba apto para ellos. Cuando se hace un proceso y una política es para las dos empresas. En Contabilidad, se contrataron 4 personas de HMC pero todas porque sabían que operativamente, iba a ver sobre carga laboral. 


\section{Resultados producto de las encuestas}

Por otro lado, como otra fuente de medición, se realizaron 100 encuestas a colaboradores de la compañía entre administrativos que pertenecían a Cassinelli y a HMC (40) y, al personal de tiendas, es decir; a los operarios, los ejecutivos de ventas y los de despacho (60). A continuación, se presentan los resultados obtenidos y su respectivo análisis.

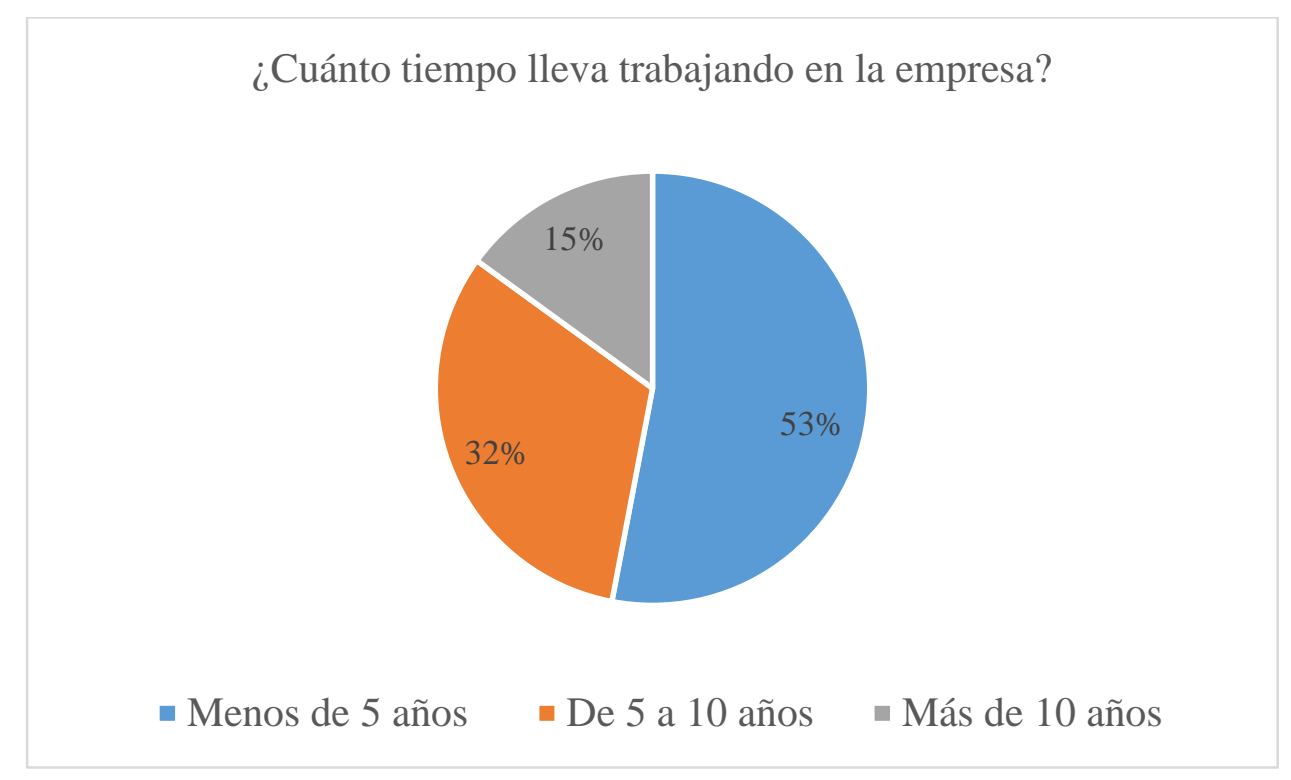

Fuente: elaboración propia

El 53\% de los colaboradores tienen menos de 5 años en la empresa, debido a que la gran mayoría de los puestos son operarios o de ventas. Por lo que el personal posee entre 18 a 27 años y suelen estar un periodo corto en la organización. El promedio de permanencia es de 1 a 3 años y luego, cambian de empresa para diversificar el rubro. Sin embargo, otro 47\% de colaboradores, cuentan de 5 a más de 10 años laborando en la empresa. Lo que se traduce en un buen clima laboral y gestión de fidelización que tienen hacia el personal. 


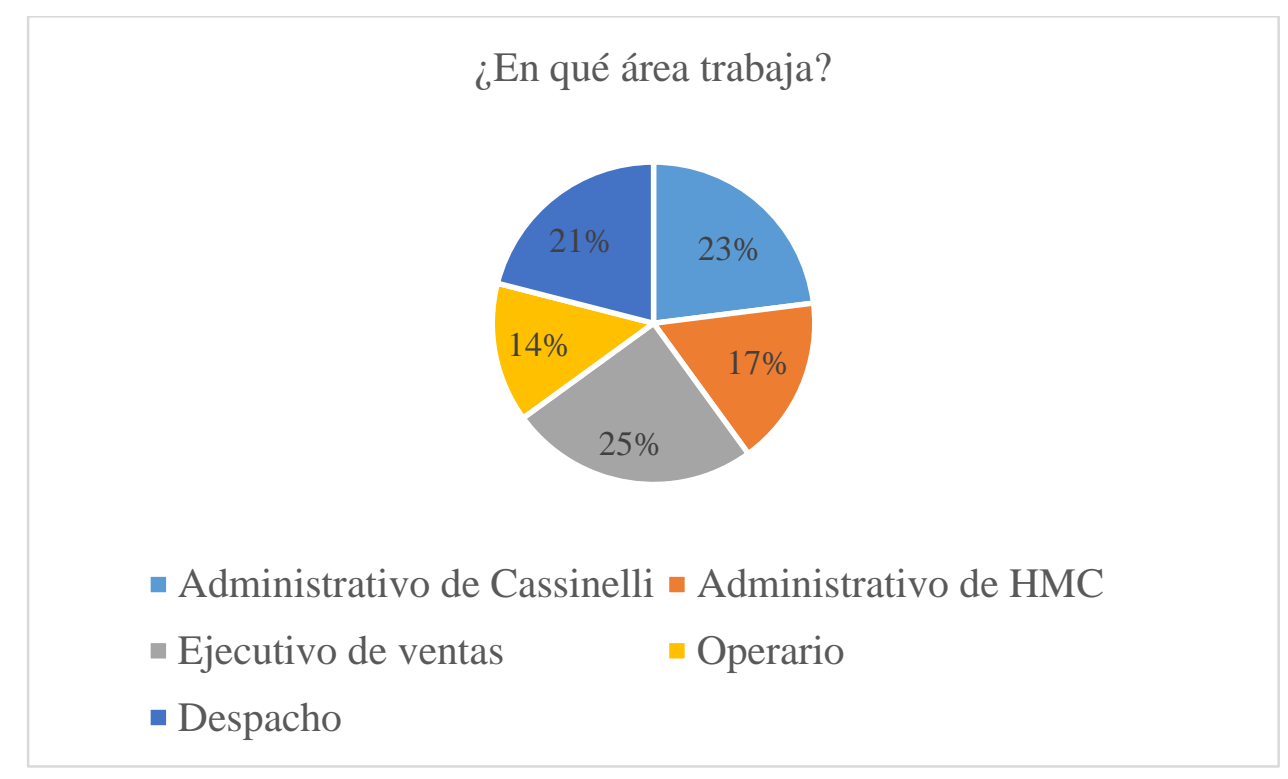

Fuente: elaboración propia

El 25\% de los encuestados trabaja en el área de ventas y son la muestra más representativa, debido a que son 760 ejecutivos en total. El 63\% pertenece a Hipermercado Cerámico y están repartidos en sus 27 tiendas: Lima (Ate, Chorrillos, Comas, Lurín, Puente Piedra, San Juan De Lurigancho I, San Juan De Lurigancho II, San Martín De Porres, Ventanilla y Villa El Salvador), Sur (Arequipa Norte, Arequipa Quiroz, Arequipa Jesús 1, Arequipa Jesús 2, Ayacucho, Juliaca, Huánuco, Chincha, Ica, Huacho, Barranca, Chiclayo, Chimbote y Piura) Oriente (Iquitos, Moyobamba y Pucallpa). Por otro lado, el 37\% les pertenece a los representantes de venta de Cassinelli que trabajan en sus 13 tiendas: Lima (Surquillo, Surco, San Miguel, Ate, Independencia, San Juan de Miraflores y San Juan de Lurigancho) y Provincias (Piura, Chiclayo, Cusco, Arequipa, Trujillo I y Trujillo II). Elegimos esta muestra, ya que fue la más vulnerable al afrontar la fusión empresarial por la alta rotación y, además, por el "nuevo" clima laboral. Por otro lado, el 40\% está dividido entre el personal administrativo de Cassinelli y de HMC. Son 631 en su totalidad (el 74\% pertenece a Cassinelli y el 26\% a HMC). 


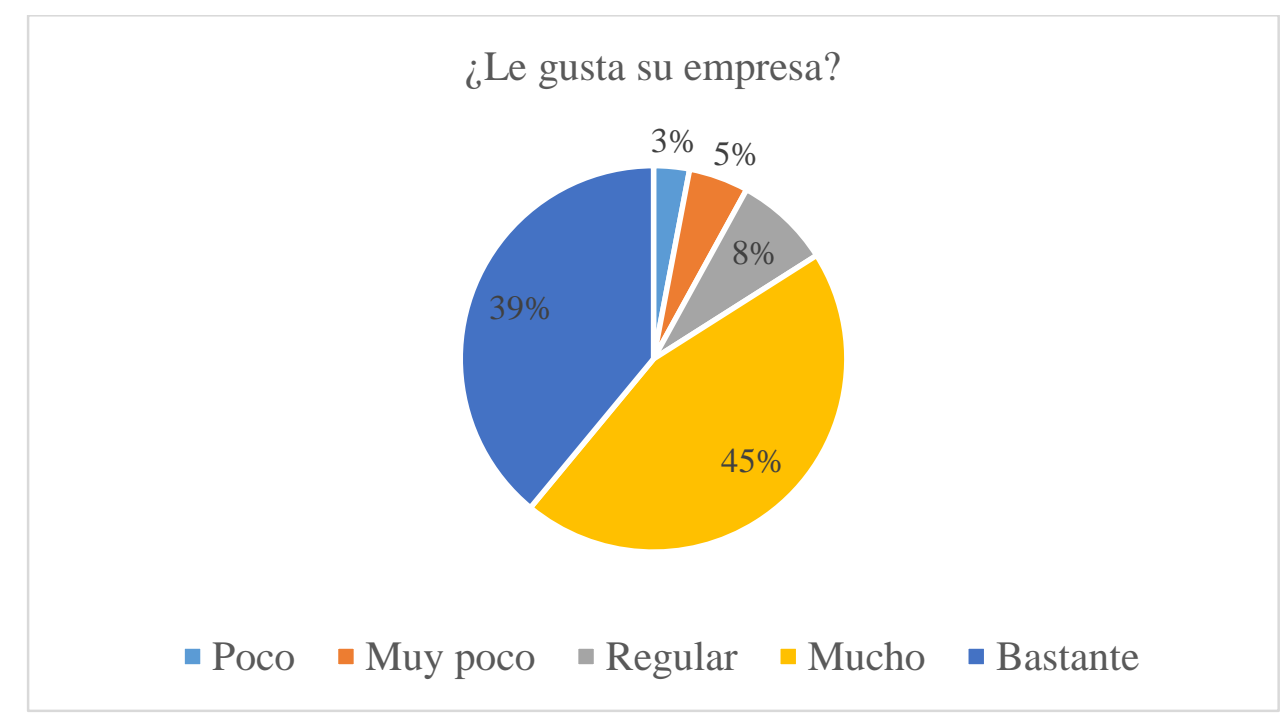

Fuente: elaboración propia

La mayoría de los empleados señalaron que les gusta mucho la empresa (45\%). Esto se debe, a que Cassinelli realiza diversas actividades para sus colaboradores a lo largo del año con el fin de generar cohesión entre los nuevos equipos, buen clima, confianza para con la empresa, fidelización y confortabilidad. Por ejemplo, los agasajos por el día de la madre, del padre, cumpleaños, aniversario de la empresa, fiesta de navidad y fiesta de fin de año. Además, se encuentran las actividades extraoficiales como "traer a celebridades" a que firmen autógrafos o la noche de talentos. En todos los eventos participan las dos empresas.

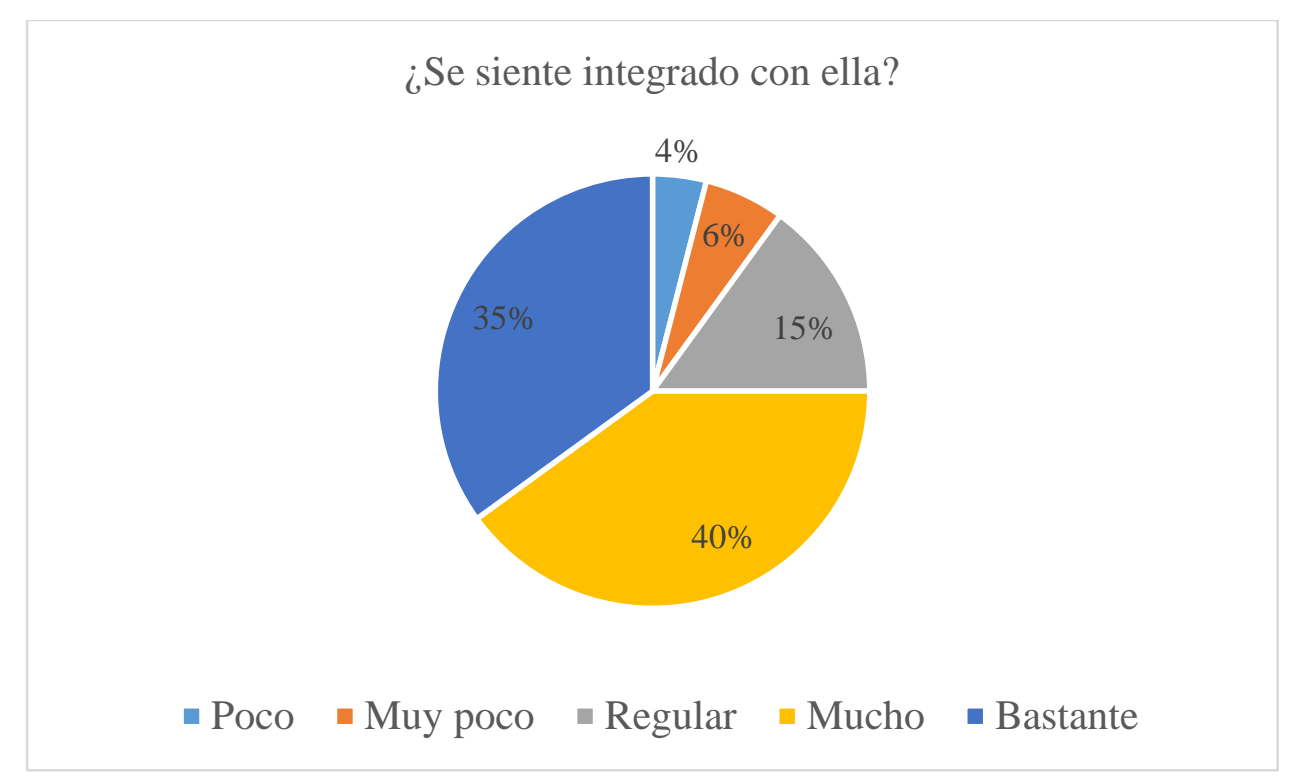

Fuente: elaboración propia 
El 75\% de los encuestados afirmaron que se sienten integrados con la organización. Esto se debe, a que atravesaron de la mejor manera la etapa de fusión y la empresa logró generar confianza y fidelización en sus colaboradores. Este indicador es muy importante para el estudio, ya que se busca medir la efectividad de la fusión y si es que trajo consigo aspectos negativos en cuanto al clima laboral. En este caso, se da modo contrario, ya que los empleados se encuentran a favor de la nueva gestión administrativa y respaldan la labor de integridad que tuvieron que ellos. Como se mencionó en el punto anterior, se realizó un despliegue de actividades para neutralizar los efectos post fusión, los cuales, dieron un resultado positivo en el personal.

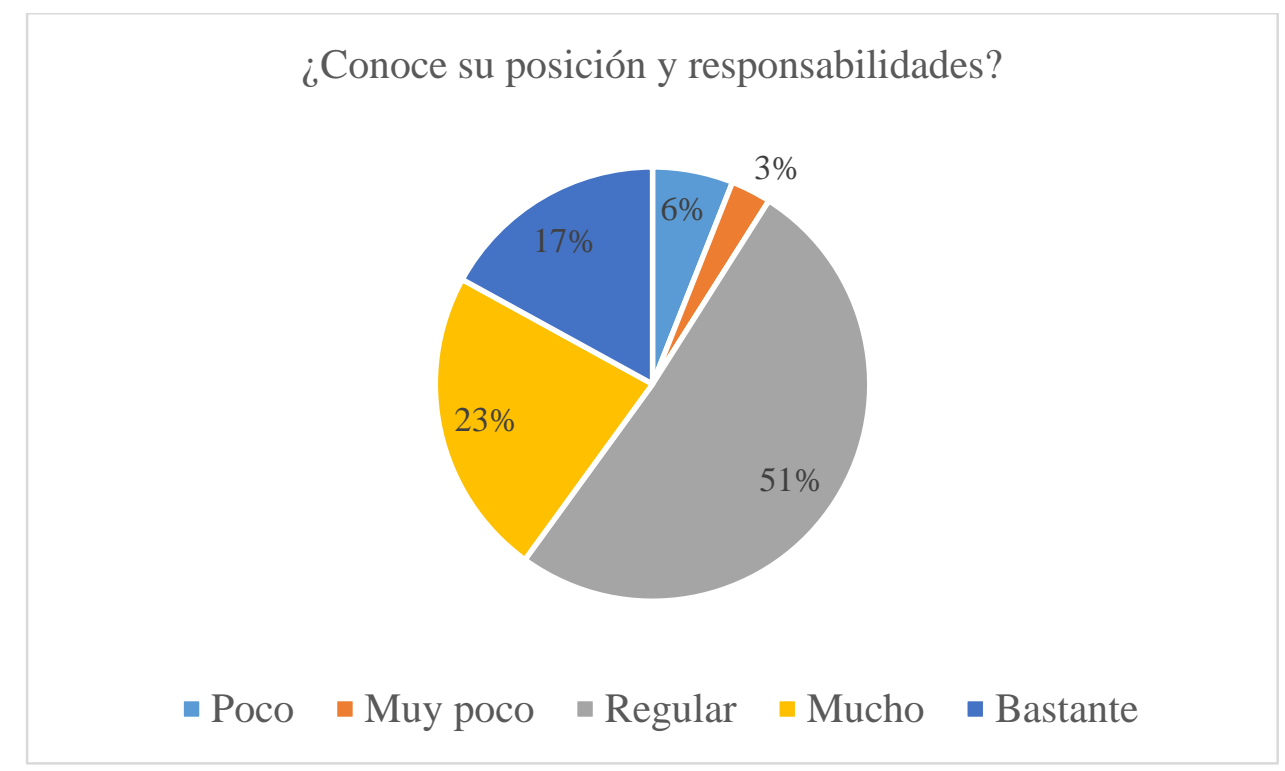

Fuente: elaboración propia

El $51 \%$ sostuvo que no conoce su posición y responsabilidades en la empresa, ya que hay puestos similares entre sí, por lo que el personal no conoce la limitante de sus funciones. Luego de la fusión, quedó el 20\% del 50\% de colaboradores de Hipermercado Cerámico, por lo que son pocos los que terminaron viendo cosas relacionadas a HMC. En el caso de RRHH, solo 1 persona es de la empresa y se encarga de ver el reclutamiento, bienestar y planillas de HMC. Sin embargo, el área de RRHH de Cassinelli realiza funciones muy similares para todo el personal (incluyendo HMC): onboarding y seguimiento, actividades para colaboradores, asistencia social, entre otros. Por lo que no quedan tan delimitadas las labores del colaborador de Hipermercado Cerámico. Por otro lado, en el caso del área de Compras, solo queda 1 persona que realiza la adquisición de materias primas nacionales e 
internacionales al igual que el personal de Cassinelli. En el caso de Contabilidad, Cassinelli realiza la integración del libro contable de ambas empresas, pero existen 4 puestos del lado de HMC que realizan funciones similares en cuanto a la medición del presupuesto, finanzas y el balance mensual de ambas compañías.

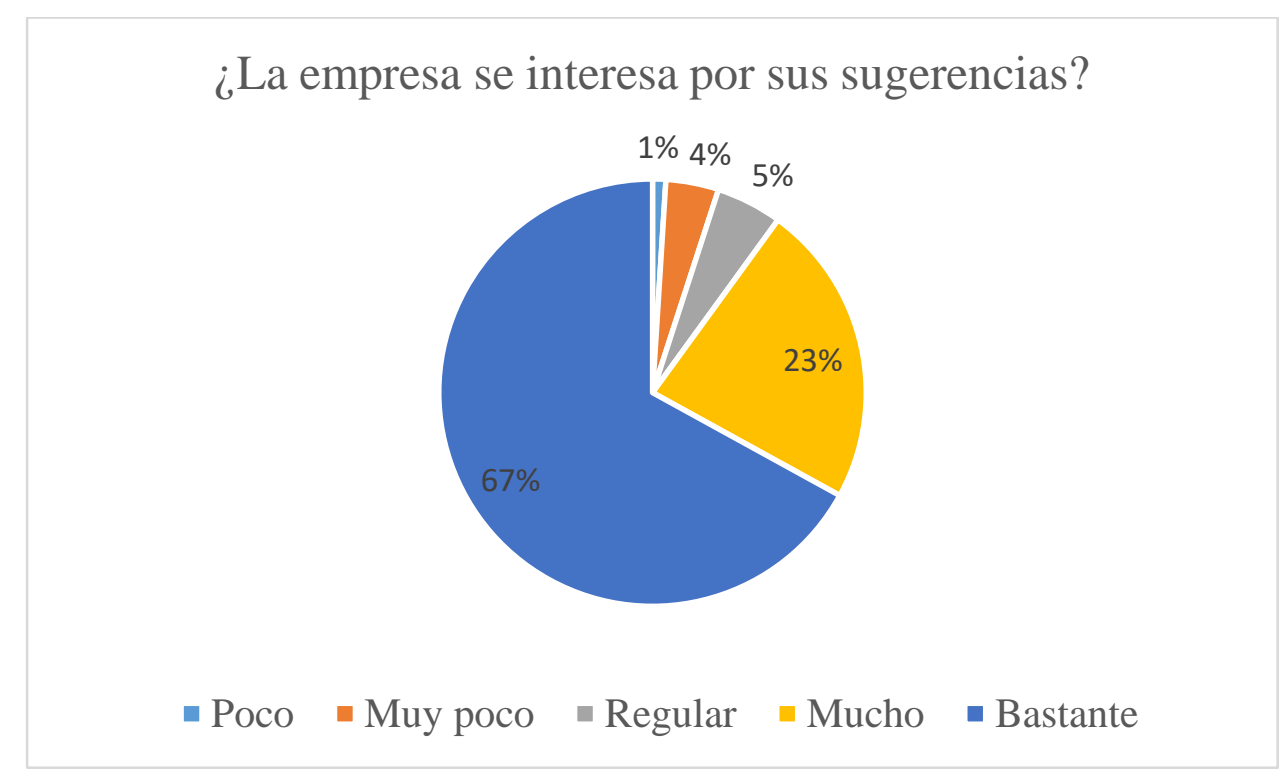

Fuente: elaboración propia

El mayor porcentaje que respondía al interés de la empresa por las sugerencias de sus colaboradores fue de $67 \%$. Esto es, debido a que existen diversos medios o canales de comunicación interna por los cuales, el personal puede manifestar sus emociones, pensamientos y quejas. Entre ellos se encuentran: el manual del empleado, buzón de sugerencias, paneles de anuncios, intranet, reuniones 1 a 1 con los líderes de equipo de trabajo, newsletter institucional, comunidad interna cerrada en Facebook, grupos de WhatsApp por áreas, desayunos productivos, eventos mensuales y encuestas de satisfacción que se dan trimestralmente. En ella, se evalúa el desempeño del colaborador, clima dentro del equipo de trabajo y el liderazgo del jefe directo. 
¿La empresa se preocupa por mantener elevado el nivel de motivación personal?

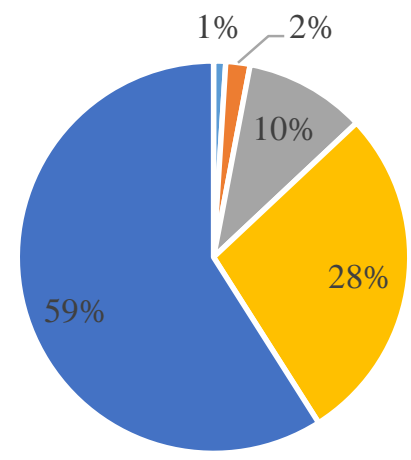

- Poco $\quad$ Muy poco $\quad$ Regular $\quad$ Mucho $\quad$ Bastante

Fuente: elaboración propia

El 59\% sostuvo que Cassinelli se preocupa bastante por mantener el nivel de motivación en su personal de trabajo. Esto es porque a lo largo del año, realiza un despliegue de acciones lúdicas, capacitaciones, charlas motivacionales, cursos profesionales, pausas activas, eventos de integración y, por último, de desarrollo de talento que permiten a los colaboradores integrarse con diversas áreas, conocerse y mejorar continuamente. Asimismo, realiza encuestas de satisfacción sobre el clima laboral y visión del puesto de trabajo.

¿Me siento informado de las cosas importantes que ocurren en mi empresa?

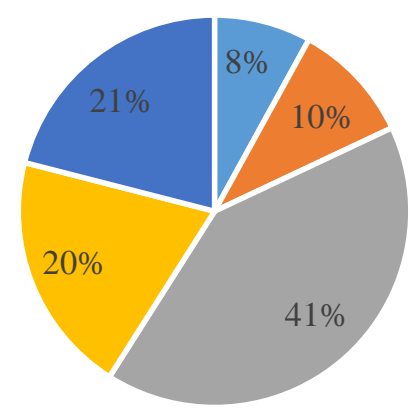

- Poco - Muy poco - Regular " Mucho - Bastante

Fuente: elaboración propia 
El gran porcentaje de respuesta fue regular, ya que muchas acciones importantes no se comunicaron a tiempo y el personal se enteraba por rumores que se esparcían entre áreas. Por ejemplo, el cambio de imagen que tuvo Cassinelli. Solo 2 áreas estuvieron involucradas en el proceso, testing e investigación de mercado y cuando salió a la luz esta información, muchos colaboradores no se identificaron con el cambio. Esta reforma implicó el selling line (de "Moda hecha acabados" a "Inspiramos el cambio en tu hogar"), los colores permitidos en el manual de marca (el uso del azul con amarillo y fucsia), el concepto corporativo (de "referente de moda" a "cosmopolita"), el rediseño de tiendas a nivel nacional, entre otros. Era un cambio grande que se debió comunicar en el momento respectivo; sin embargo, esto tardó un año y medio, y los colaboradores se empezaron a dar cuenta del cambio de imagen cuando vieron vestidas las tiendas de forma diferente a la usual. Luego, empezaron a cambiarse los uniformes y el diseño interno de las tiendas. Por otro lado, otro hito importante fue el relanzamiento de marca. Las comunicaciones y publicidades empezaron a cambiar bruscamente de un año a otro y se dejó de ver a Maricarmen Marín en las portadas de las revistas de Cassinelli. Ahora, se empezaba a ver a Gianella Neyra y a la maratón de ofertas. Fue un cambio abrupto para muchos, ya que Maricarmen no solo estaba en las portadas, sino también, animaba los eventos mensuales de ventas y estaba presente en las activaciones internas que realizaba RRHH en la empresa (firma de autógrafos, día de la madre, navidad de los niños). Con Gianella Neyra no pasó de la misma forma y por eso, los colaboradores no llegaron a conectar del todo con la nueva celebrity.

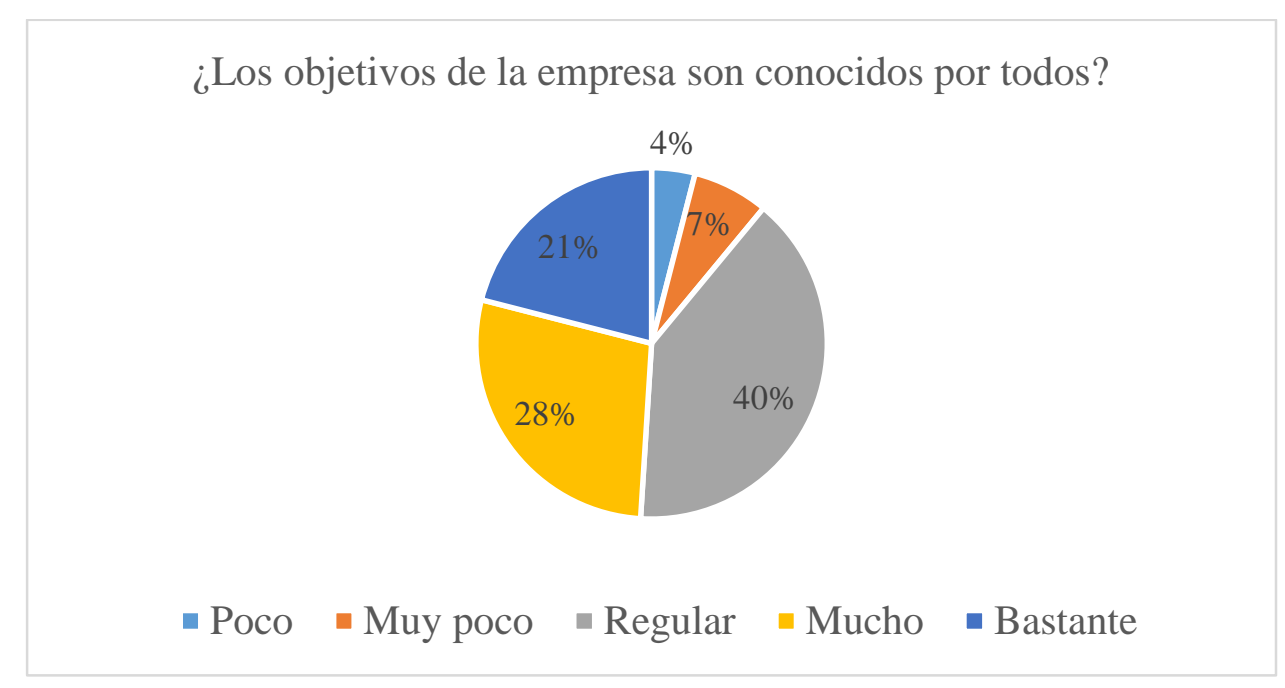

Fuente: elaboración propia 
Esta pregunta se enlaza con la anterior. Muchas comunicaciones importantes no se daban a tiempo y, por tanto, los objetivos de la empresa llegaban a anunciarse tarde. Como fue el caso de la fusión con Celima - Trébol. Los empleados se enteraron 2 años después de que se iba a hacer efectiva esta fusión y muchos, no estuvieron preparados para el cambio. Por lo que hubo mucha rotación de personal, traslados de oficina, desacuerdos entre áreas y duplicidad de funciones en la empresa. El personal desconocía los objetivos de expansión de mercado por parte del Grupo Celima - Trébol, ya que Hipermercado Cerámico tenía 27 tiendas que no se estaban administrando bien y empezaron a fluctuar las pérdidas. En la actualidad, los encuestados manifestaron que ya existe mayor conocimiento de los objetivos de la organización, pero se comunican tarde.

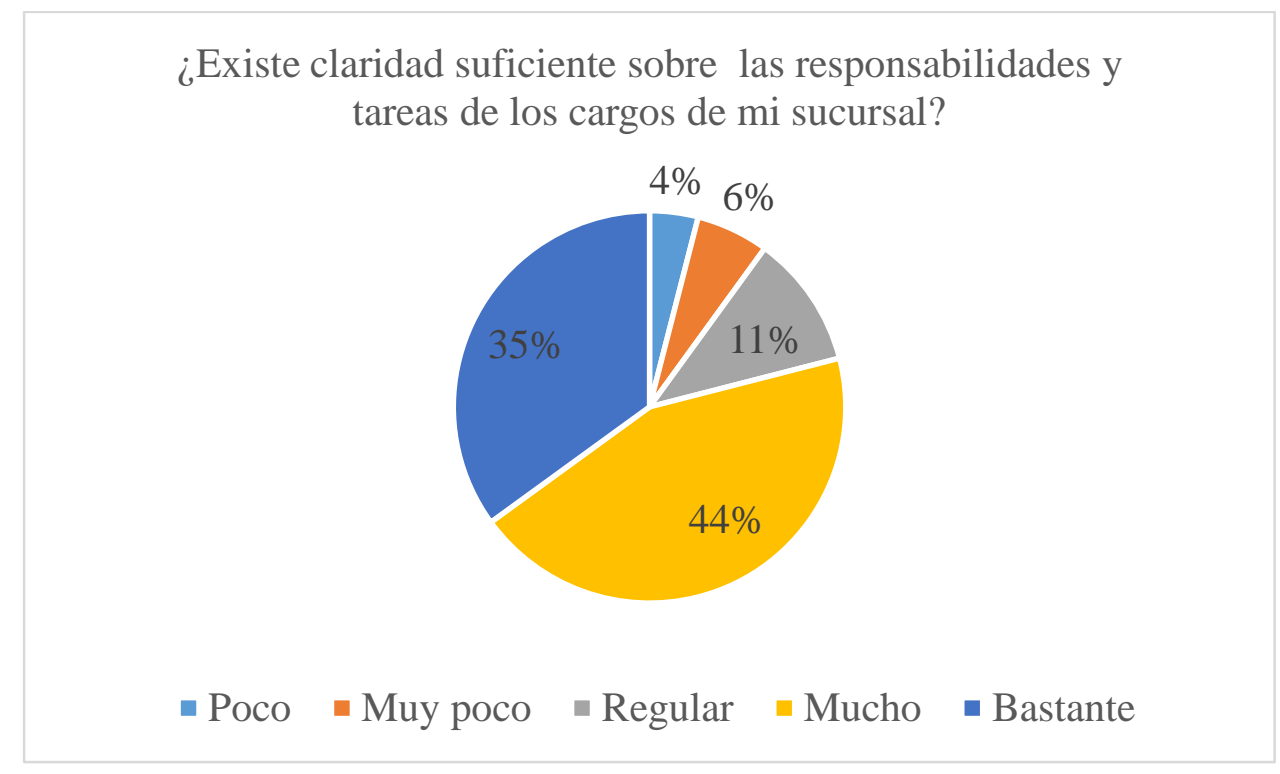

Fuente: elaboración propia

A nivel macro, el personal señaló que sí existe una claridad en cuanto a los roles y tareas que tienen en su área o sucursal (44\%). Esto se debe, a que luego de la fusión los líderes hicieron hincapié en sacar adelante los nuevos objetivos de la empresa, por lo que, en una primera etapa, el trabajo fue duro y muchas veces, se trabajó más del horario establecido. En la actualidad, cada área conoce los KPI's que debe lograr, aunque en situaciones no sepan delimitar cada rol/puesto entre HMC y Cassinelli. 
¿Mis valores personales coinciden con los valores de la empresa?

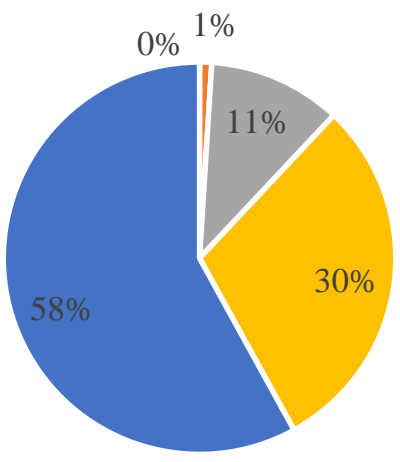

- Poco - Muy poco $\quad$ Regular $\quad$ Mucho - Bastante

Fuente: elaboración propia

El 58\% de los encuestados manifiestan que sus valores personales coinciden con los valores de Cassinelli. Este es un buen indicador, ya que permite que el personal se sienta identificado con la empresa y que, además, trabaje en función a sus principios y objetivos personales.

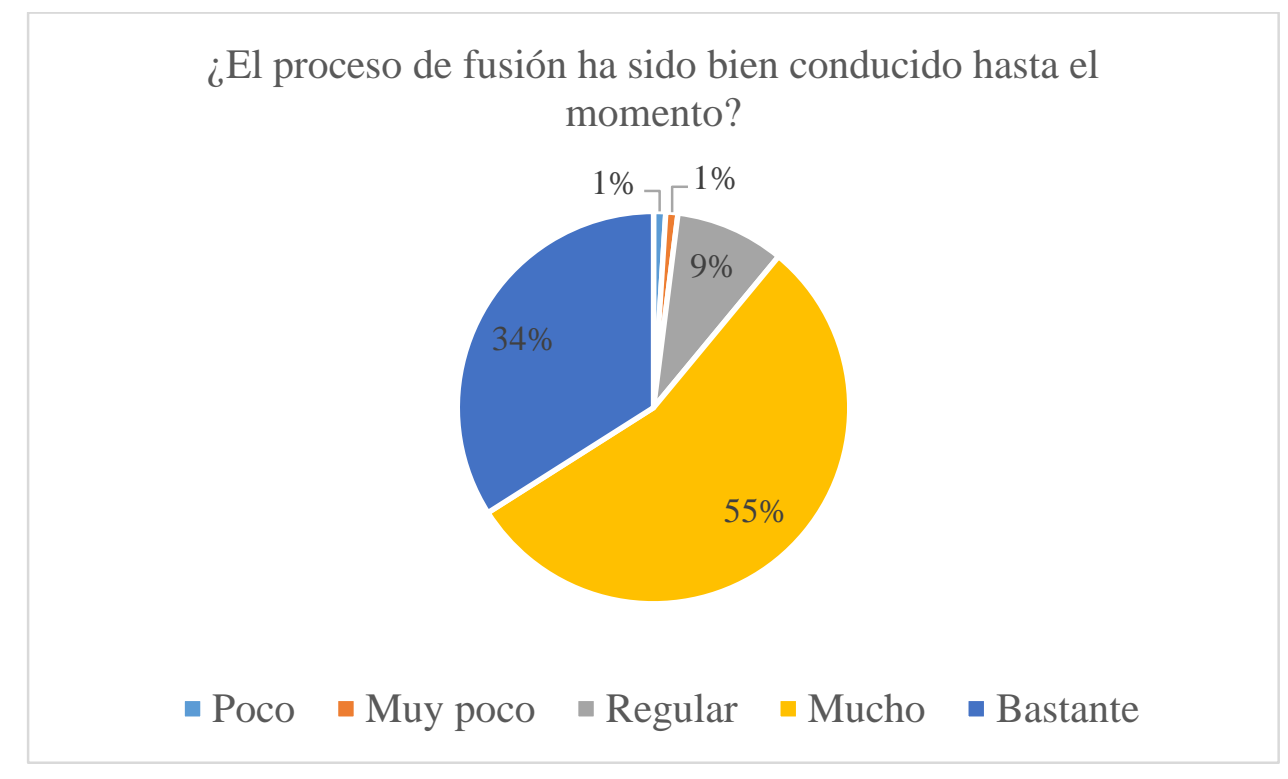

Fuente: elaboración propia

La gran mayoría de los encuestados sostuvieron que el proceso de fusión fue bien conducido hasta la actualidad, debido a que mejoraron las condiciones laborales en las tiendas de Hipermercado Cerámico, las ventas de HMC crecieron un $2 \%$ más por la nueva apuesta 
publicitaria (relanzamiento de la web, tratamiento activo de Redes Sociales y publicidad en tiendas), RRHH estaba más pendiente de la satisfacción e integración del personal, se realizaron más encuestas sobre el clima laboral, se hicieron muchas actividades de integración que permitieron que ambas empresas se conozcan dentro y fuera del centro laboral y mejoraron los beneficios de los colaboradores (programa de recompensas, descuentos en tiendas, gratificaciones, etc.).

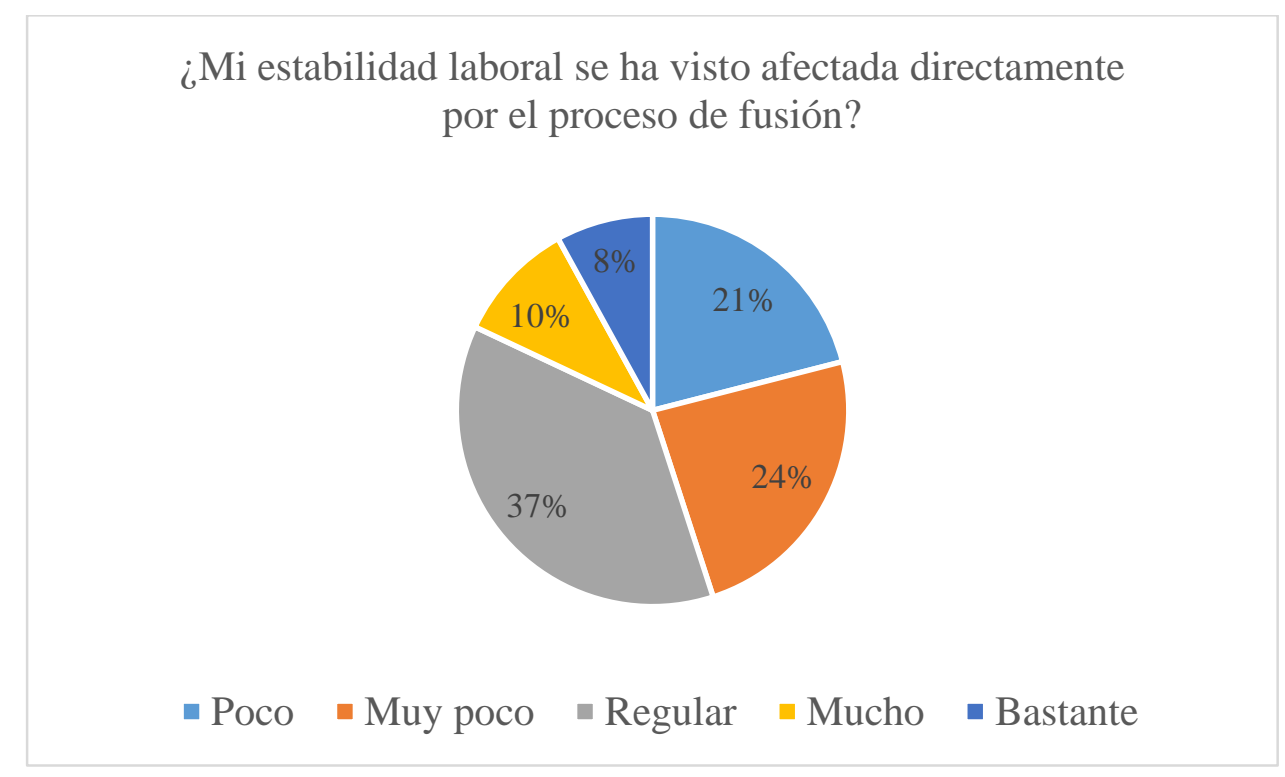

Fuente: elaboración propia

La estabilidad laboral de la mayoría de los colaboradores no se ha visto afectada del todo, ya que la gran masa del personal que quedó en la organización fue de Cassinelli. HMC contaba con muy pocos trabajadores, por lo que, en muchos casos, indispusieron de ellos. Por ello, los encuestados manifestaron que la gran mayoría conservó sus puestos de trabajo y que, además, mejoraron sus condiciones laborales. 
En mi sucursal, ¿se ha generado mayor presión de trabajo como producto del proceso de fusión?

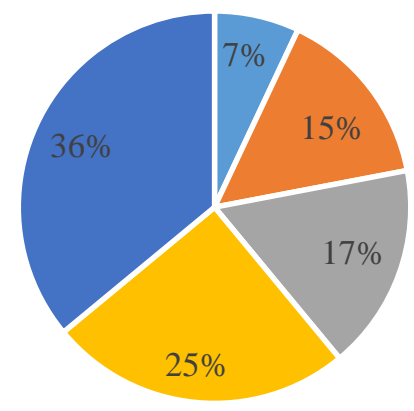

- Poco - Muy poco $\quad$ Regular $\quad$ Mucho - Bastante

Fuente: elaboración propia

El 25\% de colaboradores sostuvo que sí se generó mayor presión, ya que muchas de las funciones que realizaba Celima - Trébol en cuanto a la administración de Hipermercado Cerámico, fueron trasladados a un $80 \%$ a Cassinelli, por lo que veían dos marcas en paralelo con diferente segmentación, presupuesto, publicidad y venta de materias primeras. Esto implicó un doble esfuerzo de trabajo bajo el mismo salario y muchas horas extras después del horario laboral. En la actualidad, el personal no ha incrementado mucho (10\% en su totalidad). Por ello, continúan con la misma carga de trabajo y además, se le suma que deben ser los encargados de unificar la información de ambas marcas para presentárselas al directorio del Grupo Celima - Trébol. 


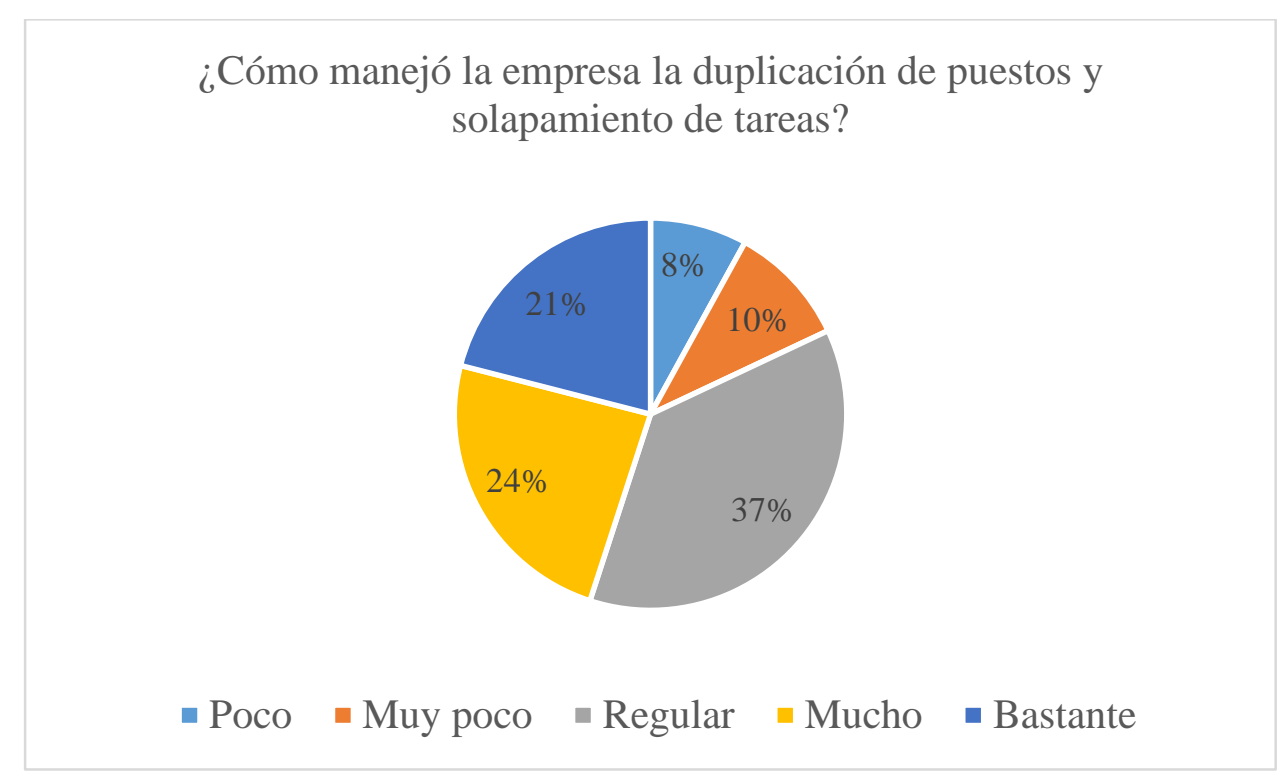

Fuente: elaboración propia

Como se ha mencionado anteriormente, en muchos casos se siguen duplicando las funciones, debido a que no están muy bien establecidos los límites de los puestos. Es decir, una persona de Cassinelli puede desempeñar la misma labor que alguien del personal de HMC y no saber qué se está trabajando lo mismo, ya que aún trabajan como marcas independientes por más que estén dentro del mismo espacio físico y compartan ciertas estrategias comerciales. Usualmente, ambas empresas se dan cuenta que han duplicado una campaña o un reporte cuando ya está por salir a la luz o cuando se lo presentan a alguien del directorio. Esta también es una descoordinación entre organizaciones del grupo y aquí se evidencia la poca comunicación existente cuando se trata de lo laboral. 


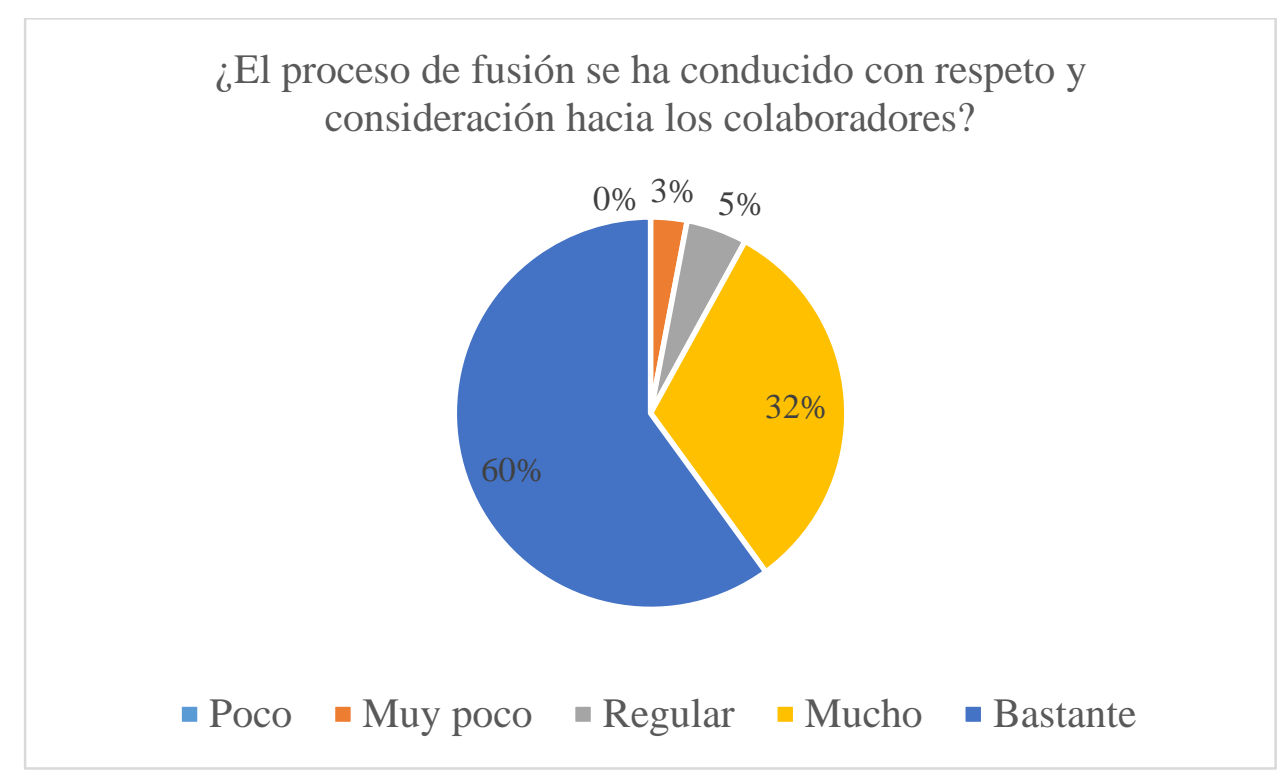

Fuente: elaboración propia

El 60\% del personal manifestó que el proceso de fusión se condujo con bastante respeto y consideración, ya que RRHH se encargó de mantener las buenas relaciones entre colaboradores, establecer vínculos entre áreas/empresas, mejorar las condiciones laborales, incentivar las buenas prácticas, motivar al personal y brindarles constantes charlas para indicarles cómo iba el proceso de fusión. Los colaboradores estuvieron al tanto sobre lo que implicó la fusión (rotación de personal y nuevo clima laboral), los objetivos a largo plazo (expansión de mercado tanto nacional como internacional y, ser un potencial competidor para Sodimac y Maestro) y lo que esperan de los colaboradores (compromiso, dedicación, entrega, fidelización, etc.). 


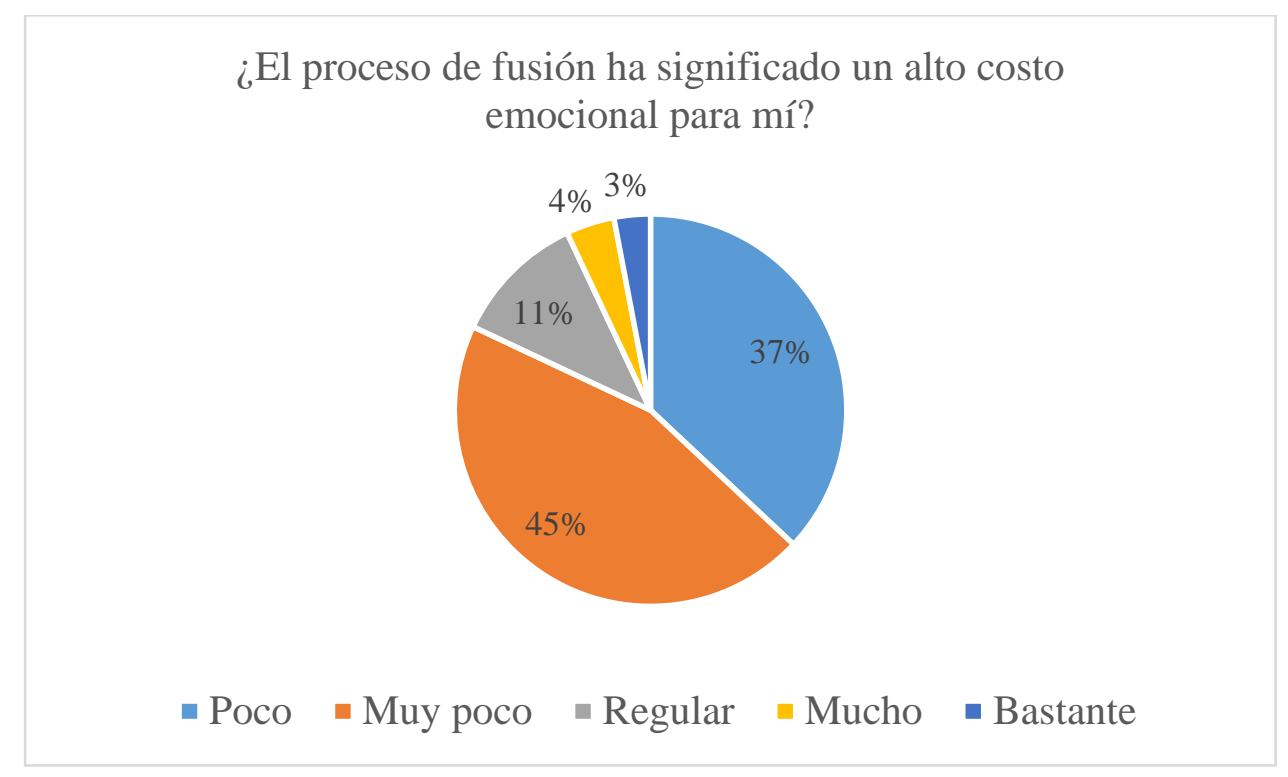

Fuente: elaboración propia

El $45 \%$ de los encuestados señalaron que la fusión no tuvo un costo emocional muy alto. Esto es porque la mayoría del personal era de Cassinelli y ellos se mantuvieron en la empresa. En casos puntuales, el personal de HMC se quedó con el puesto, debido a la confianza que había logrado con el tiempo. Por ejemplo, los Jefes Zonales conservaron su rol, ya que la fuerza de ventas de la empresa conocía la forma de trabajo $y$, además, porque habían generado vínculos fuertes de confianza.

En tu opinión, ¿cuál que el principal reto que enfrentaste durante el proceso de fusión?

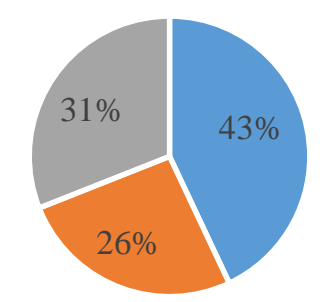

- Establecer relaciones de confianza

- Sentirme identificado con la nueva integración de la empresa

- Estabilidad laboral

Fuente: elaboración propia 
La mayoría de los colaboradores manifestaron que el principal reto de la fusión laboral fue entablar relaciones de confianza, debido a que HCM, al ser la minoría, debía adaptarse a la nueva forma y ritmo de trabajo de Cassinelli. Además, debía generar vínculos laborales para tener cohesión con el equipo y poder trabajar de la mejor manera. En segundo lugar, señalaron la estabilidad laboral, ya que muchas personas fueron retiradas de su puesto de trabajo y otras fueron recolocadas en la sede de Cassinelli. Por lo que, en un comienzo, el proceso de fusión causó incertidumbre en los colaborares al no comunicarse nada al respecto.

\section{¿Cuáles son los principales factores que motivaron tu} participación en un proceso de fusión?

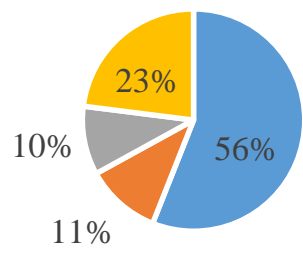

- Sinergias operativas

- Acceso a la misma industria

- Acceso a nuevos mercados (extranjero u otras industrias)

- Reducción de riesgos

\section{Fuente: elaboración propia}

Por último, el 56\% sostuvo que la principal razón por la que participó de este proceso de fusión fue la sinergia operativa, ya que el $80 \%$ del trabajo iba a pasar a manos de Cassinelli, por lo que tendrían más control sobre ambas empresas y, además, verían dos marcas diferentes, lo que significaba un reto para ellos. En segundo lugar, manifestaron que fueron parte del proceso de fusión, debido a la reducción de riesgos laborales. Esto implica un despido o una reducción de carga laboral. 


\section{CONCLUSIONES Y RECOMENDACIONES}

En la elaboración del presente trabajo, se realizó una búsqueda tanto bibliográfica como cibergráfica acerca de las fusiones y adquisiciones empresariales, y su impacto en la cultura organizacional.

Partiendo de la información adquirida tras la investigación de la Gestión Comunicacional en procesos de cambio por fusión en las empresas peruanas Cassinelli y Celima-Trebol, la consulta bibliográfica acerca de los cambios en la organización, su acompañamiento entorno al eje de comunicaciones, el análisis y las valoraciones de los resultados obtenidos; se manifiestan las conclusiones de la presente investigación.

a) Se valida la hipótesis de la investigación: La escasa gestión comunicacional en el proceso de fusión empresarial entre las compañías Cassinelli y Celima-Trébol, generó impactos negativos en la imagen y en la reputación internas.

b) Sobre la pregunta de investigación: ¿En qué medida el proceso de fusión empresarial generó impactos positivos o negativos en la imagen y reputación internas de las compañías Cassinelli y Celima-Trébol?, se manifiesta que un 55\% de los encuestados señaló haber estado conforme con la conducción del proceso de fusión y que ha sido favorable para la compañía HMC al mejorar en su cultura e identidad. Sin embargo, describen en repetidas oportunidades que existió desinformación en cuanto a sus nuevas funciones, la ola de despidos masivos, el cambio de instalaciones, de jefaturas, entre otros. Por tanto, se concluye que, en primera instancia, el proceso de cambio provocó cierta confusión e inestabilidad, pero el término de éste trajo resultados positivos para ambas empresas.

c) La gestión comunicacional dentro de las organizaciones Cassinelli y Celima-Trebol fue débil, ya que los canales de comunicación utilizados en el proceso de fusión de ambas empresas fueron escasos, por lo que los mensajes difundidos no llegaron de manera adecuada a todos los colaboradores de la institución. Asimismo, no se tuvo una segmentación comunicacional eficaz en base a puesto de trabajo que ejercen dentro de la organización o la dependencia del trabajo laboral. Por tanto, existió mucha desconfianza y preocupación ante el cambio, debido a que los colaboradores 
manifestaban que podría existir una canibalización de productos entre ambas entidades, despidos masivos o inestabilidad laboral a largo plazo. Con ello, se establece que la escasa dimensión comunicacional en el proceso de cambio por fusión trajo resultados negativos y ocasionó un ambiente de inestabilidad. Asimismo, esto impactó de manera directa en los activos intangibles de la compañía, tales como la cultura e identidad porque provocó tensión, desinformación, rumores, suposiciones y desequilibrio en los públicos internos. Sobre este punto, Correa (2011) manifiesta que los instrumentos de acompañamiento para los procesos de fusiones y/o adquisiciones procuran tener énfasis en la comunicación directa para poder efectuar un conjunto de acciones segmentadas y poder así, llegar a los usuarios identificados de la manera más eficaz. Para esto, es fundamental aprovechar los medios internos de la compañía e identificar los criterios de intervención con los colaboradores, con el fin de conocer lo que se les quiere comunicar, lo que quieren saber, qué esperan sentir cuando conozcan esa información y por último, qué cambios espera la entidad que ellos realicen (p. 11).

d) Ambas empresas no cuentan con un área de comunicaciones, por lo que se desconoce el alcance y la efectividad que tienen los mensajes difundidos a los colaboradores, debido a que comunican de la misma manera a todos sin importar el perfil del puesto que ejerzan. Asimismo, no poseen una política ni estrategia de comunicación interna puntual y unificada con el resto de las áreas que transmiten mensajes; por lo que, Recursos Humanos es el encargado de promover la Comunicación Interna y realizar acciones para ambas entidades. De este modo, existió un arduo proceso de adaptación del personal de HMC en cuanto al nuevo ambiente laboral, nuevos roles y funciones, nuevos jefes y compañeros de trabajo. Es por esta razón, que identificar los componentes en el acompañamiento de la gestión comunicacional se tornó complicado, debido a que fue limitado y se trabajó sobre la marcha en el proceso de cambio. Bajo esta premisa, el área de Recursos Humanos debe aplicar ciertas herramientas que Cruz (2004) establece para la contribución de la comunicación interna en procesos de cambio durante la fusión y/o adquisición. Estas son las siguientes: creación de espacios de conversación, formar comités de comunicación para determinar los materiales que impulsan la participación de los colaboradores, establecer canales de acompañamiento para focalizar las incertidumbres del proceso 
de cambio y por último, tener listo el plan de comunicación interna antes de empezar el proceso de fusión (p. 77).

e) La investigación permitió concluir que es de suma importancia para los colaboradores el contar con canales de comunicación permanentes para que sean informados sobre la evolución de la organización por medio de canales internos y, además, que se mantenga una comunicación directa con los diversos equipos de trabajo y con los jefes para anticipar comunicaciones informales, especulaciones o rumores que perjudiquen el clima laboral de ambas empresas. Esto, se vio reflejado en el cambio de imagen y el relanzamiento de marca de Cassinelli, ya que solo 2 áreas estuvieron involucradas en el proceso y se comunicó un año y medio cuando la nueva campaña ya estaba en marcha. De esta manera, se reafirma el estudio de Ribes (2005), debido a que sostiene que en una situación de cambio es importante considerar las siguientes directrices comunicativas: solidificar espacios de comunicación e informar al 100\% de los colaboradores, auxiliar en la comprensión sin provocar ciertas expectativas que no se pueden hacer efectivas, comunicar todo (también las dificultades) y, comunicar poca convicción y determinación para no tener que reconsiderar frecuentemente las decisiones o emitir mensajes cruzados en sentidos diversos. Para lograr esto, es preciso establecer espacios sólidos y seguros que admitan la generación de vínculos con el fin de que los colaboradores logren asimilar el proceso de cambio empresarial (p. 82).

f) En el proceso de fusión, no hubo un gran apoyo por parte de la alta dirección en términos de directrices y labor comunicativa, ya que se les comunicó la gestión de cambio luego de 2 años y no se aprovechó ese plazo para realizar estrategias que aporten en este proceso; por lo que no fue de fácil tránsito a la nueva situación de las compañías. Asimismo, el nuevo compromiso e identidad del "retail" se tornó lento y frágil, en una primera instancia, para los colaboradores de HMC. De esta manera, se involucran los activos intangibles internos como el clima, la cultura e imagen de la empresa, ya que se tornan como aspectos negativos por parte de los colaboradores como consecuencia de la ausencia comunicacional en el proceso de fusión empresarial. 
Tomando como base los hallazgos de esta investigación, se presentan determinadas recomendaciones para difundir la cultura organizacional entre los colaboradores de Cassinelli y Celima-Trebol:

a) Para emprender la construcción de una gestión comunicacional como parte de una estrategia de fusión y/o adquisición, es importante partir de un análisis y diagnóstico de la cultura en las empresas comprometidas para extraer data acerca de las similitudes y divergencias para así, establecer la manera más adecuada de gestionar el cambio. Este diagnóstico servirá de base para -luego- realizar una adecuada gestión en todas las etapas del proceso.

b) Es necesaria la creación espacios de comunicación dentro de la empresa para que los colaboradores puedan expresar sus ideas, comentarios, sentimientos, malestares o críticas con el fin de generar la comunicación en doble vía.

c) Elaborar estrategias de comunicación interna segmentadas de acuerdo con el perfil laboral que ejerzan los colaboradores para que se sientan identificados con la empresa y, además, sientan que son tomados en cuenta.

d) Difundir mensajes concisos, relevantes y comprensibles a todos los colaboradores para que los impulse a mantener cierto interés en lo que se les quiere informar y conlleve a modificar la conducta y percepción frente a los cambios que se puedan presentar dentro de la entidad. Además, esto permitirá que los colaboradores se encuentren informados sobre los aspectos importantes de la organización y los motive a participar en ellos.

e) Emplear instrumentos de medición para calcular el alcance, la efectividad y la aceptación que poseen los colaboradores hacia los mensajes emitidos para saber qué medios de comunicación son más eficientes e idóneos para enviar información relevante según el perfil de trabajo de cada colaborador. Puede ser mediante encuestas, sondeos aleatorios y otras herramientas que permitan el entendimiento del proceso. De este modo, se pueden ajustar las herramientas para poder cumplir con 
los objetivos comunicacionales como base a la difusión de la estrategia y del proceso de fusión.

f) Es relevante contar personal que posean una habilidad gerencial alta para establecer una dirección correcta del proceso de integración, debido a que éste exige lecturas profundas y manejo profesional frente a los diversos comportamientos que se dan de manera natural en todo proceso de cambio. Por tanto, es crucial disponer de un equipo interdisciplinario y experto en gestión del cambio que posea elevados conocimientos de cada una de las organizaciones que serán impactadas.

Todo lo mencionado anteriormente, es relevante para enfrentar procesos de fusión o adquisición empresarial y por ello, se recomienda plantear y desarrollar una buena gestión comunicacional para mitigar posibles conflictos que afecten la cultura, identidad, imagen y reputación de la organización, con el fin de brindarle a los colaboradores un ambiente óptimo para cumplir los objetivos y desenvolverse de manera óptima dentro de la compañía.

Consideramos que este trabajo puede servir de referencia para la elaboración de futuras investigaciones relacionadas con los procesos de fusión y adquisición empresarial, gestión comunicacional, comunicación en fusiones, cultura organizacional, cambio organizacional y resistencia al cambio.

Dado que el tema planteado en este trabajo tiene una visión multidisciplinaria (gestión empresarial y gestión comunicacional), consideramos que existen oportunidades para explorar nuevas temas o profundizar en subtemas, como por ejemplo: clima organizacional en situaciones de fusiones, impacto emocional en los trabajadores, generación de herramientas comunicacionales, entre otros. 


\section{BIBLIOGRAFÍA}

Adiego Calvo, J. (2015). Puntos clave de éxito y fracaso en M\&A: Integración Post. Madrid: Pontificia Universidad de Icaide.

Alexandris, G. (2012). How have M\&A changed? Evidence from the Sixth Merge Wave. European Journal of Finance.

Amorós, E. (2007) Comportamiento organizacional. Lambayeque: Juan Carlos Martínez Coll

Ansoff, I. (2002) Corporate Strategy. Nueva York. McGraw Hill, Pág. 165.

Apoyo Consultoría (2017) Recuperado de http://www.apoyoconsultoria.com/es/estudiocrecimiento-retail-peru-2017-6478984 [Consulta: 19 de enero de 2019].

Aramburú, E. (2016) Recuperado de http://aymgestion.com/ [Consulta: 18 de enero de 2018].

$\begin{array}{llll}\text { Arellano } & \text { Marketing } & \text { (2016) } & \text { Recuperado }\end{array}$ http://www.arellanomarketing.com/inicio/inmobiliaria-3/ [Consulta: 18 de enero de 2019].

Argüello J. (2011) Identidad e imagen corporativa. Barcelona: El Cid Editor.

Arriagada, H. (2009) Comunicación Interna en Chile. Recuperado de http://www.comunicacioninternaenchile.com/2009/11/origen-y-evolucion-de-lacomunicacion.html [Consulta: 12 de septiembre de 2019].

Berens, G., \& Van Riel, C. (2004). Corporate associations in the academic literature: three main streams of thought in the reputation measurement literature. Corporate Reputation Review, 7 (2), 161-178. 
Belting H., (2007) Antropología de la imagen. Buenos Aires, Katz Editores.

Bermúdez, L. \& Rodríguez, L. (2013) Investigación en la gestión empresarial. Bogotá: Ecoe ediciones.

Bocanegra, F. (2001) Bases Metodológicas de la Investigación Científica. Trujillo: PubliCiencia

Buono A. \& Bowditch J. (2003) Human side of mergers and acquisitions: Managing collisions between people and organisations, Edit. Beard Books, Washington DC.

Cabre Q., Olivares A., Pina D. \& Salveraglio S. (2007) Fusiones y Adquisiciones en España, Máster en Mercados Financieros (6 $6^{\mathrm{a}}$ edición), Pag. 12.

Cámara de Comercio de Lima (2017) Recuperado de https://www.camaralima.org.pe/RepositorioAPS/0/0/par/EDICION741/ED_DIGI TAL741.pdf [Consulta: 20 de enero de 2020].

Capriotti, P. (2009) Branding corporativo. Fundamentos para la gestión estratégica de la identidad corporativa, Colección Libros de la Empresa.

Cardona, O.; Gómez, D. y Londoño, J., (2000) Comunicación Organizacional, Monografías, Medellín, Colombia: Pregón.

Castaño, E. y Vélez, E., (2000) Comunicación Organizacional. Monografías, Medellín, Colombia: Pregón.

Castro, C. (2003) Dirección de conflicto cultural en fusiones y adquisiciones. Investigaciones europeas de dirección y economía de la empresa. Vol. 9. Núm. 2.

Clark, R. (2000) Corporate Law. New York: Aspen Law \& Business, Pág. 418 - 424.

Cording, M. (2008) Reducing causal ambiguity in acquisition integration: intermediate goals 
as mediators of integration decisions and acquisition performance. New York: Academy of Management Journal.

Cornelissen, J. (2004) Corporate Communications: Theory and Practice, Sage, London.

Correa, B. (2011) Vivencia de procesos de cambio. Recuperado de Empresa Comunicación y Cambio S.A.S.

Costa, J. (2003) 100 años de juventud: Identidad corporativa. Recuperado de http://www.reddircom.org/textos/identidad100.pdf [Consulta: 19 de enero de 2019].

Costa, J. (2007) Señalética corporativa. Barcelona: Costa Punto Com. Pág. 46.

Creswell J. (2007) Qualitative inquirí and reaserch design. Chossing among five traditions. Thousand Oaks, CA. Sage publications.

Cruz, J. (2004) La crisis y su influencia en las estrategias de comunicación organizacional (Tesis doctoral). Universidad Autónoma de Barcelona, España.

DePamphilis, D. (2011) Mergers and acquisitions. Oxford: Elsevier.

De Quevedo, E. \& de la Fuente, J. (2003) La reputación en el contexto actual. En el estado de publicidad y el corporate en España y Latinoamérica. Pirámide, Madrid.

Devogue, S. \& Spreier, S. (2000) La organización en las fusiones. Harvard-Deusto, Finanzas \& Contabilidad, 35, Pág. 46-52.

Diario Gestión (2015) Recuperado de https://gestion.pe/economia/empresas/mejoramientohogar-mercado-crece-reestructura-94276 [Consulta: 19 de enero de 2019].

Diario Gestión (2015) Recuperado de https://gestion.pe/economia/cuatro-principalescadenas-mejoramiento-hogar-reportaron-89-tiendas-cierre-2015-148706 
[Consulta: 20 de enero de 2020].

Diario Gestión (2018) CCL: Fusiones y adquisiciones en sector retail de Perú suman US\$ 2,160 millones. Recuperado de https://gestion.pe/economia/ccl-fusionesadquisiciones-sector-retail-peru-suman-us-2-160-millones-227347noticia/?ref=gesr [Consulta: 21 de enero de 2020].

Dupuy, E., Devers, T. \& Raynaud, I. (2001) La Communication Interne: vers 1'entreprese transparente. Paris: Les Éditions D'Organisation.

El Peruano (2015) Diario Oficial del Bicentenario. Recuperado de http://busquedas.elperuano.com.pe/normaslegales/ley-que-modifica-la-ley26887-ley-general-de-sociedades-so-ley-n-30354-1307649-1/ [Consulta: 18 de enero de 2019].

Equilibrium (2017) Recuperado de http://www.equilibrium.com.pe/sectorialretailmar15.pdf [Consulta: 19 de enero de 2019].

EY (2016) Fusiones y adquisiciones para ganar mercados. Recuperado de https://perspectivasperu.ey.com/2016/03/15/fusiones-adquisiciones-para-ganarmercados/ [Consulta: 18 de enero de 2019].

Ferguson, T., Deephouse, D. \& Ferguson, W. (2000) Do Strategic Groups Differ in Reputation? Strategic Management Journal Vol. 21, No. 12, University of Alberta School of Business Research Paper. Pag. 2013-410.

Fernández, C. (2005) La comunicación en las organizaciones. 4 ed. Editorial Trillas, México.

Forsythh, A. (2011) Adquisiciones de empresas y activos de negocios: Un enfoque práctico. En: Themis 59. Revista editada por los alumnos. Lima: Pontificia Universidad Católica del Perú, Facultad de Derecho, Pág. 126.

Franco Hilario, L. (2011) Fusiones y Adquisiciones: El caso de Microsoft y Nokia. Lisboa: 
Universidad Católica Portuguesa.

Galpin, T.; Herndon, M.; Montealegre, M.; Sarrión, J. \& Franco, M. (2000) Guía completa sobre fusiones y adquisiciones, Ediciones Díaz de Santos, S.A., $1^{\text {a }}$ ed., $1^{\text {a }}$ imp. Pág. 280.

Giorgia, D., Schultz M. y Corley, K (2000) Organizational Identity, image, and adaptive instability, Academy of Management Review, vol. 25 nº 1, p. 63-81.

Giner, F. (2009) La Institución Libre de Enseñanza. Nuevas perspectivas. Madrid, Fundación Francisco Giner de los Ríos/Institución Libre de Enseñanza/Acción Cultural Española, Pág. 105.

Graebner, M. (2012) Success and Failure in Technology Acquisitions: Lessons for Buyers and Sellers. Texas: Academy of Management Perspectives.

Heimeriks, K., \& Schijven, M. (2009) Caution or causation? The underlying mechanisms of deliberate learning in the context of post. Montreal: Academy of Management.

Hernández Sampieri, R., Fernández C., y Baptista L. (2010) Metodología de la investigación. México. Ed. Mc Graw Hill.

Hernández Sampieri, R. y Mendoza, C (2018) Metodología de la investigación. Las rutas cuantitativa, cualitativa y mixta. México: Editorial Mc Graw Hill Education.

Hoang, T. (2008) Critical Success Factors in Merger \& Acquisition Projects. Umeå: Umea University.

Iborra, M. (2002) La rotación de la alta dirección en los procesos de fusión y adquisición: el caso de la banca privada española 1987-1993, Revista de trabajo y Seguridad Social, Centro de Estudios Financieros, nº 208, Pág. 153-180.

Ind, N. (2000) The Corporate Brand. Nueva York: New York University Press. 
Ind, N. (2007) La imagen corporativa: estrategias para desarrollar programas de identidad eficaces. Nueva York: Ediciones Díaz de Santos.

Jaramillo, J. (2004) Modelo de Comunicación Pública Organizacional e Informativa para entidades del Estado (MCPOI), Bogotá, Colombia: Usaid- Casals \& Associates Inc.

Koontz \& O’Donnell (2004) Un análisis de sistemas y contingencias de las funciones administrativas, México, Editorial Ingramex S.A.

La cámara. La revista de la CCL (2018) El boom de las fusiones y adquisiciones. Recuperado de https://www.camaralima.org.pe/repositorioaps/0/0/par/edicion814/edicion814 [Consulta: 19 de enero de 2019].

La Comunidad de Madrid (2017) Estrategias de Crecimiento de la Empresa. Fondo Social Europeo de la Unión Europea. Recuperado de http://www.madrid.org/cs/StaticFiles/Emprendedores/GuiaEmprendedor/tema6/F 38_6.2_ESTRATEGIAS_CRECIMIENTO.pdf [Consulta: 18 de enero de 2019].

Laniado, D. y Beltrando, P. (2003) ¿Por qué fallan las fusiones y las adquisiones? Ejecutivo de finanzas.

León, D. (2009) ReDiseño de Marca, Manual de Identidad Corporativa y desarrollo de sitio web para la empresa Taller Industrial Allen Ltda. Recuperado de http://bdigital.uao.edu.co/bitstream/10614/295/1/T0003420.pdf [Consulta: 18 de enero de 2019].

López, D. (2006) La comunicación como herramienta gerencial, Bogotá, Colombia: Ecoe Ediciones.

López, E. (2004) Leveraged buyouts a la luz de la regulación societaria peruana sobre asistencia financiera prohibida. Advocatus 10. Revista editada por los alumnos. 
Lima: Universidad de Lima, Facultad de Derecho, Pág. 57.

López, E. (2015) Leveraged Buyouts y Asistencia Financiera Prohibida. Rodrigo Elías y Medrano Abogados, Lima.

Marín, J. (2008) Fusiones y adquisiciones en la en la práctica. México: Cengage Learning.

Martínez, C. (2011) La gestión empresarial. España. Editorial Díaz de Santos.

Martinicorena, P. (2007) Estrategia y Gestión de Negocios. Recuperado de www.esyges.com [Consulta: 18 de enero de 2019].

Martín, F. (2010) Comunicación empresarial e institucional, Madrid, España: Universitas.

Mascareñas, J. (2005) Fusiones y Adquisiciones de Empresas (4 ${ }^{\mathrm{a}}$ Ed.) McGraw Hill. Madrid. 2000 (ISBN: 84-481-2815-X). Pág. 438.

Mergerstat (2000) Recuperado de www.mergerstat.com [Consulta: 19 de enero de 2019].

Monclús, A. (2004) El capital intelectual de la empresa. Partida Doble, 154: 18-25.

Montoya, I. (2000) Comunicación Organizacional. Monografías, Medellín, Colombia: Pregón.

Mora, V. \& Montoro, S. (2006) R\&D cooperative agreements between firms and research organizations: a comparative analysis of the characteristics and reasons depending on the nature of the partner, International Journal of Technology Management, 35 (1/2/3/4), pp. 156-181.

Neville, B., Bell, S. y Mengüc, B. (2005) Corporate reputation, stakeholders and the social performance - financial performance relationship, European Journal of Marketing, vol. $39, n^{\circ}$ 9/10, p. $1184-1198$. 
Nomen, E. (2005) Los activos de Propiedad Industrial y la creación de valor económico. En núcleo de la política de gestión en el siglo XX. Instituto Nacional de Propiedad Industrial (INPI).

Ochoa, J. (2003) KM Europe 2002: Explorando y explotando el conocimiento de las empresas. Capital Humano, No. 163, p. 36.

Oren Refsnes, F. (2012) What Explains Mergers' Success or Failure? The Role of Organizational Structures, Strategies and External Environments in Mergers Empirical evidence from two contrasting cases. Oslo: The European InterUniversity.

Oxford Business Group (2016) Recuperado de https://oxfordbusinessgroup.com/news/10nuevos-centros-comerciales-en-18-meses-para-impulsar-el-comercio-minoristaen-el-per\%C3\%BA [Consulta: 20 de enero de 2019].

Página Web de Ace Home Center (2018) Recuperado de http://www.maestro.com.pe/quienes [Consulta: 15 de junio de 2018].

Perú Retail (2017) Recuperado de https://www.peru-retail.com/mercado-mejoramientohogar-peru/ [Consulta: 15 de junio de 2018].

Perú 21 (2013) Recuperado de https://peru21.pe/economia/ventas-tiendas-mejoramientohogar-sumaran-s-3-460-millones-118602 [Consulta: 20 de enero de 2019].

Prieto, J. (2011) Gestión estratégica organizacional. Bogotá: Ecoe ediciones.

Ramírez, A. (2009) Gestión empresarial de las microempresas ubicadas en el Municipio de Jalpatagua, Tesis Universidad Rafael Landívar.

Real Academia Española (2017) Diccionario de la Lengua Española. Vigésimo Segunda Edición. Tomo I (a/g). Editorial Espasa Calpe. España, Pág. 1101. 
Retamal, G. (2002) Cambio y resistencia al cambio. Recuperado de http://www.leonismoargentino.com.ar/INST253.html [Consulta: 19 de enero de 2018].

Ribes, G. (2005) Estudio de los factores intangibles en los procesos de Fusiones y Adquisiciones de empresas IX Congreso de Ingeniería de Organización Gijón. Recuperado en http://www.adingor.es/Documentacion/CIO/cio2005/items/ponencias/147.pdf [Consulta: 20 de enero de 2020].

Ribes, G. (2005) El valor de los factores soft en las operaciones de crecimiento externo de la empresa vía fusiones y adquisiciones, en IX congreso de ingeniería de la organización, Gijón. Recuperado en http://www.adingor.es

Ritter, M. (2005) El rol de la comunicación en el proceso de fusiones y adquisiciones, Máster Dircom, La Paz, Bolivia: Grupo editorial Design.

Rodríguez, L. (2009) Inversión en Intangibles: efectos sobre la información y el comportamiento de la empresa. Tesis Doctoral. Universidad de Salamanca.

Rodríguez Peñuelas, M. (2010) Métodos de investigación. 1ra. Edición, México. Ed. Universidad Autónoma de Sinaloa.

Ross, S.; Westerfiel, R. \& Jaffe (2000) Corporate Finance. Editorial Mcgraw-Hill Education. Décima edición. Estados Unidos, Pág. 774.

Salguero, Amado (2006) Indicadores de gestión y cuadro de mando, Ediciones Díaz. Santos, Madrid, p. 32.

Sánchez, J. y Pintado, T. (2009) Imagen corporativa. Influencia en la gestión empresarial. Madrid. ESIC Editorial.

Saniz, J. (2015) El plan estratégico en la práctica. Madrid: Esic editorial. 
Semana Económica (2014) Recuperado de http://semanaeconomica.com/article/sectores-yempresas/comercio/156478-tiendas-de-mejoramiento-del-hogar-crecen-pese-a-ladesaceleracion/ [Consulta: 20 de enero de 2019].

Smaiziene, I. y Jucevicius, R. (2009) Corporate reputation: Multidisciplinary Richness and earch for relevant Definition, Inzinerine Ekonomika - Engineering Economics, no2, p. 91-100.

Tamayo, M. (2007) El proceso de la investigación científica. 4ta. Edición, México. Ed. Limusa.

Tejedo, F. (2011) Información divulgada del Capital intelectual en el Marco de la Responsabilidad Social Empresarial del Gobierno Corporativo: Evolución y Factores determinantes. Tesis Doctoral. Universidad de Castilla-La Mancha.

Villafañe, J. (2013) La comunicación empresarial y la gestión de los intangibles en España y Latinoamérica, Pearson.

Walker, K. (2010) A Systemactic Review of the Corporate Reputation Literature, Corporate Reputation Review, 12, p. 4, Macmilian Publishers Ltd.

Whetten, D. y Mackey, A. (2002) A social actor conception of organizational identity and its implications for the study of organizational reputation, Business and Society, vol. $41, n^{\circ} 4$, p. 393-414.

Zhang, D. (2003) "Intangible assets and stock trading strategies", Managerial Finance, Vol. 29 Issue: 10, pp.38-56.

Zarco, F. (2007) Manual Práctico de Sociedades Comerciales. Editorial La Ley. $1^{\text {a }}$ Edición. Buenos Aires, Argentina, Pág. 160.

Zozaya, N. (2015) Las fusiones y adquisiciones como fórmula de crecimiento empresarial. 


\section{ANEXOS \\ MODELO DE ENCUESTA}

\section{DATOS GENERALES}

¿Cuánto tiempo lleva trabajando en la empresa?

Menos de 5 años

De 5 a 10 años

Más de 10 años

¿En qué departamento trabaja?

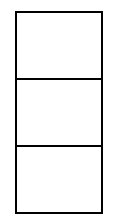

PUNTÚE CADA PREGUNTA DEL 1 AL 5, SIENDO 1 EL MENOR VALOR Y 5 EL MAYOR

\begin{tabular}{|c|c|c|c|c|c|c|}
\hline & SOBRE LA EMPRESA & 1 & 2 & 3 & 4 & 5 \\
\hline a) & ¿Le gusta su empresa? & & & & & \\
\hline b) & ¿Se siente integrado con ella? & & & & & \\
\hline c) & ¿Conoce su posición y responsabilidades? & & & & & \\
\hline d) & ¿La empresa se interesa por sus sugerencias? & & & & & \\
\hline e) & $\begin{array}{l}\text { ¿La empresa se preocupa por mantener elevado el nivel de } \\
\text { motivación personal? }\end{array}$ & & & & & \\
\hline f) & $\begin{array}{l}\text { ¿Me siento informado de las cosas importantes que ocurren en } \\
\text { mi empresa? }\end{array}$ & & & & & \\
\hline g) & ¿Los objetivos de la empresa son conocidos por todos? & & & & & \\
\hline h) & $\begin{array}{l}\text { ¿Existe claridad suficiente sobre las responsabilidades y tareas } \\
\text { de los cargos de mi sucursal? }\end{array}$ & & & & & \\
\hline i) & $\begin{array}{l}\text { ¿Mis valores personales coinciden con los valores de la } \\
\text { empresa? }\end{array}$ & & & & & \\
\hline
\end{tabular}

\begin{tabular}{|c|c|c|c|c|c|c|}
\hline & SOBRE LA FUSIÓN ORGANIZACIONAL & 1 & 2 & 3 & 4 & 5 \\
\hline a) & $\begin{array}{l}\text { ¿El proceso de fusión ha sido bien conducido hasta el } \\
\text { momento? }\end{array}$ & & & & & \\
\hline b) & $\begin{array}{l}\text { ¿Mi estabilidad laboral se ha visto afectada directamente por } \\
\text { el proceso de fusión? }\end{array}$ & & & & & \\
\hline c) & $\begin{array}{l}\text { En mi sucursal, ¿se ha generado mayor presión de trabajo } \\
\text { como producto del proceso de fusión? }\end{array}$ & & & & & \\
\hline d) & $\begin{array}{l}\text { ¿Cómo manejó la empresa la duplicación de puestos y } \\
\text { solapamiento de tareas? }\end{array}$ & & & & & \\
\hline
\end{tabular}


g) ¿El proceso de fusión se ha conducido con respeto y consideración hacia los colaboradores?

h) ¿El proceso de fusión ha significado un alto costo emocional para mí?

En tu opinión, ¿cuál que el principal reto que enfrentaste durante el proceso de fusión?

a) Establecer relaciones de confianza

b) Sentirme identificado con la nueva integración de la empresa

c) Estabilidad laboral

¿Cuáles son los principales factores que motivaron tu participación en un proceso de fusión?

- Sinergias operativas

- Acceso a la misma industria

- Acceso a nuevos mercados (extranjero u otras industrias)

- Reducción de riesgos 